\title{
Fondos cartográficos y documentales de la Comisión de Límites de Brasil en el siglo XVIII en el Museo Naval de Madrid
}

Cartographic and Documentary Funds of Brazil's Border Commission in the Eighteenth Century at Madrid's Navy Museum

\section{Luisa Martín-Merás}

\section{OpenEdition}

Journals

\section{Edición electrónica}

URL: https://journals.openedition.org/terrabrasilis/402

DOI: 10.4000/terrabrasilis.402

ISSN: 2316-7793

\section{Editor}

Rede Brasileira de História da Geografia e Geografia Histórica

Edición impresa

Fecha de publicación: 1 enero 2007

ISSN: 1519-1265

\section{Referencia electrónica}

Luisa Martín-Merás, «Fondos cartográficos y documentales de la Comisión de Límites de Brasil en el siglo XVIII en el Museo Naval de Madrid», Terra Brasilis [En línea], 7 - 8 - 9 | 2007, Publicado el 05 noviembre 2012, consultado el 05 diciembre 2022. URL: http://journals.openedition.org/terrabrasilis/ 402 ; DOI: https://doi.org/10.4000/terrabrasilis.402

Este documento fue generado automáticamente el 5 diciembre 2022.

All rights reserved 


\title{
Fondos cartográficos y documentales de la Comisión de Límites de Brasil en el siglo XVIII en el Museo Naval de Madrid
}

\author{
Cartographic and Documentary Funds of Brazil's Border Commission in the \\ Eighteenth Century at Madrid's Navy Museum
}

Luisa Martín-Merás

Mi trabajo ha consistido en el estudio de esta documentación, que no estaba muy definida en el archivo del Museo Naval, para poder adscribirla a su correspondiente partida para lo que he consultado las hojas de servicio y expedientes personales de cada marino participante que se encuentran en el Archivo General de la Marina "Viso del Marqués". Un problema mayor ha sido el examen de los mapas, croquis y borradores de las diferentes partidas que en muchos casos no tienen título, año, ni autor, no están situados con sus correspondientes coordenadas geográficas y representan zonas geográficas poco reconocibles, como los diferentes afluentes de los ríos objeto de la demarcación con una toponimia de la época que, a menudo no se ha conservado. También nos hemos fijado en los meridianos utilizados en los mapas; mientras que Valera y Ulloa utilizaba el meridiano de Buenos Aires, Azara escogió como primer meridiano el de Asunción, Francisco Requena el de Hierro y las cartas generales suelen partir del meridiano de Cádiz y a veces del de París. Los mapas estaban firmados por los comisarios si eran mapas generales y políticos pero eran los oficiales geógrafos y astrónomos los que los levantaban, por lo que, cuando un mapa no esta firmado pero sabemos a que partida correspondía, podemos, sin mucha dudas, adjudicar la autoría al geógrafo que trabajó en ella. Los mapas están ordenados por los tratados correspondientes a los que pertenecen, en segundo lugar por la demarcación que los generó (del norte de Brasil o del sur en el caso del tratado de 1750) y finalmente por lugar geográfico. Todo lo anterior constituye una justificación por los errores que haya 
podido cometer en la asignación del lugar geográfico y en la adjudicación a una u otra comisión o autor.

\section{Introducción histórica}

2 Brasil fue descubierto por Vicente Yañez Pinzón en 1499, unos meses antes de que lo hiciera Cabral, (Valera, 2000) como aparece documentado en la carta de Juan de la Cosa ${ }^{1}$ con el siguiente rótulo: "este cabo se descubrió en el año de 1499 por Castilla, siendo descubridor Vicens ians". En la carta también se representa la tierra que descubrió Cabral como una isla en azul ya que el portugués la consideró isla y la llamó Vera Cruz o Santa Cruz, como aparece en mapas posteriores. Como ya sabemos, la aplicación del Tratado de Tordesillas otorgó el "cabo" descubierto por Pinzón, además de amplios territorios a Portugal. La línea demarcadora que el Tratado de Tordesillas establecía fue imposible de situar en su correcta posición geográfica porque se desconocía la coordenada de la longitud y las juntas de cartógrafos y pilotos, que asesoraban a los monarcas portugueses y españoles en siglos XVI y XVII, no se pusieron de acuerdo en el trazado de dicha línea, como lo atestiguan los mapas de la época. (Martín-Merás, 1993)

3 A lo largo del siglo XVII, coincidiendo con la unión de las coronas de España y Portugal, los colonos portugueses se fueron internando en el continente, atraídos por las riquezas mineras del interior y por medio de la ocupación efectiva de tierras deshabitadas, se expandieron hacia el río Paraguay y Paraná, alcanzando también el Río de la Plata donde establecieron un provechoso comercio con las colonias españolas.

Efectivamente, al unirse las coronas de España y Portugal en 1580, Buenos Aires adquirió protagonismo al convertirse en puerto suministrador de harinas, cuero $\mathrm{y}$ ganado al Brasil, recibiendo a cambio esclavos y hierro de Europa. Este comercio se mantenía con la plata que venía del Perú que acababa en Portugal y los Países Bajos. Este tráfico comercial, lesivo para los intereses españoles, motivó que las autoridades españolas clausuraran el puerto de Buenos Aires en el siglo XVII. Cuando se separaron las dos coronas ibéricas, el tráfico mercantil que seguía fluyendo, se cortó totalmente, continuando sin embargo el contrabando que o bien lo hacían los españoles por Buenos Aires o los portugueses por el sur de Brasil.

5 En 1680 fuerzas portuguesas, procedentes de Río de Janeiro, se asentaron en la banda septentrional del Río de la Plata, el actual Uruguay, fundando la colonia del Sacramento en la isla de Santa Catalina, de la que fueron inmediatamente expulsados por los españoles. La importancia estratégica de la colonia de Sacramento consistía en que servía de base a los portugueses e ingleses para comerciar con los territorios españoles del Plata y alto Perú en detrimento de Buenos Aires. (Bermejo de la Rica, 1920)

6 En 1683 por medios diplomáticos, la colonia pasó a manos de Portugal. En 1705 con motivo de la guerra de Sucesión de España, los españoles recuperaron el territorio en disputa, pero en 1714 por el tratado de Utrecht pasó otra vez a los portugueses. La política de neutralidad de Fernando VI le llevó a intentar resolver de manera pacífica el crónico problema de la colonia del Sacramento para lo que se firmó en 1750 el tratado de límites con Brasil. Según sus estipulaciones, España recobraría la colonia del Sacramento y toda la banda oriental de la desembocadura del Plata, esto es, el futuro Uruguay, a cambio de concesiones territoriales en la cuenca del Amazonas y en las regiones mineras del Matto Grosso. La puesta en práctica del tratado tuvo muchas 
dificultades para demarcar los límites en un territorio mal conocido y originó un doloroso conflicto.

7 En 1761, con la subida al trono de España de Carlos III y la firma del tratado del Pardo, quedó anulado el tratado de límites de 1750 pues los portugueses no querían perder la colonia del Sacramento ni Carlos III hacer concesiones que le parecieron muy costosas, con lo que las fronteras quedaron en las anteriores posiciones. Durante la guerra de los Siete Años pasó la colonia del Sacramento temporalmente a España, volviendo en 1763 otra vez a Portugal, con motivo de paz de París. Estas pertinaces tensiones en la frontera sur con Brasil y la presencia creciente de barcos ingleses en el Atlántico sur hicieron necesario el establecimiento en 1776 del nuevo virreinato de Buenos Aires, que aglutinó las antiguas gobernaciones del Plata (Tucumán, Buenos Aires, Paraguay y las Malvinas)

En 1776 los portugueses recuperaron el río Grande de San Pedro, (río Grande do Sul), lo que provocó el envío desde España de una potentísima flota al mando del marqués de Casa Tilly para apoyar el ataque del gobernador de Buenos Aires, Pedro Ceballos que entró en la plaza el 4 de mayo de 1777 y expulsó a todos los habitantes portugueses, arrasando sus fortificaciones.

9 Finalmente por el tratado de San Ildefonso en 1777, obtuvo España, a cambio de concesiones territoriales en Brasil, la colonia del Sacramento, el Río de la Plata, en África la colonia de Guinea y el abandono de las reclamaciones portuguesas sobre Filipinas y Marianas. En el inmediato tratado del Pardo de 1778 se consiguió obtener concesiones comerciales de Portugal y separar a esta de Inglaterra en los próximos años cruciales.

\section{Demarcaciones del Tratado de Madrid de 1750}

10 El tratado de límites de 1750 , firmado por Fernando VI, un rey que se propuso mantener la paz durante su reinado y que estaba casado con Bárbara de Braganza, princesa portuguesa, tendía a fijar las fronteras ateniéndose a los límites físicos del territorio, es decir a través de los ríos y montañas, obviando la línea imaginaria del tratado de Tordesillas sobre la que en un principio pretendían basarse los españoles, y ayudándose de levantamientos topográficos basados en métodos astronómicos. Se pretendía establecer los límites desde Castillos Grandes, en el actual Uruguay, hasta los montes que pensaban que separaban el Amazonas del Orinoco y de allí hasta la costa, con lo que se conseguía dejar el área de influencia del Amazonas a Portugal y el del Plata para España. Los ministros que gestionaron el tratado fueron Alexandre de Gusmao por parte de Portugal y José de Carvajal, español. Los españoles contaban con el trabajo de Jorge Juan y Antonio de Ulloa la Disertación histórico-geográfica sobre el meridiano de demarcación publicada el año anterior, lo que "permitió a los españoles encarar con ciertas garantías las argumentaciones portuguesas, pero no afrontar las cuestiones de tipo cartográfico" (Lucena, 1991a: 77). Como los españoles no disponían de un mapa de todo el territorio a demarcar, aceptaron basarse en un mapa portugués que Gusmao había remitido a la corte española, convenientemente manipulado, que se conoce como mapa de las Cortes.

11 Se organizaron dos comisiones de límites, compuestas cada una por un número igual de portugueses y españoles: una al norte de los territorios en litigio, y otra al sur. Ambas a su vez se dividieron en tres subdivisiones o "partidas" para poder abarcar un extenso 
territorio en su mayor parte desconocido. La delimitación del tratado de 1750 se llevó a cabo siguiendo el curso del río Uruguay, lo que implicaba ceder a los portugueses siete pueblos guaraníes de las misiones jesuíticas que se encontraban en la banda oriental de dicho río. Los portugueses por su parte cederían a España la conflictiva Colonia del Sacramento. Pero ni los guaraníes estaban dispuestos a quedar en manos de los portugueses ni los jesuitas a que se arruinase su modélica labor misionera. Las guerras guaraníes duraron desde 1754 a 1756 hasta que los indios trasladaron sus pueblos a la orilla derecha del río Uruguay. Esta situación y la oposición de los jesuitas al tratado contribuyeron a que fueran expulsados de Portugal en 1759 y de España en 1767.

Los trabajos demarcatorios obligaron a desplazar a los territorios en litigio a un grupo de expertos: los comisarios de límites. El tratado de limites de 1750 en su articulado (XIXXII) decía que "comisarios inteligentes...visitando todos los limites, ajusten con la mayor distinción y claridad los parajes por donde ha de correr la demarcación....poniendo marcas en los lugares que les parezca conveniente" (Justo Guedes, 2000: 127).

13 Para proveerse de un personal técnico adecuado, el ministro Carvajal, asesorado por Jorge Juan, que acababa de venir de la expedición de medición de un grado en el ecuador, recurrió a poner al frente de las comisiones demarcadoras a oficiales de marina. Con esta decisión, el gobierno español aprovechaba los medios materiales y humanos, utilizados en la ya citada expedición. Estos profesionales, por sus estudios en el Observatorio Astronómico de Cádiz, estaban especialmente preparados para los levantamientos astronómicos, además de estar capacitados para manejar los instrumentos de medición que se adquirieron en París y Londres para la comisión del meridiano y que pasaron a sus manos para estas tareas. La decisión de que los participantes fueran marinos era explícita y el caso de Félix de Azara es ilustrativo ya que era teniente coronel de ingenieros pero para la misión de demarcador fue nombrado capitán de fragata ya que el rey "había juzgado conveniente que fuéramos todos oficiales de marina" (Albiac, 2000: 37). La única vez que no se cumplió esta regla fue con Eugenio de Alvarado, comisario de la segunda partida de límites del Orinoco y coronel del ejército. Las relaciones con el jefe de la comisión, el capitán de navío José de Iturriaga, fueron desastrosas y supusieron un serio contratiempo para la misión encomendada.

14 Una característica de las partidas de límites es que estaban muy jerarquizadas y militarizadas, pues el oficial de mayor graduación era siempre el comisario principal, independientemente de sus méritos. Las instrucciones del comisario principal eran seguidas por los demás comisarios sin vacilación. El comisario Valdelirios seguía de cerca el desarrollo de la comisión y a él se le dirigían todas las dudas aunque no estuviera en el día a día de la comisión. Pero no sólo se necesitaban comisarios inteligentes sino también astrónomos, geógrafos y cartógrafos para lo que Portugal no tenía personal especializado por lo que tuvo que contratar catorce técnicos en otros países, principalmente en Italia y Alemania, con el consiguiente riesgo y político y vergüenza científica que ello conllevaba (Justo Guedes, 2000).

Los diarios eran una de las ocupaciones de los miembros de los equipos, principalmente del geógrafo, en los que se reflejaban las demarcaciones hechas, la ruta efectuada y los levantamientos pero también el recuento de historia natural, etnografía y antropología, no así la clasificación botánica. En este sentido las mejores descripciones las aportó la segunda partida del sur que demarcó y describió los ríos Uruguay, Pepiri, S. Antonio, 
Iguazú, Paraná y sus afluentes. Lo que se esperaba de estas partidas es que aportaran cartografía y sus diarios para controlar las fronteras y que los resultados fueran conjuntos con los portugueses. En el articulo XXIX se dice que en las horas de descanso se reúnan las noticias en dos diarios iguales que se deben mandar a las cortes respectivas firmados y certificados por los comisarios astrónomos y geógrafos de ambas naciones. Aunque los demarcadores en general estaban muy capacitados, como los marinos Alvear, Oyarvide, Solano y Cabrer, eso no garantizaba una mejor comisión pues a veces se encontraron solos con instrucciones imprecisas de sus respectivos mandos y con problemas políticos y militares propios de zonas no pobladas, muy difíciles de resolver.

Otro rasgo de la demarcación es su carácter aventurero y de descubrimiento. Las características del territorio, el transporte de la impedimenta, instrumentos científicos y demás utensilios, la conservación de los alimentos, las enfermedades, las distancias inmensas, los peligros y los indios trasformaron la misión en una aventura ya que algunos territorios no habían sido pisados antes. (Sala Catalá, 1990) Además las malas relaciones con las autoridades virreinales que debían ayudarles y las divergencias entre los comisarios portugueses y españoles hicieron que a veces no se alcanzaran los objetivos propuestos.

17 La organización de la expedición de Iturriaga, minuciosamente descrita por Ramos, sirvió de banco de pruebas para el resto de expediciones. Todos los expedicionarios salieron de Cádiz adonde acudieron apresuradamente y se les entregó instrucciones secretas para evitar que los franceses y holandeses conocieran los planes, por este motivo la expedición se llamó en la época "expedición secreta". Se ascendió a todos los componentes un grado superior de la carrera militar "atendiendo al terreno que han de pisar los destinados a la expedición, excede dos mil leguas, casi todas situadas debajo de la zona tórrida de un tipo destempladísimo, lleno de fieras y de insectos venenosos, cubierto de selbas desiertas y cortado por ríos acúdalos ...ha resuelto el Rey ascender a todo los que en ella se ocupen a grados superiores" (Ramos, 1946: 49).

18 Así José de Iturriaga fue ascendido a jefe de escuadra, Eugenio Alvarado a coronel, Antonio Urrutia a capitán de navío, José Solano a capitán de fragata. Ignacio de Mendizábal pasaba también a teniente de fragata. Solano fue nombrado por consejo del marqués de la Ensenada por su conocimiento de la geografía y cartografía aunque por el artículo XXII del tratado sólo se nombraban tres comisarios.

19 La comisión del norte o expedición al Marañon, llamada actualmente expedición al Orinoco (Ramos, 1946; Lucena, 1992), tenía que delimitar el cauce del Orinoco, empezando la demarcación por el río Javarí, afluente de la margen derecha del Amazonas hasta llegar al río Negro y siguiendo el Amazonas llegar a la boca más occidental del Japurá, y siguiendo hasta su nacimiento, llegar por medio de alguno de sus afluentes hasta la cordillera situada entre el Orinoco y el Amazonas por el este hasta los límites de las dos coronas (Guerreiro, 1999: 32).

20 Los comisarios de la comisión del norte eran: Francisco Xavier de Mendoça Furtado por la parte portuguesa y D. José de Iturriaga por la española. El resto de los demarcadores españoles eran: Eugenio Alvarado, encargado de la segunda partida, Antonio de Urrutia, nombrado tercer comisario pero murió sin iniciar los trabajos en 1755, siendo sustituido por provisionalmente por Juan Ignacio Madariaga. Fue la única comisión de límites que contó con un botánico, el discípulo de Linneo Pier Loefling por expreso deseo de los ministros Grimaldi y Carvajal que pretendían, además de la demarcación 
de límites, la introducción del cultivo de la canela en América y otra serie de informes sobre el virreinato. Las partidas debían reunirse en el río Negro en la aldea de Mariuá luego llamada Barcelos. La rapidez de la organización, urgida por cumplir los término del tratado en cuanto a la demarcaciones, las confusas instrucciones que les dio Carvajal, y las conflictivas relaciones de Iturriaga con el gobernador de Cumaná y los misioneros capuchinos fueron los responsables de que ni siquiera se reuniera con la partida portuguesa que llevaba varios años esperando en río Negro para iniciar la demarcación (Lucena, 1991a: 104).

Los comisarios, detenidos en Cumaná desde 1754 y ante la inacción de Iturriaga, se dedicaron a realizar toda suerte de trabajos geográficos. Solano y sus hombres en la isla Margarita y Trinidad. Alvarado y Urrutia en la Guayana. Más adelante Solano consiguió pasar los raudales de los Atures y Maipures en su intento de llegar al Alto Orinoco y río Negro donde esperaban los portugueses. En 1758 se reiniciaron los trabajos con nuevas instrucciones del ministro Wall: se ascendió a José Solano a comisario de la tercera partida; se nombró a José Diguja para una nueva partida y se dió la orden a Iturriaga de reunirse enseguida con los comisarios portugueses en río Negro. Pero todas estas decisiones llegaron demasiado tarde pues el año 1759 murió Fernando VI y se suspendieron todas las negociaciones del tratado de Madrid (Lucena, 1991a: 179).

La comisión del sur de Brasil, en España conocida como expedición de Valdelirios por el nombre del virrey que la organizó, se desarrolló durante los años de 1750-1759 y debía demarcar desde Castillos Grandes en Uruguay hasta el Amazonas. Los comisarios eran Gomes Freire de Andrada, por parte portuguesa y el Marqués de Valdelirios por parte de España.

De acuerdo con lo consignado en el artículo IV del tratado, la primera partida debía demarcar desde Castillos Grandes hasta el río Ibicuí. Los comisarios eran Francisco Antonio de Meneses e Sousa, portugués y el capitán de navío español Juan Echeverría. Participaban como geógrafos o cosmógrafos Miguel Ángel Blanco por parte portuguesa y el marino Ignacio de Mendizábal por la española. Los trabajos se iniciaron en 1752 pero fueron interrumpidos al año siguiente por el inicio de las llamadas guerras guaraníes. Hasta el año de 1758 no fueron reanudados los trabajos, estando ahora al mando de la demarcación portuguesa José Custodio de Sá e Faria. Los trabajos de esta partida terminaron en julio de 1759 en la horqueta de Ibicuí en un clima de de franca colaboración entre todos los integrantes.

La segunda partida inició los trabajos en 1759; debía demarcar, según el artículo V del tratado, desde el río Ibicuí hasta el río Igurei por encima del salto grande del Paraná. Las demarcaciones finalizaron en diciembre del mismo año, dejando algunos flecos por problemas entre los comisarios que eran José Fernandes Pinto Alpoim por Portugal y Francisco de Arguedas, junto con Francisco Milláu, como geógrafo y Juan Norberto Marrón como astrónomo. Esta partida, aunque estuvo detenida por los conflictos con los indios, al final fue la que cumplió todos sus objetivos demarcatorios, sin problemas y los dos geógrafos incluso terminaron un mapa de conjunto.

La tercera partida debía demarcar desde el río Paraguay hasta el río Jaurú. Los integrantes de la partida eran: José Custodio de Sá e Faria y Miguel Ángel Ciera; Manuel Antonio Flores y Atanasio Varanda y Alonso Pacheco por parte española. Esta partida, menos afectada por los conflictos con los indios, cumplió todos sus objetivos demarcatorios desde 1753 a 1754, volviendo al principio de 1755 a Asunción del Paraguay, pero las relaciones entre los dos comisarios fueron muy tensas. 


\section{Demarcación del Tratado de 1777}

En 1775 fue publicado en España el Mapa geográfico de la América Meridional por Juan de la Cruz Cano y Olmedilla que había sido encargado en 1764 por el ministro de Estado, marqués de Grimaldi a Tomás López y a Juan de la Cruz Cano y Olmedilla con el fin de tener un documento donde se recogieran todos los territorios de la corona de España, colocados en su correcta posición y puestos en relación con los de Portugal. Se pretendía tener un documento para utilizar en las negociaciones del tratado y que no ocurriera como sucedió con el anterior tratado donde Portugal ofreció como documento de trabajo el famoso mapa de las Cortes, hecho a medida de sus pretensiones. Para este trabajo se puso a disposición de Juan de la Cruz toda la documentación cartográfica que se guardaba en archivos oficiales, por lo que el cartógrafo tuvo que hacer una labor de ensamblaje de distintas fuentes que se nota en el mapa. Lo mismo sucedió con los aspectos jurídicos y de fronteras que no estaban bien contrastados en la cartografía que utilizó, por lo que gobierno, aunque en un principio lo distribuyó a la corte portuguesa y a los demarcadores, luego lo encontró contrario a los intereses españoles e impidió su venta y distribución (Almeida, 2001).

Podemos considerar al tratado de 1777 como una continuación de lo ya hecho en el tratado de Madrid. Se reconoce como principio general el derecho de posesión de los territorios ya ocupados. Por los artículos II, IV y V recupera España la colonia del Sacramento y la isla de San Gabriel, así como la margen septentrional del Río de la Plata y la navegación del río Uruguay hasta la cuenca del río Pepiri en su margen occidental. La nueva frontera contorneaba ahora la laguna Mirim y se dirigía al nacimiento del Río Negro. Los pueblos guaraníes, contencioso de que influyó tan negativamente en todas las negociaciones del anterior tratado, se traspasan a la soberanía española trasladándolos a la margen izquierda del río Uruguay al norte del río Ibicuí. A partir de ese punto la frontera se quedaba como en el tratado de Madrid, perfeccionada por la experiencia de los demarcadores del segundo tratado. De forma genérica el tratado dejaba la libre navegación de los ríos que servían como frontera a las dos potencias, quedando privativa de una de las dos potencias en el punto en que cesase la soberanía de la otra (Guerreiro, 1999: 34-35)

En esta ocasión la experiencia de las demarcaciones del tratado de 1750 sirvió para una organización más meticulosa y técnica tanto en hombres como en instrumentos científicos. El portugués Jacinto Magallanes fue encargado por Lisboa de comprar instrumentos científicos en Londres, encargo que también se le hizo desde Madrid. En abril de 1780 se mandaron desde Londres 11 colecciones de instrumentos; seis fueron a Madrid y cinco a Lisboa. En Europa se quedó una colección en manos de los portugueses y dos en manos de los españoles. Cada colección se componía de 12 cajas de libros e instrumentos. Los instrumentos científicos que componían cada una de las ocho colecciones que llegaron a Europa eran²:

291 péndulo astronómico de Grahan a segundos muertos; 2 anteojos acromáticos de Dollon de triple objetivo de $31 / 2$ pies de foco y el otro de 2 pies; 2 lunetas o anteojos acromáticos de triple objetivo con bastidor de 3 hilos horizontales y 1 vertical; 2 tubos de oculares para objetos celestes y terrestres, vidrios ahumados y verde para observaciones del sol; 1 iluminador de marfil para estrellas; 1 espejo de reflexión de acero con plomo oblicuo de $45^{\circ}$ para practicar fácilmente la medición del zenit; 2 
anteojos de mano portátiles; 1 reloj de plata de faltriquera a segundos libres de Grahan; 1 cuarto de circulo de 1 pie de radio fabricado por Simsson; 1 teodolito de 10 pulgadas de diámetro montado sobre un pedestal de madera de 3 pies, ideado por Magallanes; varias agujas de navegar; 2 teodolitos de faltriquera con bastones para fijarlos en tierra y marcar objetos; 1 sectante de ebano de 12 pulgadas de radio con anteojos acromático para observaciones de cara a los astros; 1 instrumento circular de laton de 10 pulgadas de diámetro con luneta acromática, propuesto por Mayer en 1770; 1 barómetro de Nairme y Blunt de $31 / 2$ pies de largo con 2 escalas francesa e inglesa desde 13 hasta 22 pulgadas; 2 termómetros de Nairme y Blunt de faldriquera; 1 miriámetro filar para medir los diámetros del sol y los planetas colocándolo en el ocular del anteojo grande; varios otros nicómetros pequeños; 2 estuches completos de matemática con compás simple de proporción, transferidor, escalas etc; 1 transferidor de latón de 5 pulgadas de radio dividido en $360^{\circ}$; varias reglas de ingeniosa construcción; 1 cadena de 20 toesas con 120 eslabones de 1 pie de rey de parís cada uno; Barras magnéticas artificiales en su estuche de madera; 1 caja con colores y pinceles.

En el capítulo de los libros se incluían, entre otros, las Efemérides y el Conocimiento de los tiempos, el mapa de la América Meridional de Juan de la Cruz Cano y Olmedilla y la Disertación histórico-geográfica del meridiano de demarcación de Jorge Juan y Antonio de Ulloa.

31 Las demarcaciones del Tratado de San Ildefonso, se desarrollaron en los años de 1777-1795 y los plenipotenciarios encargados de las demarcaciones fueron Martinho Melo e Castro y el virrey Juan de Vertiz y Salcedo. Se establecieron cuatro partidas mixtas, estando compuestas por dos comisarios uno español y otro portugués, dos geógrafos, dos ingenieros y dos prácticos del país. Los demarcadores españoles, casi todos marinos y procedentes del Observatorio Astronómico de la Marina, embarcaron con los portugueses en Lisboa hacia Río de Janeyro.

Una vez sobre el terreno los comisarios decidieron dividir las cuatro comisiones en ocho, cuatro de España y cuatro de Portugal, que trabajarían independientes aunque deberían reunirse para contrastar los trabajos; quizás por esta circunstancia en los textos de la época se denominaron "partidas" o "divisiones". Esta forma de trabajar produjo en principio problemas ya que cada partida debía usar el mismo juego de instrumentos para evitar errores y los portugueses y españoles debía turnarse en el uso de la colección, aunque Diego de Alvear señala que no fue un problema en su comisión porque se llevaba muy bien con los demarcadores portugueses. Cuatro colecciones se enviaron al Pará para uso de las divisiones del Orinoco y Amazonas y cuatro fueron a Río de Janeiro para las partidas de Buenos Aires y Paraguay. La colecciones se repartieron aleatoriamente, así la tercera colección de instrumentos española fue para la primera división de Varela. La cuarta española fue a la cuarta división de Juan Francisco Aguirre; la cuarta portuguesa recayó en la segunda división de Alvear y la quinta portuguesa para la tercera comisión mandada por Azara.

Los virreyes Martinho Melo e Castro y Juan de Vertiz y Salcedo debían señalar los lugares donde se juntarían los miembros portugueses y españoles de cada partida y establecer el rumbo y parajes por donde caminar, además de establecer las vías para resolver desacuerdos entre portugueses y españoles. El trabajo técnico de cada comisión se convino en dividirlo en tres partes: la demarcación, catálogo de observaciones astronómicas y catálogo de observaciones físicas o historia natural. 
34 La primera partida española estaba al mando del comisario general José Varela y Ulloa que ya había sido enviado por el gobierno a África para cartografiar las posesiones africanas recibidas en virtud de dicho tratado. Participaban además Bernardo Lecoq como segundo comisario y Joaquín Gundín, geógrafo. La segunda partida española estaba compuesta por el comisario Diego de Alvear, Andrés de Oyarvide, geógrafo y José $\mathrm{M}^{\mathrm{a}}$ Cabrer. Salieron ambas de Montevideo y los portugueses de Río Grande do Sul para empezar las demarcaciones en el arroyo del Chuy según los artículos, 3, 4, 5 y 6 adonde llegaron en 1784; desde allí, pasando por el río Uruguay y el Ybicui hasta llegar al Peperi-guaçu donde los miembros de la primera partida volvieron a Buenos Aires en 1792. La segunda se había separado en 1788 para ir al salto grande del Paraná, desarrollándose las demarcaciones con grandes retrasos y problemas con los portugueses.

La tercera partida estaba formada por Félix de Azara, acompañado de Ignacio de Pazos, José de la Peña, Pedro Cerviño y Martín Boneo y debía empezar en Asunción para ir a los pueblos de misiones hasta el río del Corpus o la Candelaria y por la banda oriental del Paraná subir hasta el salto grande del Iguazú que distaba 3 leguas de la boca del Paraná y llegar al río de San Antonio que es afluente del Paraná por la banda austral para reconocer su origen hasta la unión con el Pepiriguazú, lugar donde se reunirían las dos partidas. A la vuelta debían hacer las marcaciones desde la boca del Iguazú hasta el Salto grande del Paraná conforme al artículo $8^{\circ}$ del tratado. Esta partida no llegó a subir el río Uruguay ni a reunirse con la portuguesa, a pesar de ello sus participantes hicieron reconocimientos del rió Paraguay y levantaron de forma totalmente individual diversos mapas de aquellas regiones.

La cuarta partida debía demarcar el río Jaurú, río de la Madera hasta Japurá y fue encomendada en un principio al capitán de fragata Juan Francisco Aguirre, junto con Rosendo Rico Negron; Antonio Álvarez de Sotomayor sustituyó a Rico cuando este murió. Esta partida tampoco se reunió con la portuguesa.

Por medio de una instrucción de 1778 se creó una cuarta partida conocida como la comisión del Marañon que debía demarcar la zona del Amazonas. La comisión española estuvo primero al mando del gobernador de Maynas: Ramón García de León y Pizarro, sustituido luego por Francisco de Requena, que también era gobernador de la provincia. Los trabajos se prolongaron hasta 1792 (Beerman, 1996, Lucena, 1991b). En 1801 los miembros de todas las expediciones recibieron la orden de volver a España.

La organización de estas comisiones demarcadoras y en especial los trabajos cartográficos y astronómicos que se llevaron a cabo en territorios desconocidos $\mathrm{y}$ hostiles, aunque no alcanzaran en algunas ocasiones las metas establecidas, constituyeron un desafío científico de primera magnitud para las autoridades del estado ilustrado y para los estamentos científicos de la Marina y fueron un banco de pruebas y un modelo para las sucesivas expediciones científicas que se realizaron durante el último tercio del siglo XVIII. 


\section{ANEXOS \\ I - MAPAS GENERALES DE LA EPOCA SIN RELACION DIRECTA CON LAS DEMARCACIONES DE LÍMITES}

AMAZONAS (Río). Mapas hidrográficos. 1639

Copia del contorno y nomenclatura del Plano que acompaña al MS. original L. 196 de la Biblioteca Nacional, titulado, Descubrimiento del río de las Amazonas y sus dilatadas provincias / Dirigido al Rey en 1639 por D. Martín de Saavedra y Guzman Gobernador y Capitán General del No. reino de Granada y presidente de la Rl. Audiencia y chancilleria de Sta. Fe de Bogotá. - Escala indeterminada. - 1639

1 mapa : ms montado sobre tela; $117 \times 48,9 \mathrm{~cm}$.

Señala las distancias entre los puntos más importantes. - Vista y escudo de la ciudad de Quito.

Signaturas: MN. 37-C-4

Moreno Escandón, Francisco Antonio

AMERICA DEL SUR. Mapas generales. 1:2863685. 1772

Plan Geográfico del Virreynato de Santa Fé de Bogotá Nuevo Reyno de Granada : que manifiesta su demarcación Territorial, islas, ríos principales, provincias, y plazas de Armas; lo que ocupan los indios barbaros y naciones extrangeras; demostrando los confines de los reynos de Lima y Mexico, y establecimientos de Portugal sus lindantes: con notas historiales del ingreso anual de sus rentas reales y noticias relativas a su actual estado civil, político y militar / Formado en servicio del Rey Nuestro Señor por el D. A. Francisco Antonio Moreno Escandón, fiscal protector de la Rl. Audiencia de Sta. Fe y Juez Conservador de Rentas. Gobernando el Reyno el Excmo. Señor Bailio Frey Don Pedro Mesia de la Cerda Marqués de la Vega Armijo.- Escala [ca. 1:2863685]

1 mapa : ms., col. ; $146 \times 202,5 \mathrm{~cm}$

Comprende desde la isla de Lobos en Perú hasta el lago de Nicaragua y desde la desembocadura del río Amazonas hasta el cabo Gracias a Dios en Nicaragua. - Escala gráfica de 300 millas de 60 al grado ó 100 leguas de 20 al grado [= 19,4 cm]. Graduado según el meridiano de Quito. Orientado con rosa de 16 vientos y lis. - Relieve de perfil. Manuscrito coloreado a la acuarela en gris y rojo. - Figura hidrografía y orografía, destacando la cordillera de los Andes. - Señala divisiones administrativas, vegetación, misiones y toponimia. - En el márgen inferior, extensas notas relativas a la historia, virreinato y su administración, estadísticas de los gobiernos militares y políticos, y provinsión y plazas de armas, Audiencia y Chancillería de Santa Fe y Quito, misiones de distintas órdenes, economía, ejercito y Real Hacienda. - Incluye: "Vista de la parte occidental de la ciudad de Sta. Fé de Bogotá". Leyenda coronada con escudo real y filacterias.

Signaturas: MN. P-104

Brito, Pedro Torcuato Javier de

BRASIL. Mapas generales. 1:7407400. 1867 
Nova Carta Chorographica do Imperio do Brazil / Reducida pelo Bacharel Pedro Torquato Xr. de Brito Tenente Coronel Gro. do Corpo d'Engenheiros e Socio effectivo do Instituto Polytechnico Brasileiro ; da que foi confeccionada pelo Coronel conrado Jacob de Niemeyer e outros Officiaes Engenheiros em 1856 ; Gravada na Litha. do Archo. Militar porAlvaro e Pereira do dia 3 a 7 de Abril 1867. - Escala [ca. 1:7407400] .- [Brazil] : Archivo Militar, 1867

1 mapa : montado sobre tela; 70 x $67 \mathrm{~cm}$

Escala de 40 leguas [= $3 \mathrm{~cm}]$. - Graduada

Signaturas: MN. 37-C-2

Riudavets y Monjó, José

BRASIL. Mapas generales. 1:1200000. 1788

[Carta topográfica de América del Sur : comprendida aproximadamente entre los $23^{\circ} \mathrm{S}$ y los $31^{\circ} \mathrm{S}$ de latitud y $2^{\circ} \mathrm{O}$ y $9^{\circ} \mathrm{E}$, longitud del meridiano de Buenos Aires] / J. Riudavets lo grabó.- Escala [ca. 1:1200000] 1788

1 mapa ; $78 \times 100 \mathrm{~cm}$

Título propio redactado a partir del contenido del documento. - Escala hallada a partir de un grado de latitud. Coordenadas referidas al meridiano de Buenos Aires y Cádiz. Inserta "Plano del gran Salto del Iguazú o Río Grande de Curitiva" Escala [ca. 1:46500]. "Plano del primer Salto grande del Río Piquiry Guazú". Escala [ca. 1:18000]

Signaturas: MN. 43-B-9

López, Tomás

BUENOS AIRES (Argentina) (Obispado). Mapas generales. 1:15000000. 1758

Parte del Paraguay y el Obispado de Buenos-Ayres. 1758 / [Thomas Lopez]. - : Escala [ca. 1:15000000]. - [Paris : Thomas Lopez Pensionista de S. M..., Año de 1758 (Se hallará en Madrid : en casa de antonio Sanz Plazuela de la Calle de la Paz)

1 mapa $; 12 \times 8 \mathrm{~cm}$

Comprende el obispado de Buenos Aires, el estado de Uruguay, las provincias argentinas de Corrientes, Entre Ríos, norte de Buenos Aires y prácticamente la totalidad del estado brasileño de Rio Grande do Sol, habiéndose representado, igualmente, los departamentos paraguayos de Neembucú, Misiones e Itapúa. - Mención de responsabilidad y pie de imprenta tomados de la portada del atlas. - Escalas gráficas de 40 leguas españolas de 17,1/2 al grado [=1,7 cm] y 4 leguas de 20 al grado [= 1,45 cm]. Coordenadas referidas, al parecer, al meridiano de Tenerife (O $44^{\circ} 30^{\prime}-033^{\circ} 30^{\prime} / \mathrm{S}$ $\left.23^{\circ} 00^{\prime}-\mathrm{S} 37^{\circ} 00^{\prime}\right)$. Red geográfica de $5^{\circ}$ en $5^{\circ}$. - Relieve de perfil. - En: López de Vargas Machuca, Tomás : "Atlas Geographico de la America Septentrional y Meridional". 1758, [mapa 33] p. 108

Signaturas: MN-I2-585- map. [33] p. 108

Wagner, Frederico

MINAS GERAIS (Brasil) (Estado). Mapas generales. 1:2000000. 1855

Carta Chorographica da Provincia de Minas Geraes : coordenada e dezenhada em vista dos Mappas chorographicos antigos e das observaçoes mais recentes de varios 
Engenheiros por Orden do Illmo. E Exmo. Sr.Dovtor Francisco Diogo Pereira de Vasconcellos Presidente desta Provincia / por Frederico Wagner Escala: Escala [ca. $1: 2000000], 40$ legoas [= $11 \mathrm{~cm}] .-1855$

1 mapa : ms. ; 69'5 x 79'5 cm

Manuscrito firmado y fechado. A plumilla en tinta negra. - Coordenadas referidas al meridiano de Pao d'Assucar (O 9-E 5으 $12^{\circ}-\mathrm{S} 24^{\circ}$ ). - Relieve representado por normales. - Relación de las islas, montes, ríos, etc. indicados por clave alfabética. - Tabla de signos convencionales para indicar núcleos de población de distinta categoría, capillas y minas de oro en explotación. - En el margen inferior se señala que es una litografía del Archivo Militar y que el grabador es Alvaro María da Silva Roiz, es el borrador preparado para grabar.

Signaturas: MN. 39-C-5

Garçao, B.S.

PARANÁ (Río). Mapas hidrográficos. 1:32500. 1859

Carta Reduzida do Alto Paraná / Levantada por orde do Illmo. e Exmo. Senr. J. Lamego Costa Commandante da Divizao Naval do Rio da Prata Pelo $1^{\circ}$ Tenente da ANI FF de BS Garçao Coadjuvado pelo Piloto da ANI FD Simas ; Organisada e desehada por LYM Penha. - Escala [ca. 1:32500].- 1859

1 mapa en 2 h. : ms. ; h. de $68^{\prime} 1 \times 117^{\prime} 4 \mathrm{~cm}$

Comprende desde la ciudad de Corrientes hasta la ensenada de Ibicuá. - Manuscrito firmado y fechado. A plumilla en tinta negra. - Escala hallada a partir de un minuto de latitud $\left[=5^{\prime} 7 \mathrm{~cm}\right]$. Coordenadas referidas al meridiano de Río de Janeiro (O 15²44'-O

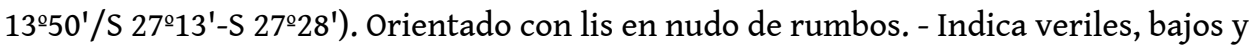
sondas batimétricas en palmos. - Curso del río dividido en tramos, tres en cada hoja, con coordenadas propias Materias: Corrientes (Argentina), Neembucú (Paraguay)

Signaturas: MN. 39-C-3-4

López, Tomás

PARAGUAY. E. Mapas generales. 1:8200000. 1758

El Paraguay. 1758 / [Thomas López] .- Escala [ca. 1:8200000] .- [Paris : : Thomas Lopes Pensionista de S. M., Año de 1758 (Se hallará en Madrid : en casa de Antonio Sanz Plazuela de la Calle de la Paz)

1 mapa $; 12$ x $8 \mathrm{~cm}$

Presenta la parte oriental de Paraguay, situada entre los rios Paraná y Pataguay, y el sureste del estado brasileño de Matogrosso do Sul, Comprendido entre el segundo rio y la siera de maracaju. - Mención de responsabilidad y pie de imprenta tomados de la portada del atlas. - Escalas gráficas de 40 leguas españolas de 17,1/2 al grado [= 3,1 cm] y 40 leguas de 20 al grado $[=2,8 \mathrm{~cm}]$. Coordenadas referidas, al parecer, al meridiano de Tenerife $\left(\mathrm{O} 41^{\circ} 45^{\prime}\right.$-- $\mathrm{O} 36^{\circ} 15^{\prime} / \mathrm{S} 19^{\circ} 45^{\prime}$-- S $\left.27^{\circ} 00^{\prime}\right)$. Red geográfica de $5^{\circ}$ en $5^{\circ}$. Orografia de perfil. - En : López de Vargas Machuca, Tomás : "Atlas Geographico de la America Septenrrional y Meridional". 1758, [map. 32] p. 106

Signaturas: MN-I2-585- map. [32] p. 106 
Baptista, H.A.

PARAGUAY (Brasil) (Río). Mapas hidrográficos. 1:525000. 1857

Reconhecimento da parte do Río Paraguay : Comprehendida entre os Dourados, e villa Maria / Feito pelo $1^{\circ}$ tenente d'Armada Commandante do Vapôr Japará H.A. Baptista. Escala [ca. 1:525000]. - 1857 agosto

1 mapa : ms. ; $61^{\prime} 0$ × 42'4 cm

Manuscrito firmado y fechado. A plumilla en tinta negra. - Escala hallada a partir de un grado de latitud $\left[=21^{\prime} 2 \mathrm{~cm}\right.$ ]. Coordenadas referidas al meridiano de París (0 5945'-O $58^{\circ} 57^{\prime} / \mathrm{S} 15^{\circ} 47^{\prime}-\mathrm{S} 18^{\circ} 08^{\prime}$ ). - Relieve representado por normales. Sondas batimétricas en pies ingleses. - En el ángulo inferior izquierdo se señala que es una litografía del Archivo Militar ; es el borrador preparado para grabar.

Signaturas: MN. 39-C-2

Baleato, Andrés

Soler, Joaquín, Fr.

PERU. N. Mapas generales. 1:4444444. 1795

Plano General de las montañas Orientales al Reyno del Perú : pertenecientes a la Corona de España y confines de Portugal, que comprehende desde 1 hasta $20^{\circ}$ de Latitud S. y desde el Meridiano de Lima hasta $20^{\circ}$ de Latitud / Formado sobre los reconocimientos que verifico el Rdo. Pe. Fr. Joaquin Soler. Misionero Apco. en el discurso de 15 añs. que estuvo exercitando en las Conversiones, y en el acopio de noticias que adquirió, teniendo presentes todas las incursiones y descubrimientos que hay hasta la fecha de lo que dedujo el giro y confluencias de todos los rios considerables, la dirección de las serranías principales y la posición geográfica de los Países y Naciones así Cristianas como Barbaras del modo que manifiesta el plano ; Hecho de Orden del Exmo. Sor. Virrey B ${ }^{\circ}$ Fr. Dn. Franco. Gil y Lemos por Dn. Andres Baleato, año de 1795. - Escala [ca. $1: 4444444]$

1 mapa : ms., col., montado sobre tela ; $57,4 \times 79,6 \mathrm{~cm}$

Graduado, un grado de latitud $[=2,5 \mathrm{~cm}]$. - Orientado con lis sobre rosa de 8 vientos. Texto detallado sobre los "conocimientos geográficos que resultan de las incursiones hechas en las montañas hasta la actualidad". Hace también una reflexión sobre la línea divisoria. Al final del texto hay una rúbrica.

Signaturas: MN. 34-A-3

\section{MAPAS DEL TRATADO DE 1750}

BRASIL. Mapas generales. 1:5555556. [1751]

Mapa Geográfico dos confins do Brazil : com as terras da Coroa de Espanha na America Meridional. : o que esta de amarelo se acha ocupado pelos portugueses, o que esta de colorado esta ocupado pelos espanholes. A linha encarnada que principia en el rio Tavari y se termina en el arroyo de Chuy es la de la demarcacion - Escala [ca. $1: 5555556]$.

1 mapa : ms., col. ; 93,3 x $80 \mathrm{~cm}$ 
Graduado, 1 grado de latitud [= $2 \mathrm{~cm}$ ]. - Manuscrito en colores.- Relieve de perfil. Señala la frontera que delimita las posesiones portuguesas y españolas, indicadas por distintos colores. - Pertenece a los planos levantados para el tratado de 1750.- Es una copia del Mapa de las Cortes que se usó como documento diplomático para la negociación del tratado de 1750.

Signaturas: MN. 38-C-10

BRASIL. Mapas generales. 1:5500000. 1750

Demostracao Geographica de todo o Brasil : [...] mai exactas noticias. - Escala [ca. 1:5500000]

1 mapa : ms., montado en tela; $93,5 \times 65,5 \mathrm{~cm}$

Escala gráfica de 100 leguas $[=10,5 \mathrm{~cm}]$. Orientado con lis en rosa de 8 vientos.

Representación de la línea equinocial o Ecuador y el Trópico de Capricornio. Representa las zonas españolas y portuguesas ; toponimos portugueses en rojo y españoles en negro - Posiblemente forma parte de los documentos en que se basaron las cuestiones de límites. - Incompleto, falta parte del título.

Signaturas: MN. 37-C-5

A-COMISIONES DE LIMITES DEL NORTE DE BRASIL. ORINOCO

Esquiaqui, Domingo

AMERICA DEL SUR. N. Mapas generales. 1:2415459. 1799

Plano geográfico de Arzobispado de Sta. Fé en el Nuevo Reyno de Granada en su antiguo estado, y Obispados sufraganeos de Popayan Cartagena y Sta. Marta : formado por algunos planos conformes de la Secretaría de este Virreynato, de varias observaciones, y de noticias adquiridas por individuos practicos en sus distritos... / arreglado este mapa por el Coronel del Rl. Cuerpo de Artilleria Dn. Domingo Esquiaqui, Comandante del Departamento de Cartagena de Indias en 31 de Agosto de 1799. - Escala [ca. $1: 2415459]$

1 mapa ; ms., $53 \times 62 \mathrm{~cm}$

Graduado, 1 grado de latitud [= 4,6 cm]. - Relieve de perfil. - Toponímia de los montes, ríos, núcleos de población y misiones de la zona .

Signaturas: MN-32-B-14

AMERICA DEL SUR. Mapas generales. 1:1207730. 1762

[Mapa original del Amazonas y sus afluentes del Sur] / [José Solano y Bote] - Escala [ca. $1: 1207730]$

1 mapa : ms., col. ; 158 × $241 \mathrm{~cm}$ (irrregular)

Titulo tomado del verso del mapa . - Escala hallada según grado de meridiano $[=9,2 \mathrm{~cm}]$. Orientado con media lis. - Abarca desde los $12^{\circ} \mathrm{N}$ hasta $4^{\circ} \mathrm{S}$, y desde los $61^{\circ}$ hasta los $83^{\circ}$, estando representada la laguna de Maracaibo hasta el rio de la Madera y las costas orientales y occidentales de América del Sur.- - Manuscrito coloreado a la acuarela en verde; entelado, le falta el ángulo superior izquierdo - Figura hidrografía y orografía muy detallada. - Señala la localización de las misiones. - Toponimia. - Posiblemente sea el mapa del "Curso del rio Orinoco, el de los rios que le entran, aguas que da al gran rio 
de las Amazonas, con las provincias que comprende, citado por Bauzá y hecho por José Solano y Bote (Lucena, 1991a: 246)

Signaturas: MN. G.E.27

Rotella, Padre

AMERICA DEL SUR. Mapas hidrográficos. 1740

Mapa del Pe. [i. e. Padre] Rotella q. acompaña a la relación .- Escala indeterminada 1 mapa : ms., montado en tela ; $57,7 \times 78,0 \mathrm{~cm}$

Título tomado del verso del mapa.- Comprende desde el Darién hasta el río Marañón, con el curso del Orinoco y su comunicación con el Amazonas. - Leyendas relativas a los ríos representados. - Toponimia. - Indica núcleos de población, misiones y tribus indígenas de la zona. - En el margen inferior, nota explicativa con interesantes datos sobre los ríos representados.

Signaturas: MN-32-B-11

APURE (Venezuela) (Río). Mapas hidrográficos. 1759

Afluentes del río Apure / Doz, Vicente ; Guerrero, Nicolás]. - Escala indeterminada 1 mapa : ms. ; $42,7 \times 31,2 \mathrm{~cm}$

Título redactado a partir del contenido del documento. - Manuscrito a plumilla en tinta negra. - Señala los afluentes del Apure. - Notas a lápiz hechas con posterioridad.

Signaturas: MN. 30-E-37

Centurión Guerrero de Torres, Manuel

BRASIL. Mapas generales. 1:66000. 1770

Plano General de la Probincia de Guayana : que con la actitud posible y respecto a su dilatada circunferencia e ynconito centro / ha formado con las noticias adquiridas hasta el 31 de diciembre de 1770 el Comte Gl de ellas Dn Manuel Zenturion. Escala [ca. 1:66000].- 1770

1 mapa : ms. ; 49,1 x 64,6 cm

Presenta la zona comprendida desde el río Amazonas hacia el sur. - Escala hallada a partir de 1 minuto [= 2,8 cm]. Coordenadas referidas unicamente a la latitud. - Tabla de signos convencionales.

Signaturas: MN. 37-A-1

CARONI (Venezuela) (Río). Mapas hidrográficos. 1759

Río Caroní : Afluente del Orinoco / Expedición de Límites. - Escala indeterminada. 1 mapa : ms. ; 31,9 × 40,9 cm

Manuscrito a plumilla en tinta negra. - Notas relativas al tiempo que tardaron en desplazarse desde un punto a otro. - Toponimia costera. Croquis.

Signaturas: MN. 30-E-22

CAYENA (Guayana Francesa) (Isla). Cartas náuticas. 1:19700.1700?

Plano de la isla Cayena y sus inmediaciones.- Escala [ca. 1:197000] 
1 cartas náutica : ms. ; 39,6 x 41,5 cm

Escala gráfica de 3 leguas comunes de $[=8,5 \mathrm{~cm}]$. Orientado con media lis. - Señala la toponimia de la costa.

Signaturas: MN. 37-A-5

Diguja; Josef; Dubuchet, Máximo

CUMANÁ. Mapas generales. 1:455373. 1765

Plano de las Provincias de la nueva Andalucia, y nueva Barcelona, dela Governacion de Cumana / enmendado sobre el remitido por Dn. Josef Diguja, conque da cuenta á S.M. su Governador y Comandante gral. Capitan de Navío Dn . Maximo Dubuchet, añadiendosele, desde la Boca del Rio Unare hasta Cavo Guadera, terreno que se supone usurpado por la Provincia de Caracas y se halla en litigio, 1765. - Escala [ca. 1:455373], 10 leguas de a 20 en grado [= $12,2 \mathrm{~cm}]$

1 mapa : ms., col., montado sobre tela ; 93,5 x 155,5 cm

Comprende el norte oriental de Venezuela con las islas de Trinidad y Margarita. Orientado con lis. - Relieve representado por sombreado. - Manuscrito a plumilla en tinta negra y coloreado a la acuarela en varios colores. - Tabla de signos convencionales para indicar núcleos de población de distinta categoría. - Indica masas forestales. - Nota sobre las características de los terrenos conquistados por los españoles.

Signaturas: MN. 30-A-11

Blanco, Joseph; Iturriaga, José de

CUMANÁ. Cartas náuticas. 1:51441. 1754

Descripción Dela Punta de Araya, parte de la Consta del C. Golfo de Cariaco, Bahía de Cumana (Situado su Castillo según observacion astronómica la Lattd. de 10 g. 28 m. N.), consta de Bordones hasta el Puerto de Mana, con los dos Puertos que hay Yntermedio que son Mochina y Escondido, con su sonda en brazas, bajos y placeres / dado a luz por el Capitán y el Piloto de la Fragata de S. M. que vino a operaciones del Real Servizio a ésta bajo las hordenes del Gefe de Esquadra de la Real Armada Dn. Jph. de Yturriaga Comandte. de la espedizión secreta, hecho el año de 1754 ; Jph Blanco .- Escala [ca. 1:51441], 2 leguas de 20 en grado [= 21,6 cm]

1 carta náutica : ms., col. ; 96,1 x $64 \mathrm{~cm}$ pleg. a 48,2 x $64 \mathrm{~cm}$

Orientado con lis en rosa de 8 vientos prolongados. - Indica veriles, bajos, fondeaderos y sondas batimétricas. - Manuscrito a plumilla en tinta negra y coloreado a la acuarela en verde. - Nota explicativa sobre las mareas. - Título enmarcado en cartela decorada con instrumentos geográficos.

Signaturas: MN. 30-C-8

Iturriaga, José de; Badaraco, José Francisco; Hernández, Manuel, cop.

CUMANÁ. Cartas náuticas. 1:51441. 1754?

Plano ó Descripción de la Punta de Araya y su fondeadero, parte de la Costa del el parte del Golfo de Cariaco, Bahía de Cumana (Cituado su Castillo segun observon. astronomicas en la Lattd. Norte de 10 g. 28 m.) Costa de Bordones, Pto. Escondido, Costa y Pto. de Mochina con sus puntas, bajos, ensenadas y sondas / dado a luz por los Pilotos 
de la Fragata de S. M. nombrada la Pura y limpia concepción y Sn. Marcos, que bino a operaciones del Rl. Servicio ha esta bajo las Ordenes del Gefe de Esquadra Dn. Joseph de Yturriaga Commte. de la Espedicion Secreta Año de 1754 ; copiado por Manuel Fernandez Concurrente de la Real Escuela de Navegación bajo la corrección de Dn. Joseph Franco. Badareco, Mro. Dor. p. S. M. - Escala [ca. 1:51441], 2 leguas de 20 leguas en grado $[=12,5 \mathrm{~cm}]$

1 carta náutica : ms., col., montado sobre tela ; 38,6 x 50,3 cm

Presenta una vista de la ruta de Araya. - Orientado con lis en nudo de rumbos. - Indica veriles, bajos, fondeaderos y sondas batimétricas. Clave hidrográfica para determinar la calidad del fondo. - Manuscrito a plumilla en tinta negra y carmín y coloreado a la acuarela en verde, gris y amarillo. - Señala núcleos de población de distintas categorías y fortificaciones. - Sello de la Real Escuela de Navegación de Cádiz.

Signaturas: MN. 30-C-7

Zuloaga, Santiago; Blanco, Joseph; Iturriaga, José de;

CUMANÁ (Venezuela) (Sucre) (Golfo). Cartas náuticas. 1:88653. 1754

Descripción de la Punta de Araya, parte de la costa del E. Golfo de Cariaco, Bahía de Cumana (situado su castillo segun observacion. astronomicas la Lattd. de 10 g. $28 \mathrm{~m} \mathrm{~N}$ ), Costa de Bordones hasta el Campanario con los Ptos. que hay en este Intermedio con su sonda en braz. bajos y plazeres / dado a luz por los Pilotos de la Fragta. de S.M. que vino a operaciones del Real Servicio a esta, Bajo las Ordenes del Geje de Esquadra de la Real Armada, Dn. Jph. de Iturriaga, Cmte. principal de la espedición secreta ; Dn. Santiago Zuloaga ; Jph. Blanco Escala: Escala [ca. 1:88653], 3 leguas de 20 en grado [= 18,8 cm]

1 carta náutica : ms. ; 55,7 x 45,7 cm

Orientado con lis en rosa de 8 vientos prolongados. - Indica veriles, bajos, fondeaderos y sondas batimétricas. - Manuscrito a plumilla en tinta negra y gris. - Señala toponimia costera. - Título enmarcado en cartela decorada con instrumentos geográficos.

Signaturas: MN. 30-C-3

Solano, José; Urrutia, Antonio; Albarado, Eugenio

CUMANA (Venezuela) (Sucre). Planos de población. 1:1036. [1760]

Plano de una parte de la ciudad de Cumaná con el Castillo de San Antonio / Dn. Jph. Solano, Dn. Antonio Urrutia, Dn. EugenioAlbarado Escala [ca. 1:1036]

1 mapa : ms., col. ; 61,6 x 91,7 cm

Título redactado a partir del contenido del documento. - Presenta los edificios, el puerto y un lugar llamado Toporo. - Escala gráfica de 60 toesas [= 11,3 cm]. - Relieve de perfil. - Manuscrito coloreado a la acuarela en varios colores. - Indica la corriente del río con una flecha. - Al verso un mapa de algún lugar imposible de determinar.

Signaturas: MN. 30-A-7

Moreno, Miguel

CUMANA (Venezuela) (Sucre). Cartas náuticas. 1:54466. 17--

Plano de Cumaná / M. Moreno Escala: Escala [ca. 1:54466] 
1 mapa : ms. ; $22,3 \times 33,4 \mathrm{~cm}$

Presenta un pequeño plano de la población y la costa de alrededor. - Manuscrito firmado y rubricado por el autor. - Escala gráfica de 2 millas $[=6,4 \mathrm{~cm}]$. Orientado con nudo de 4 rumbos y media lis. - Indica sondas batimétricas, fondeaderos y calidad del fondo. - Señala la toponimia costera.

Signaturas: MN. 30-A-4

CUMANA (Venezuela) (Sucre). Planos de población. 1:1320. 1754-61

Plano de la Ciudad de Cumaná en la Nueva Andaluzia : Situada en gs. ms. de Latid. Boreal y en la Longitud Gs. Ms. a Occidente. de Merno. del Rl. Observatorio de Guardias Maris. de Cádiz.: Escala [ca. 1:1320], 300 varas [= $19 \mathrm{~cm}$ ]

1 plano : ms., col. ; 73,3 x $95 \mathrm{~cm}$

Relieve representado por sombreado y de perfil. - Orientado con lis en rosa de 4 vientos. - Manuscrito a plumilla en tinta negra y coloreado a la acuarela en gris y verde. - Relación de los principales edificios religiosos, fortificaciones, barrios, etc. indicados por clave alfabética. - Indica las corrientes del río y su desembocadura con flechas.

Signaturas: MN. 30-A-10

FAJARDO (Venezuela) (Isla). Castillo de San Carlos. Cartas náuticas 1:3167. 1777

Plano de la Ysla de Faxardo en el Río Orinoco acompañado del Proyecto para fortificarla con el nombre de Castillo de San Carlos / Agustín Crame.- Escala [ca. 1:3167] Guayana el 15 de marzo de 1777

1 carta náutica : ms., col. ; 49,7 x $70 \mathrm{~cm}$

Manuscrito firmado por el autor. - Escala gráfica de 500 varas [= 13,2 cm]. Orientado con lis. - Relieve representado por sombreado. - Indica sondas batimétricas. - Manuscrito coloreado a la acuarela en varios colores. - Inserta: Planta de los pisos superior e inferior del castillo, con tabla explicativa de la misma. Escala [ca. 1:470] y 2 perfiles de dicha planta. Escala [1:230]

Signaturas: MN. 32-B-8

GUAYANA. Cartas náuticas. 1:390000. 1700?

Plano del río Orinoco al Esequibo. - Escala [ca. 1:390000]

1 cartas náutica : ms. ; 62,1 x 93,7 cm

Título propio tomado del verso del documento. - Escala gráfica de 10 leguas de 20 al grado [ $=14,2 \mathrm{~cm}]$. Orientado con media lis. - Indica la toponimia con un índice númérico. - Documento con forma irregular.

MN. 37-A-6

GUAYANA. Perspectivas de costa. 1754

Fortificaciones de Guayana y vistas de costa / D. Elias Caro Guerrero.- Escala indeterminada

1 mapa: ms. ; $34 \times 43 \mathrm{~cm}$ 
Comprende 6 vistas de costa del río Orinoco, río Caroní, isla Fajardo y de ciudad Guayana con los fuertes del padrastro y el castillo de S. Francisco de Asís.- El nombre del autor aparece al verso.

Signaturas MN. 30-E-26

CIUDAD GUAYANA (Venezuela) (Delta Amacuro). Fuerte de San Francisco.

Fortificaciones. 1:330.1759

Plano Proyecto para el Padrastro del Fuerte de Sn. Franco. de la Guaiana.- Escala [ca. $1: 330]$

1 plano. : ms., col. ; 34'5 x 44'9 cm

Escalas gráficas de 15 toesas $[=8,8 \mathrm{~cm}]$ y 40 varas castellanas $[=10,3 \mathrm{~cm}]$. - Manuscrito coloreado a la acuarela en rosa, amarillo y gris. - Clave alfabética para explicar las distintas partes del plano. - Nota en el margen superior "Guayana, Río Orinoco (Costa Firme)".

Signaturas: MN. P-15-A-1

ESMERALDA (Venezuela) (Sucre) (Ensenada). Cartas náuticas. 1:29395. 1754

Plano de la Ea. de la Esmeralda Escala [ca. 1:29395], una milla dividida en cables [= 6'3 $\mathrm{cm}$ ]

1 carta náutica : ms. ; 20'1 x 29'1 cm

Manuscrito a plumilla en tinta negra. - Coordenadas referidas al meridiano de San

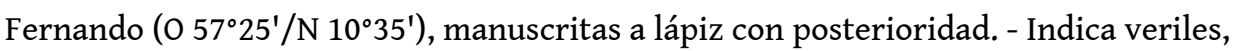
bajos, fondeaderos y sondas batimétricas en brazas de 6 pies de Burgos. Clave hidrográfica para determinar la calidad del fondo. - En margen superior de la hoja, "Costa de tierra firme. No. 4".

Signaturas:MN. 30-C-5

GUAYANA FRANCESA. Mapas generales. 1.4200000. 1773

[Mapa general de la Guayana Francesa, parte oriental de Surinam y Norte de Brasil] . Escala [ca. 1:4200000]

1 mapa : ms. ; $20,2 \times 29,3 \mathrm{~cm}$

Título redactado a partir del contenido del documento. - Escala hallada a partir de un grado de latitud $[=2,6 \mathrm{~cm}]$. Coordenadas referidas a un meridiano que no se especifica. Señala la toponimia. - Nota explicativa sobre la colonización de Surinam y de la Guayana.

Signaturas: MN. 37-A-2

Solano; José

MARGARITA (Venezuela). (Isla) Cartas náuticas. 1:606060.1754

Carta que comprende parte de la costa venezolana, desde la isla Margarita y golfo de Cariaco hasta el cabo Codera incluyendo la isla de la Tortuga.- Escala [ca. 1:606060], 18 leguas de 20 al grado $[=16,5 \mathrm{~cm}]$

1 carta náutica : ms., col. ; 37 x 45,4 cm 
Título propio redactado a partir del contenido del documento- Orientado con lis en nudo de rumbos. - Indica sondas batimétricas. - Manuscrito a plumilla en tinta negra y coloreado en gris. - Relación de los principales accidentes geográficos costeros indicados por clave alfabética. - Indica la ciudad de Cumaná mediante un edificio de perfil. - En el margen superior izquierdo, mapa de configuración de toda la costa de Venezuela.

Signaturas MN. 30-A-13

Solano; José

MARGARITA (Venezuela) (Isla). Mapas generales. 1:920000. 1754

Mapa del norte de Venezuela, recogiendo de un lado parte del curso del rio Orinoco, desde su afluente el río Tomo hasta su desembocadura en el océano Atlántico y de otro, las islas Margarita, y Trinidad.- Escala [ca. 1:920000]

1 mapa : ms., col. ; 102 x 143,7 cm

Presenta los principales ríos, sus afluentes más destacados y las aguas interiores (lagos, lagunas) del área representada. - Título propio redactado a partir del contenido del documento. Posiblemente hecho por José Solano o Alvarado - Graduado, 1 grado de latitud [=12,5 cm]. - Relieve de perfil. - Manuscrito coloreado a la acuarela en varios colores. - Tabla de signos onvencionales informando de los núcleos de población más relevantes. - Inserta mapas, a escala mayor, de las islas de Trinidad y Margarita.

Signaturas: MN. 31-B-9

Solano, José

MARGARITA (Venezuela) (Isla). Cartas náuticas. 1:200000. 1754

Plano de la Isla Margarita, Golfo de Cariaco / José Solano.- Escala [ca. 1:200000]

1 carta náutica : ms., col. ; 48,5 x 64,2 cm

Título propio tomado del verso del documento. - Relieve de perfil. - Indica veriles y sondas batimétricas. - Manuscrito a plumilla en tinta negra y coloreado a la acuarela en varios colores. - Relación de la fauna y flora que aparece en la cartela indicadas por clave alfabética. - Señala masas forestales. - En el margen izquierdo cartela con adornos de fauna y flora y escrito a lápiz con posterioridad: "Isla Margarita"

Signaturas:MN. 31-A-7

MARGARITA (Venezuela) (Isla). Cartas náuticas. 1754

Plano de Isla Margarita .- Escala indeterminada

1 carta náutica : ms., col. ; 45,5 x $60 \mathrm{~cm}$

Comprende la Isla Margarita, islas adyacentes de Cubagua y Codre y N. de la Península de Araya. - Título propio tomado del verso del documento. - Relieve representado por sombreado. - Indica veriles, bajos y sondas batimétricas. - Manuscrito coloreado a la acuarela en ocre, verde y gris.

Signaturas:MN. 31-A-6

NEGRO (Brasil) (Río).Mapas hidrográficos. 1759

Río Negro / Expedición de Límites. - Escala indeterminada 
1 mapa : ms. ; $18 \times 49,8 \mathrm{~cm}$

Título redactado a partir del contenido del documento . - Presenta el plano y situación del pueblo de Costanheiro. - Manuscrito a plumilla en tinta negra. - Al verso, plano de Pueblo Dari.

Signaturas: MN. 30-E-19

Ramery, Tomás de ; Academia de Pilotos de El Ferrol

ORINOCO (Venezuela) (Río). Mapas hidrográficos. 1:2583977 1:6006000. 1759

Río del Orinoco : cuyas bocas son las que se trafican en él ignorandose todo de ellas copiado en los mismos términos por el que se transfloró / Academia de Pilotos de Ferrol ; Tomas de Ramery .- Escala [ca. 1:2583977-1:6006000]

1 mapa : ms., col. ; 49,8 x 66,4 cm

Manuscrito firmado por el autor. - Escalas gráficas de 20 leguas $[=4,3 \mathrm{~cm}]$ y de 40 leguas [= 3,7 cm]. - Orientado con lis y nudo de rumbos. - Manuscrito coloreado a la acuarela en verde, gris y amarillo. - En ángulo superior izquierdo, recuadro que incluye título y clave toponímica. - En el ángulo inferior izquierdo, recuadro conteniendo notas y relación de lugares representados.

Signaturas: MN. 32-B-5

ORINOCO (Venezuela) (Río). Mapas hidrográficos. 1:222222. 1759

Desembocadura del río Apure, afluente del Orinoco / Expedición de Límites

Escala [ca. 1:222222], 1 legua $[=2,5 \mathrm{~cm}] 1759$

1 mapa : ms. ; $21,4 \times 31,3 \mathrm{~cm}$

Título redactado a partir del contenido del documento. - Presenta la zona de la desembocadura del río Apure. - Manuscrito a plumilla en tinta negra y a lápiz .

Signaturas: MN. 30-E-20

Ortiz-Berea, Pascasio; de la Camara, Francisco; Núñez

ORINOCO (Venezuela) (Río). Cartas náuticas 1:148148. 1754-1761. (1816)

Plano topográfico de los ríos Negro, Meta, Orinoco y sus adyacentes con demostración de los caños que los engrandecen / levantado en el viage del Presvro. [i. e. Presbitero] Josef Cortes Madariaga (alias el Canónigo de Chile) por Pascasio Ortiz-Berea y Franco. de la Camara de regreso de Sta. Fé a Caracas; es copia para el uso del Fxto. [i.e. Exercito] Expediciones Pacificador, Sta. Fé y Septiembre de 1816, Nuñez. - Escala [ca. 1:148148]

1 mapa : ms., col., en papel vegetal ; 42,2 x 116,3 cm, pleg. en $42,2 \times 31,5 \mathrm{~cm}$

Firma del autor. - Dedicatoria : "Dedicado a los dos Estados de Caracas y

Cundinamarca". - Escala gráfica de 2 leguas marítimas [= 7,5 cm $]$. - Orientado con 2 medias lises. - En ángulo superior izquierdo, clave toponímica y nota explicativa. Manuscrito lavado en varios colores.

Signaturas: MN. 32-B-1

ORINOCO (Venezuela) (Río). Cartas náuticas. 1759

Río Orinoco / Expedición de Límites. - Escala indeterminada 1759 
1 carta náutica : ms. ; 54,5 x 22 cm ó menos

Presenta la situación de Ciudad Guayana. - Manuscrito a plumilla en tinta.

Signaturas: MN. 30-E-28

ORINOCO (Venezuela) (Río). Mapas hidrográficos. 1:6883. 1747

Carta y descripción hidrográfica de una parte del gran Río Orinoco : que comprehende desde el caño de Guarapo hasta la Ysla de Fajardo.- Escala [ca. 1:6883], 300 toesas [= 8,5 $\mathrm{cm}$ ] A 24 de Marzo de 1747

1 mapa : ms., col. ; 59,4 x 39,6 cm

Orientado con lis. - Relieve de perfil. - Manuscrito coloreado a la acuarela en varios colores. - Toponimia de los afluentes del río, montes que lo circundan y misiones de los capuchinos catalanes establecidos en la zona.

Signaturas: MN. 32-B-13

ORINOCO (Venezuela) (Río). Mapas generales. 1759

Confluencia de los ríos Atabapo y Guaviare con el Orinoco] / Expedición de Límites .Escala indeterminada

1 mapa : ms. ; $38,3 \times 49,4 \mathrm{~cm}$

Título propio redactado a partir del contenido del documento. - Manuscrito a plumilla en tinta negra. - Indica situación, plano y noticia histórica de San Fernando de Atabapo que fue fundado en 1757.

Signaturas: MN. 30-E-27

ORINOCO (Venezuela) (Río). Mapas hidrográficos. 1:506366. 1754-61

[Curso del río Orinoco desde su unión con el río Caroni hasta sus bocas] / José Solano .Escala [ca. 1:506366]

1 mapa : ms. ; $64,9 \times 47,8 \mathrm{~cm}$

Título propio redactado a partir del contenido del documento. -esta indicado san fernando de atabapo.- Escala gráfica de 17,5 leguas españolas [= 19,2 cm]. - Relieve de perfil. - Indica la toponimia de los afluentes del río, montes que lo circundan y misiones existentes en la zona. - En ángulo inferior izquierdo, nota explicativa. - Borrador.

Signaturas: MN. 32-B-6

ORINOCO (Venezuela) (Río). Mapas hidrográficos. 1759

Río Orinoco / Expedición de Límites. - Escala indeterminada.- 1759

1 mapa : ms. ; $31,2 \times 21 \mathrm{~cm}$

Manuscrito a plumilla en tinta negra. Croquis.

Signaturas: MN. 30-E-1

ORINOCO (Venezuela) (Río). Mapas hidrográficos. 1:222222. 1759

Río Orinoco / Expedición de Límites. - Escala [ca. 1:222222], 2 leguas [= 2,5 cm]. - 1759

1 mapa : ms. ; 31,4 x $43 \mathrm{~cm}$ 
Manuscrito a plumilla en tinta negra. - Notas explicativas sobre lo que le acontecía a la expedición, con día y hora. Croquis.

Signaturas: MN. 30-E-30

ORINOCO (Venezuela) (Río). Mapas hidrográficos. 1759

Río Orinoco / Expedición de Límites. - Escala indeterminada. - 1759

1 mapa : ms. ; $31,5 \times 21,5 \mathrm{~cm}$

Manuscrito a plumilla en tinta negra. Croquis.

Signaturas: MN. 30-E-3

ORINOCO (Venezuela) (Río). Mapas hidrográficos. 1759

Río Orinoco / Expedición de Límites. - Escala indeterminada. - 1759

1 mapa : ms. ; $31,2 \times 21,5 \mathrm{~cm}$

Manuscrito a plumilla en tinta negra. Croquis.

Signaturas: MN. 30-E-4

ORINOCO (Venezuela) (Río). Mapas hidrográficos. 1759

Río Orinoco / Expedición de Límites. - Escala indeterminada. - 1759

1 mapa : ms. ; $31,2 \times 21,2 \mathrm{~cm}$

Manuscrito a plumilla en tinta negra. Croquis.

Signaturas: MN. 30-E-5

ORINOCO (Venezuela) (Río). Mapas hidrográficos. 1759

Río Orinoco / Expedición de Límites. - Escala indeterminada.- 1759

1 mapa : ms. ; $31,1 \times 21,1 \mathrm{~cm}$

Manuscrito a plumilla en tinta negra. Croquis.

Signaturas: MN. 30-E-6

ORINOCO (Venezuela) (Río). Mapas hidrográficos. 1759

Río Orinoco entre el Ocamo, Venturi y Yahú] / Díaz de la Fuente, Apolinar. - Escala indeterminada.- 1759

1 mapa : ms. ; 19,7 x $29 \mathrm{~cm}$

Relieve de perfil. - Manuscrito a lápiz. Croquis.

Signaturas: MN. 30-E-7

ORINOCO (Venezuela) (Río). Mapas hidrográficos. 1759

Río Orinoco / Expedición de Límites.- Escala indeterminada.-: 1759

1 mapa : ms. ; $28,5 \times 20 \mathrm{~cm}$

Manuscrito a plumilla en tinta negra. Croquis.

Signaturas: MN. 30-E-8

ORINOCO (Venezuela) (Río). Mapas hidrográficos. 1759 
Río Orinoco / Expedición de Límites.- Escala indeterminada.- 1759

1 mapa : ms. ; $32 \times 21,4 \mathrm{~cm}$

Manuscrito a plumilla en tinta negra. Croquis.

Signaturas: MN. 30-E-9

ORINOCO (Venezuela) (Río). Mapas hidrográficos. 1759

Río Orinoco / Expedición de Límites.- Escala indeterminada.-1759

1 mapa : ms. ; $43 \times 31,2 \mathrm{~cm}$

Manuscrito a plumilla en tinta negra. - Croquis.,- Al verso, un bosquejo de un caballero.

Signaturas: MN. 30-E-10

Solano, José

ORINOCO (Venezuela) (Río). Mapas hidrográficos. 1759

Río Orinoco / Expedición de Límites.- Escala indeterminada.- 1759

1 mapa : ms. ; 53,5 x 37,3 cm

Orientado con nudo de rumbos. - Manuscrito a lápiz. - Notas ilegibles. - En el margen superior: "Borradores inútiles de Solano" Croquis.

Signaturas: MN. 30-E-11

ORINOCO (Venezuela) (Río). Mapas hidrográficos. 1759

Río Orinoco / Expedición de Límites.- Escala indeterminada.- 1759

1 mapa : ms. ; 36,5 x 33,5 cm ó menos

Manuscrito a plumilla en tinta negra. Croquis.

Signaturas: MN. 30-E-14

ORINOCO (Venezuela) (Río). Mapas hidrográficos. 1759

Río Orinoco / Expedición de Límites.- Escala indeterminada.- 1759

1 mapa : ms. ; $29 \times 39,9 \mathrm{~cm}$

Manuscrito a plumilla en tinta negra. - Indica los nombres de los grupos étnicos que habitaban la zona. - Croquis.- Notas a lápiz hechas con posterioridad.

Signaturas: MN. 30-E-15

ORINOCO (Venezuela) (Río). Mapas hidrográficos. 1759

Río Orinoco / Expedición de Límites.-: Escala indeterminada.- 1759

1 mapa : ms. ; $26,1 \times 37,9 \mathrm{~cm}$

Relieve representado por sombreado. - Manuscrito a plumilla en tinta negra. - Indica masas forestales. Croquis.

Signaturas: MN. 30-E-16

ORINOCO (Venezuela) (Río). Mapas hidrográficos. 1759

Río Orinoco / Expedición de Límites.- Escala indeterminada.- 1759 
1 mapa : ms. ; $21 \times 31 \mathrm{~cm}$

Relieve representado por sombreado. - Manuscrito a plumilla en tinta negra. Croquis.

Signaturas: MN. 30-E-17

ORINOCO (Venezuela) (Río). Mapas hidrográficos. 1759

Río Orinoco / Expedición de Límites.- Escala indeterminada.- 1759

1 mapa : ms. ; $21,2 \times 31,5 \mathrm{~cm}$

Comprende una pequeña parte del cauce del río. - Manuscrito a plumilla en tinta negra.

- Notas explicativas sobre la hora y el lugar donde estuvieron. Croquis.

Signaturas: MN. 30-E-18

ORINOCO (Venezuela) (Río). Mapas hidrográficos. 1:222222. 1759

Río Orinoco / Expedición de Límites.- Escala [ca. 1:222222], 1 legua [= 2,5 cm] .-: 1759

1 mapa : ms. ; 21,4 × 31,3 cm

Presenta la zona de la desembocadura del río Apure. - Manuscrito a plumilla en tinta negra y a lápiz . Croquis.

Signaturas: MN. 30-E-20

ORINOCO (Venezuela) (Río). Mapas hidrográficos. 1759

Río Orinoco / Expedición de Límites.- Escala indeterminada.- 1759

1 mapa : ms. ; $31,1 \times 21,5 \mathrm{~cm}$

Manuscrito a plumilla en tinta negra. Croquis.

Signaturas: MN. 30-E-21

ORINOCO (Venezuela) (Río). Mapas hidrográficos. 1759

Río Orinoco / Expedición de Límites.- Escala indeterminada.- 1759

1 mapa : ms. ; 60,7 x 30,7 cm ó menos

Manuscrito a plumilla en tinta negra. - Notas a lápiz hechas con posterioridad. Croquis.

Signaturas: MN. 30-E-24

ORINOCO (Venezuela) (Río). Mapas hidrográficos. 1:222222. 1759

Río Orinoco / Expedición de Límites.- Escala [ca. 1:222222], 1 legua [= 2,5 cm].- 1759

1 mapa : ms. ; $31,4 \times 21,3 \mathrm{~cm}$

Manuscrito a plumilla en tinta negra y a lápiz. - Notas explicativas sobre el día y hora en que estuvieron en cada punto y otras a lápiz hechas con posterioridad. Croquis

Signaturas: MN. 30-E-23

ORINOCO (Venezuela) (Río). Mapas hidrográficos. 1759

Río Orinoco / Expedición de Límites Escala: Escala indeterminada

1 mapa : ms. ; 54,5 x 22 cm ó menos 
Presenta la situación de Ciudad Guayana. - Manuscrito a plumilla en tinta negra. Croquis.:

Signaturas: MN. 30-E-28

ORINOCO (Venezuela) (Río). Mapas hidrográficos. 1:222222. 1759

Río Orinoco / Expedición de Límites.- Escala [ca. 1:222222], 2 leguas [= 2,5 cm].-: 1759

1 mapa : ms. ; $31,4 \times 43 \mathrm{~cm}$

Manuscrito a plumilla en tinta negra. - Notas explicativas sobre lo que acontecía a la expedición, con día y hora. Croquis.

Signaturas: MN. 30-E-30

ORINOCO (Venezuela) (Río). Mapas hidrográficos. 1759

Río Orinoco / Expedición de Límites.- Escala indeterminada.- 1759

1 mapa : ms. ; 39,4 x $29 \mathrm{~cm}$

Manuscrito a lápiz. - Señala un largo recorrido del río con numerosos topónimos.

Croquis.

Signaturas: MN. 30-E-32

ORINOCO (Venezuela) (Río). Mapas hidrográficos. 1:16835 -1:46296. 1754

Río Orinoco : nuevamente observados sus raudales, bajos, angosturas y aguas que recibe en estas 400 leguas descubiertas, notanse las naciones de indios comarcanas, conocidas asta oy, es en todo más lo q. flata q. descubrir de este famosorio río.- Escala [ca.

1:16835-1:46296]

1 mapa : ms. ; $31,5 \times 116 \mathrm{~cm}$

Precede al título: "JHS". - Escala gráfica de 2 millas [= 2,2 cm] y de 1 milla [= $4 \mathrm{~cm}]$, ésta, imprecisa por la rotura del papel. Orientado con rosa y lis. - Relieve de perfil. - Tabla de signos convencionales utilizados en el mapa. - Señala la toponimia de los afluentes del río, misiones y pueblos indígenas. - Notas explicativas, dispersas por el documento y señalización de los lugares donde murieron misioneros víctimas de los indios.

Signaturas: MN. 32-B-9

Solano, José

ORINOCO (Venezuela) (Río). Mapas hidrográficos. 1755

Curso del río Orinoco desde su unión con el río Caroni hasta sus bocas / José Solano. Escala indeterminada

1 mapa : ms. ; 46,3 x $67 \mathrm{~cm}$

Título propio redactado a partir del contenido del documento. - Relieve de perfil. Señala la toponimia de los afluentes del río, de los núcleos de población y de las misiones de la zona. - Borrador sin terminar. - Notas explicativas al verso: "Original de Solano".

Signaturas: MN. 32-B-7

ORINOCO (Venezuela) (Río). Mapas hidrográficos . 1759 
Curso del río Orinoco y costa venezolana : desde el río Moroca hasta el puerto San Juan / José Solano.- Escala indeterminada.

1 mapa : ms., montado sobre tela ; 78,7 x $123 \mathrm{~cm}$

Comprende el rio Orinoco hasta San Fernando de Atabapo y parte del rio Meta.- Titulo deducido del contenido del documento. - Relieve representado por sombreado. Manuscrito a plumilla en tinta negra y gris. - Indica datos de medidas radiales desde varios puntos.

Signaturas: MN. 30-E-36

ORINOCO (Venezuela) (Río). Mapas hidrográficos. 1759

Delta del Orinoco / Expedición de Límites. - Escala indeterminada. 1759

1 mapa : ms. ; 37,6 x 49,2 cm

Orientado con lis. - Manuscrito a plumilla en tinta negra. - Indica núcleos de población.

Signaturas: MN. 30-E-13

ORINOCO (Venezuela) (Río). Cartas náuticas . 1:920000. 1759

Mapa del norte de Venezuela, recogiendo de un lado parte del curso del rio Orinoco, desde su afluente el río Tomo hasta su desembocadura en el océano Atlántico y de otro, las islas Margarita, y Trinidad, ésta última perteneciente a Trinidad y Tobago]. - Escala [ca. 1:920000]

1 carta náutica : ms., col. ; 102 x 143,7 cm

Presenta los principales ríos, sus afluentes más destacados y las aguas interiores (lagos, lagunas) del área representada. - Título propio redactado a partir del contenido del documento. - Graduado, 1 grado de latitud [= 12,5 cm]. - Relieve de perfil. - Manuscrito coloreado a la acuarela en varios colores. - Tabla de signos convencionales informando de los núcleos de población más relevantes. - Inserta mapas, a escala mayor, de las islas de Trinidad y Margarita.

Signaturas: MN. 31-B-9

ORINOCO (Venezuela) (Río). Mapas hidrográficos. 1759

Noticias de Orinoco / Expedición de Límites. - Escala indeterminada

1 mapa : ms. ; 51,4 x $68,5 \mathrm{~cm}$

Título propio tomado del verso. - Manuscrito a plumilla en tinta negra. - Señala afluentes y pequeñas islas existentes en el curso del Orinoco.

Signaturas: MN. 30-E-12

Solano, José

ORINOCO (Venezuela) (Río). Mapas hidrográficos. 1:653595. 1754-61

Plano del Río Orinoco que comprende desde Punta Barima hasta el cabo Limones / José Solano.- Escala [ca. 1:653595]

1 carta náutica : ms. ; 29,3 x 49,5 cm

Comprende el curso del río entre punta de Barima hasta el cabo Limones. - Título propio tomado del verso del documento. - Escala gráfica de 10 leguas de 20 al grado [= 
$8,5 \mathrm{~cm}$ ]. Orientado con rosa de 16 vientos con lis y nudo de rumbos. - Indica fondeaderos y sondas batimétricas. - Señala la línea de derrotas que hay que seguir por el cauce del río.

Signaturas: MN. 32-B-3

Solano, José

ORINOCO (Venezuela) (Río). Mapas hidrográficos. 1:653595. 1754-61

Plano del Río Orinoco / Solano. - Escala [ca. 1:653595]

1 carta náutica : ms. ; 32,2 x 59,6 cm

Comprende el curso del río entre punta de Barima y cabo de Limones. - Título propio tomado del verso del documento. - Escala gráfica de 10 leguas de 20 al grado $[=8,5 \mathrm{~cm}]$. Orientado con media lis. - Indica fondeaderos y sondas batimétricas Materias:

Signaturas: MN. 32-B-4

ORINOCO (Ríos). Mapas hidrográficos.. 1:390000. 1750

Plano del río Orinoco al Esequivo. - Escala [ca. 1:390000]

1 plano : ms. ; 62,1 x 93,7 cm

Título propio tomado del verso del documento. - Escala gráfica de 10 leguas de 20 al grado $[=14,2 \mathrm{~cm}]$. Orientado con media lis. - Indica la toponimia con un índice númérico. - Documento con forma irregular.

Signaturas: MN. 37-A-6

Solano; José

ORINOCO (Río). Mapas hidrográficos. 1:375375. 1754-61

Plano del Río Orinoco desde su boca hasta la ciudad de Guaiana y desde la boca hasta la ciudad de Esquibo/ José Solano.- Escala [ca. 1:375375]

1 carta náutica : ms. ; 41,4 x 174,5 cm, pleg. $41,4 \times 47 \mathrm{~cm}$

Escala gráfica de 10 leguas [= 14,8 cm]. - Relieve de perfil. - Indica veriles y sondas batimétricas. - Señala la toponimia de los afluentes del río, montes que lo rodean y núcleos de población existentes a lo largo de su curso.

Signaturas: MN. 32-B-2

Solano, José

ORINOCO (Colombia) (Río). Mapas hidrográficos. 1759

Raudales [del Orinoco] / Expedición de Límites. - Escala indeterminada .- 1759

1 mapa : ms. ; $28,9 \times 40,3 \mathrm{~cm}$

Comprende el curso del río Orinoco en la región colombiana de Vichada, con sus afluentes Mataveni y Maipures. - Manuscrito a plumilla en tinta negra. - Notas explicativas sobre el caudal del río, hechas a lápiz y con posterioridad. Croquis.

Signaturas: MN. 30-E-34

ORINOCO. (Venezuela). Mapas hidrográficos. 1761 
Ríos Apure y Portuguesa con la situación de los pueblos San Antonio y San Jaime.Escala indeterminada

1 mapa : ms. col. ; $38 \times 50 \mathrm{~cm}$

Orientado. - Manuscrito en colores. - Anotaciones a lápiz al dorso.- Título deducido del contenido del mapa. Aparecen pueblos y afluentes de los ríos. - Deteriorado. Procede posiblemente de las comisiones de límites del norte de Brasil.

Signaturas 32-B-10

PERU. Mapas generales. 1:4444445. 1760

Mapa del curso de Amazona, sus afluentes y parte del Perú, 1760] - Escala [ca. $1: 4444445]$

1 mapa : ms. ; 56,4 x 53,4 cm

Título redactado a partir del contenido del documento. - Graduado, 1 grado de latitud [= 2,5 cm]. Meridiano principal, Lima. - Relieve de perfil. - Manuscrito coloreado a la acuarela en verde. - Señala la línea de demarcación entre los dominios de España y Portugal. - Forma irregular. - Pertenece a los planos levantados por la Comisión de Límites.

Signaturas: MN. 38-C-19

SURIPÁ (Venezuela) (Río). Mapas hidrográficos. 1759

Río Suripá : afluente del Apuré, afluente del Orinoco / Expedición de Límites. - Escala indeterminada

1 mapa : ms. ; $31 \times 21,4 \mathrm{~cm}$

Título redactado a partir del contenido del documento. - Comprende el lugar y situación de Santa Bárbara, junto al río. - Manuscrito a plumilla en tinta negra.

Signaturas: MN. 30-E-25

PUERTO SANTO (Venezuela) (Ensenada). Cartas náuticas. 1:29395. 1754-1761

Plano de las Ensenadas de Pto. Santo .- Escala [ca. 1:29395], una milla dividida en cables $[=6,3 \mathrm{~cm}]$

1 carta náutica : ms. ; $20,7 \times 29 \mathrm{~cm}$

Bajo el título, tachado: "... y Hernán Vazquez". - Coordenadas referidas al meridiano de San Fernando (O 56 58'30'/ N 10³6'), manuscritas a lápiz con posterioridad. - Indica veriles y sondas batimétricas en brazas de 6 pies de Burgos. Clave hidrográfica para determinar la calidad del fondo. - Manuscrito a plumilla en tinta negra. - En el margen superior, "Costa de Tierra Firme. No. 2".

Signaturas: MN. 30-C-6

SANTIAGO DE ARAYA (Venezuela). Castillo de. Fortificaciones. 1754-1760

Plano del Castillo de San Tiago de Araia : Con el Proyecto Jeneral por la parte Meridional para el Resguardo dela puerta de tierra con supuente lebadizo, foso y Bebelines y Estacada ... / delineado Josephn. Antonio de Bict .- Escala indeterminada 1 plano. : ms., col. ; 30'7 x 42'9 cm 
Presenta un índice que explica los puntos más importantes del plano. - Arrumbado y orientado con lis en nudo de rumbos. - Lavado en rosa y amarillo. - En el recto: "En Cumaná (Costa firme). - En el verso: "Cumaná (Costa firme) Proyectos castillo de Pta. de Araya".

Signaturas: MN. P15-B-2

VENEZUELA. Mapas generales. (1760). 1813

Primer Viaje Mapa topografico de la parte de misiones de capuchinos andaluces que hay en la provincia de Barinas, los ríos que de Apure al Meta comunican al Orinoco y derroteros que tomaron varios misioneros con el Procurador (autor de este) huyendo de los insurgentes desde la misma capital / Fr. Francisco de Andujar. Guayana 2 de Enero de 1813.- Escala indeterminada

1 mapa : ms. col. ; $34 \times 47.5 \mathrm{~cm}$

Pertenece a las comisiones de límites de 1750. Orientado, el norte al sur del mapa. Graduado.- manuscrito en colores, firmado y datado y anotación de copia.- Detalla itinerarios y red hidrográfica, relieve por sombreado.- Topónimos detallados de afluentes, misiones etc..- Inserta tres notas sobre las incidencias del viaje y una (nº 3) sobre la construcción del mapa, citando a Humboldt.- Presenta manchas de grasa en los ángulos superior e inferior izquierdos.

Signaturas . MN. 32-B-15

Campo, José

VENEZUELA. Cartas náuticas. 1:1010101. 17--?

Carta que comprende desde el Río Orinoco a Cabo Codera / Campo.- Escala [ca. 1:1010101]

1 carta náutica : ms., col., montado sobre papel ; 51,2 x 73,4 cm

Presenta además 5 vistas. - Título propio tomado del verso. - Manuscrito firmado y rubricado por el autor. - Escala hallada a partir de un grado de latitud [=11 cm]. Coordenadas referidas a un meridiano que no se especifica $\left(0310^{\circ} 30^{\prime}-\mathrm{O} 316^{\circ} 50^{\prime} / \mathrm{N}\right.$ $\left.12^{\circ} 30^{\prime}-\mathrm{N} 8^{\circ} 05^{\prime}\right)$. Orientado con media lis en nudo de rumbos. - Relieve representado por sombreado. - Indica veriles, fondeaderos y sondas batimétricas. - Manuscrito coloreado a la acuarela en verde y gris. - Señala toponimia de los accidentes geográficos y núcleos de población.

Signaturas: MN. 30-C-4

VENEZUELA. Cartas náuticas. 1:3800000. 177-

Carta que comprende desde el Rio Orinoco hasta el de Lagartos y Mar de las Antillas Escala: Escala [ca.1:3800000] Publicación:

1 carta náutica ms., col. ; 101,5 x 68,1 cm

Título propio tomado del verso del documento. - Escala hallada a partir de un grado de latitud. Coordenadas referidas a un meridiano que no se especifica. Orientado con rosa y lis. - Indica bajos. - Manuscrito coloreado. - Señala la toponimia de la costa.

Signaturas: MN. 14-A-10 
TRINIDAD. (Venezuela) (Cartas náuticas) 1754

Carta de la isla de Trinidad.- Escala de 10 leguas españoles $=20 \mathrm{~cm}$

1 carta náutica : ms. col. ; $78 \times 53 \mathrm{~cm}$.

Título tomado del contenido del documento.- Orientada con media lis, el norte al este de la carta.- Nos de sonda. - Posiblemete hecha por José Solano pues se parece a la 31B-9.

Signaturas : MN. 31-B-9bis

B- COMISIONES DE LIMITES DEL SUR DE BRASIL 1759

Varanda, Atanasio

BARRAGAN (Uruguay). Cartas naúticas, 1752

Lam. 4. Plano de la ensenada de Barragan. - Escala de 2000toesas=6,5 cm

1 carta náutica : ms. Col: ; 33 × $42 \mathrm{~cm}$

Orientado, el norte al sur del plano. Expresa la variación magnética.. - Manuscrito en colores. - № s de sonda.

Signaturas: MS. 628, lam. 4

Oyarvide, Andrés de

BRASIL. S. Fronteras.1:1700000. (1759). 1801

Plano del Virreinato de Buenos aires : en el qual se halla remarcada la linea divisoria y las marcas que en ella se pusieron desde Castillos en la Costa del mar hta la boca del Jaury por la 2a 3a y 4a Partida de la demarcacn de 1759 / yan debio ser trazado este mapa con areglo a los elementos y noticias que adquirieron en aquel entonces estos demarcadores, y las partes por donde hizieron sus viajes como el PARANÁ, Paraguay, Igatimi seran particularmente designadas con bastante esxactitud haviendo estado empleado el dho Custodio por parte de Portugal en la expresada demarcación ; copiado en 1801 para el Depósito Hidrográfico de Madrid ; Oyarvide. - Escala [ca. 1:170000]

1 mapa. : ms. ; $79 \times 78 \mathrm{~cm}$

Mapa general de la demarcaciónTítulo propio tomado del verso del documento. Documento graduado, sin información sobre meridiano. - Escala hallada a partir de un grado de meridiano [=6,5 cm]. - Describe detalladamente todos los accidentes geográficos. - Forma física irregular. - Orografía por normales.

Signaturas: MN. 39-A-8

Arguedas, Francisco de; Varanda, Atanasio; Marrón, Juan; Florez, Manuel Antonio; de Mendizabal, Ignacio; Millau, Francisco; Pacheco Solís, Alonso, Surville, Luis de;

BRASIL. Fronteras. 1:1683502. ( 1759). 1774

Mapa geográfico lebantado sobre el terreno en que estan comprehendidas todas las labores geographicas que practicaron por orden del Rey las partidas españolas destinadas a la América meridional por el Río de la Plata el año 1751 / los Señores Dn. Francisco de Arguedas, Dn. Atanasio Varanda, Dn. Juan Marron, Dn. Manuel Antonio de Florez, Dn. Ingnacio Mendizabal, Dn. Francisco Milhan y Dn. Alonso Pacheco Solís ; 
delineado por Dn. Luis de Surville, Profesor de Mathematicas y Maestro Delineador del Real Seminario de Nobles. Año de 1774 . - Escala [ca. 1:1683502]. - 1774

1 mapa : ms., col., montado sobre tela ; 167,5 x $93 \mathrm{~cm}$

Mapa general de la demarcación.- Coordenadas referidas al meridiano de Buenos Aires, 1 grado de latitud $[=6,6 \mathrm{~cm}]$. Orientado con rosa de los vientos prolongada con lis y nudo de rumbos. - Relieve representado por sombreado. - Manuscrito coloreado a la acuarela en varios colores. - Figura la línea de demarcación entre los dominios españoles y portugueses. - Nota explicativa sobre el método seguido para la elaboración del mapa y de aspectos importantes de éste. - En el ángulo superior derecho, cartela enmarcada por greca y coronada con el escudo de la casa real y ornamentada con dibujos de figuras humanas alusivas al área representada. - Manuscrito enmarcado por orla de tela de color azul.

Signaturas: MN. 38-C-20

Saa Faria, José Custodio / Oyarvide, Andrés de

BRASIL. SE. Fronteras. 1:1500000. 1759. (1801)

[Carta de parte de la costa E. de Brasil y de Uruguay, desde la laguna de los Patos hasta laguna de Lobos] / copia de un borrador del Brigadier Portugués Dn. José Custodio Sa faria . - Escala [ca. 1:1500000]

1 mapa : ms. ; 48,7 x 39,8 cm

Corresponde a la primera partida de límites. Título redactado a partir del contenido del documento. - Manuscrito a plumilla en tinta negra. - Escala hallada a partir de un grado de meridiano $[=7,4 \mathrm{~cm}]$. Coordenadas referidas solamente en longitud al meridiano de Buenos Aires. - Señala la toponimia de los lugares.

Signaturas: MN. 39-A-3

Saa Faria, José Custodio / Oyarvide, Andrés de

BRASIL. SE. Mapas topográficos. 1:160000. 1754-61 (1801)

Mapa topográfico del interior de Brasil desde la isla de Porcos hasta el rio Parahibe y costa sudoriental de Brasil : desde los $21^{\circ} 44^{\prime}$ latitud sur hasta los $23^{\circ} 14^{\prime}$ sur / Sa Faria ; copia de Oyarvide. - Escala [ca. 1:160000]

1 mapa : ms. ; $107,3 \times 121,3 \mathrm{~cm}$

Corresponde a la primera partida de límites. Titulo redactado a partir del contenido del documento. - Escala hallada a partir de un minuto de meridiano $[=1,2 \mathrm{~cm}]$. Coordenadas referidas a un meridiano que no se especifica. - Relieve representado por normales. Señala los accidentes geográficos. - Documento con forma irregular pues eran 11 pliegos pegados en dos cartones.

Signaturas: MN. 39-A-6

Saa Faria, José Custodio / Oyarvide, Andrés de

BRASIL. SE. Mapas topográficos. 1:160000. 1751-59 (1801)

Costa del Brasil y terreno interior correspondte : desde la Pa de Porcos hta el Río Carahiba / sacada de un plano antiguo del Brigadier Portugues Jph Custodio de Sa Faria 
; Copiada en 1801 en once pliegos para el Depósito Hidrográfico de Madrid ; Oyarvide.Escala [ca. 1:160000]

1 mapa. : ms. ; 73'4 X 71'1 cm

Corresponde a la tercera partida de límites. Título tomado del verso del documento. Carta graduada, sin información sobre meridiano. - Escala hallada a partir ed un grado de meridiano $[=1,2 \mathrm{~cm}]$. - Describe detalladamente todos los accidentes geográficos. Forma física irregular. - Orografía por normales.

Signaturas: MN. 39-A-7

Saa Faria, José Custodio / Oyarvide, Andrés

BRASIL. Cartas náuticas. 1:830000. 1751-59 (1801)

[Carta náutica de la costa meridional de Brasil y de la oriental de Uruguay] / Jose Custodio Safaria. - Escala [ca. 1:830000]

1 mapa : ms. ; 120,7 x 29,4 cm

Corresponde a la primera partida de límites. Título redactado a partir del contenido del documento. - Escala hallada a partir de un grado de meridiano [= 13,3 cm]. Coordenadas referidas sólo a la latitud. - Señala los accidentes geográficos. - Nota explicativa: "Carta Plana, copia de un borrador del Brigadier Portugues Dn Jph Custodio de Safaria, que fue uno de los comisarios de la anterior demarcación del año de 50"

Signaturas: MN. 39-A-4

Varanda, Atanasio

LA PLATA (Río) Cartas náuticas. 1752

Lam 1. Plano del Rio de la Plata nuevamente corregido y enmendado con observaciones de latitud y longitud y variación de aguja.- Escala indeterminada

1 carta náutica : ms. Col. Pleg. $56 \times 79 \mathrm{~cm}$

Graduado. Orientado con lis, el norte al sur del plano.- Indica el meridiano de parís, Tenerife y Buenos Aires.- Indica sonds y calidad del fondo por letras. orografía por normales.

Signaturas MS. 628, lam 1

Varanda, Atanasio; Oyarvide, Andrés de

MALDONADO. (Uruguay). Cartas náuticas. 1752

Lam. 2. Plano de la ensenada de Maldonado situada en la costa septentrional del Rio de la Plata.- Escala de 1000 toesaS=7,5 CM

1 carta náutica: ms. col. ; 32 × $44 \mathrm{~cm}$

Orientado. Indica la variación magnética.- №s de sonda.- Manuscrito en colores.

Signaturas Ms. 628, lam. 2

Varanda, Atanasio

MALDONADO. (Uruguay). Perspectivas de costa. 1752 
Lam. 5. Vista de la sierra de Maldonado mirada a 6 leguas de distancia; Vista el penedo de San Pedro mirado a 3 leguas de distancia. - Escala de 1 legua $=8 \mathrm{~cm}$

2 perspectivas de costa : ms. col. ; $33 \times 45 \mathrm{~cm}$

Signaturas MS. 628, lam. 5.

Saa Faria, José Custodio / Oyarvide, Andrés de

MATO GROSSO (Brasil). Fronteras.. 1:3367004. 1759 (1801)

[ Provincia de Mato Grosso] / De Saifaria. - Escala [ca. 1:3367004]

1 mapa : ms. ; 45,9 x 74,1 cm

Corresponde a la tercera partida de límites. Título redactado a partir del contenido del documento. Copia de Oyarvide. - Graduado, 1 grado de latitud [= 3,3 cm]. - Relieve representado por normales. - Manuscrito coloreado a la acuarela en verde. - Pertenece a los mapas levantados por la Comisión de Límites.

Signaturas: MN. 38-C-12

Varanda, Atanasio; Oyarvide, Andrés de

MONTEVIDEO (Uruguay). Cartas náuticas. 1752

Lam. 3. plano del puerto de Montevideo. Levantado en 1752 y situado en lat. Austral de 34 gs, 54 ms.- Escala de 1000 toesas $=7 \mathrm{~cm}$

1 carta náutica : ms. Col. ; 32 × $45 \mathrm{~cm}$

Orientada, indica la variación magnética.- Dibujado en rojo el perimetro de la ciudad de San Felipe.- Indica n⿳os $\mathrm{s}$ de sonda.

Signaturas MS. 628, lam 3

PARAGUAY. Fronteras. 1:1220000. 1759

Carta Particular de Una Parte dela Provincia del Río de la Plata : que compreende desde su Capital hasta El Paraguay con los Pueblos de Misiones de los Padres Jesuitas y la Nueva Línea que divide La Corona de España y Portugal, Por la pte. del Sur. - Escala [ca. $1: 1220000], 20$ leguas $[=9,1 \mathrm{~cm}]$

1 mapa : ms., col. ; $112,1 \times 63,3 \mathrm{~cm}$

Corresponde a la segunda partida de límites. Comprende parte de la cuenca de los ríos Paraná y Paraguay. - Coordenadas referidas a un meridiano que no se especifica.

Orientado con lis en cuadrante. - Relieve de perfil. - Manuscrito a plumilla en tinta negra y coloreado a la acuarela en gris y verde. - Señala toponimia.

Signaturas: MN. 42-B-10

PARAGUAY. Mapas generales. 1759

Plano de las misiones de los carmelitas y jesuitas portugueses en el Brasil. - Escala indeterminada

1 mapa. : ms. col. ; 65'4 x $23 \mathrm{~cm}$ 
Corresponde a la segunda partida de límites. Titulo redactado a partir del contenido del documento. - Graduado. - Lavado en verde y carmín. - Orientado con lis. Arrumbado. Símbolos de relieve, vegetación y construcciones.

Signaturas: MN. 37-C-1

Millau, Francisco

PARAGUAY . Fronteras. 1:1658374. 1762

Mapa que contiene parte de la provincia del Paraguay y los territorios pertenecientes a Brasil hasta el Atlántico, con indicación de tribus de indios / hecho por el Teniente de Navío de la Real Armada Dn. Francisco Milláu. - Escala [ca. 1:1658374]

1 mapa : ms., col. ; 46,8 x $66,7 \mathrm{~cm}$

Corresponde a la segunda partida de límites. Título redactado a partir del contenido del documento. - Escala gráfica de 20 leguas $[=6,7 \mathrm{~cm}]$. Coordenadas sin indicación de meridiano principal. - Relieve de perfil. - Mansucrito coloreado a la acuarela en varios colores. -Aparecen muchos topónimos de ríos, pueblos de indios y misiones. - En ángulo inferior derecho, cartela barroca, que incluye explicación de las fronteras por clave cromática y de los conflictos de las misiones guaranies.

Signaturas: MN-38-C-3

Echevarria, Juan de; Mendizabal, Ignacio; Pacheco, Alonso; Sa Faria, Jose Custodio de; Viera Leao, Manoel ; Cardiel de Mendoça Gonçalez, Alexandre

URUGUAY. Fronteras. 1:420000. 1759.

Mapa Geographico del Terreno que demarcaron las Primeras Partidas de Sus Magestades Catholica y Fidelissima el qual comprehende dos tramos, el primero desde el Monte de Castillos Grandes hasta el último Marco que se coloco al N.O. de Sta Tecla, y el segundo desde la Horqueta grande que forman los brazos del Río Ybicuy hasta desaguar este en el Río Uruguay : quedando aun a la decision de Sus Magestades el terreno comprehendido entre el sobre dicho y la dicha Horqueta que queda en este Plano sin colores de division, en el qual se echara la línea Divissoria quando y por donde mandasen los dos Augustos Soberanos, y para que en todo tiempo conste hicimos esta Declaracion que firmamos los Comissarios, Cosmographos y Geographos de ambas Partidas en la Horqueta del Ybicuy a 3 de julio de 1759 / Juan de Echevarria, Ignacio Mendizabal y Alonso Pacheco por parte de España y por Jose Custodio de Sa Faria, Manoel Viera Leao,y Alexandre Cardiel de Mendoça Gonçalez. .- Escala [ca. 1:420000] 1 mapa : ms., col., montado sobre tela ; 192 x $129 \mathrm{~cm}$

Corresponde a la primera partida de límites.- Dedicatoria al Rey Fernando VI inscrita en monumento. - Manuscrito firmado, rubricado y fechado por el autor. - Escala hallada a partir de un grado de latitud [= 26,5 cm]. Coordenadas referidas sólo en latitud (S 29-S $36^{\circ}$ ). Orientado con lis en rosa de 16 vientos prolongados. - Manuscrito a plumilla en tinta negra y coloreado a la acuarela en varios colores. - Indica la línea fronteriza coloreada en tono carmín. - Título enmarcado en cartela barroca. - Inserta: "Plano de la Ensenada de Montevideo" ; "Ensenada de Maldonado". Escala [ca. 1:46400] ; "Ensenada de Castillos Grandes". Escala [ca. 1:44300]

Signaturas: MN. 43-A-2, Planero 226-13 
Blasco, Angelo de

URUGUAY. SE. Fronteras. 1:1040000. 1755-1761

Mappa Que Contiene las marchas que hizieron las dos Tropas De Sus M.C. y FIDELLma. y todo el Pais Conocido desde la Colonia del Sacramto. hasta las Missiones : Comandadas por el Exmo. Señor Don Joseph de Andonaegui Tente. Genl. de las Reales Extos. de S.M. Catt. y Genal. de las Provas. del Río de la Plata / Echo, por orden de... Don Gomes Freire de Andrada... ; por Don Migel. Angelo de Blasco Coronel de Infa. con el exerco. Ingro. de la misma Magd.- Escala [ca. 1:1040000]

1 mapa : ms., col., montado sobre tela ; 101,3 x $69 \mathrm{~cm}$

Corresponde a la primera partida de límites.- Manuscrito firmado y fechado por el autor. - Escala hallada a partir de un grado de latitud [ =10,8 cm]. Graduado en latitud (S 28ㅇ-S 35ㅇ). - Relieve representado por sombreado. - Manuscrito a plumilla en tinta negra y coloreado a la acuarela en verde, siena y carmín. - Relación de la marcha de los españoles y portugueses, lugar del enfrentamiento contra los indios, etc., indicados por clave alfabética. - Indica la frontera entre los territorios españoles y portugueses y la ruta seguida por las dos expediciones. - Título enmarcado con orla y leyenda con escudo real y león.

Signaturas: MN. 43-D-4

Millau, Francisco

URUGUAY. Mapas generales. 1:600000. 1759. (1770)

Mapa que comprehende el Pays que se extiende por la Costa de el Mar, entre la ciudad de Montevideo, y el Río grande : con demostración assí de los parajes mas notables, Puestos que en el se encuentran, y Caminos, que se frequentan, como de los Ríos, que desaguan en su comedio, su calidad, ventajas y perjuicios, que pueden resultar de essa ultima Posession / Hecho de orden de el Exmo. Señor Dn. Francisco Bucareli, y Ursua siendo Capitan general de las Provincias de el Río de la Plata ; por el Teniente de navio de la Real Armada Dn. Francisco Millau. 1770. - Escala [ca. 1:600000], 10 leguas [= 9,7 cm]

1 mapa : ms., col., montado sobre tela ; 63 x 121,1 cm

Corresponde a la segunda partida de límites. Manuscrito firmado y fechado por el autor. - Orientado con lis en rosa de 8 vientos. - Relieve representado por sombreado. Manuscrito a plumilla en tinta negra y coloreado a la acuarela en varios colores. - Nota explicativa del mapa y de la línea de frontera entre territorios españoles y portugueses. - Título y leyenda enmarcados en cartela con motivos vegetales y el escudo real en el primero. - Inserta: Mapa de la misma zona, ampliando la frontera de los territorios españoles y portugueses. Escala 1:3800000.

Signaturas: MN. 43-D-3

III. ISLA DE SANTA CATALINA Y COLONIA DEL SACRAMENTO

Tilly y García de Paredes, Francisco Javier, Marqués de Casa Tilly

ATLANTICO (Océano). Guerra naval. 1:5847947. 1777

Carta reducida que contiene la Navegacion Exequtada por la Esquadra y Comboy de S.M. al mando del Marques de Casa Tilly desde la Bahia de Cadiz hasta la Ysla de Santa 
Catalina en la Costa del Brazil. - Escala [ca. 1:5847947] (O 58 19'26"-O 4 19'26"/N 37 -S 36 30'). - 1779 Marzo 8

1 carta náutica : ms., col. ; 149,8 x 109,7 cm

Manuscrito firmado, rubricado y fechado en Santa Catalina. - Escala de 20 leguas [= 1,9 $\mathrm{cm}$ ] que corresponde a un arco de meridiano. Graduado, con longitud referida a los meridianos de Londres, Tenerife, París y Observatorio Real de Marina de Cádiz. Manuscrito a plumilla en tinta negra y coloreado a la acuarela en gris, verde y carmín. Toponimia. - Inserta: "Plano del Puerto de Sta. Casthalina en la costa de Brasil : situado por Latd. Sur de $27^{\circ} 42^{\prime}$ y Longd. de $327^{\circ} 40^{\prime \prime}$. Escala indeterminada. Relación de lugares y edificios. Figura la formación de la escuadra en su entrada al mismo. Pertenece a la expedición de Cassa-Tilly.

Signaturas: MN. 40-A-7

Franco, Gerónimo; Cuesta, Andrés de la; Academia de Pilotos de El Ferrol

BRASIL. Cartas náuticas. 1:1234568. 1777

Mapa Hidrográfico que señala parte del continente Meridional de la Costa del Brasil : desde Cavo Frío hasta la Isla de Santa Catalina encuia estensión se hallan los Puertos mas principales para Navios / Su longitud al Meridiano de Tenerife es deducida de las tablas Astronómicas de la Academia de las Ciencias ; Reducido y calculado por el Alferez de Navío y Primer Piloto D. Gerónimo Franco ; En la Rl. Escula de Navegación del Departamento del Ferrol por el Mro. de Dibuxo Don Andrés de la Cuesta. Escala [ca. 1:1234568].- Año de 1777

1 carta náutica : ms., col. ; 53 x 73,5 cm Notas: Escala gráfica hallada sobre grado de latitud $[=9 \mathrm{~cm}]$. Orientado con rosa de los vientos y lis. - Indica sondas batimétricas. Manuscrito coloreado a la acuarela en verde. - Cartela barroca enmarcando el plano.

Signaturas: MN. 39-B-17

Gundín, Joaquín; Baleato, Andrés; Massa, Gaspar

COLONIA DEL SACRAMENTO (Uruguay) (Puerto). Cartas náuticas. 1:35273. 1791 Plano del Puerto de la Colonia del Sacramento : en la costa septentrional del Río de la Plata / arreglado a las operaciones del primer piloto de la Rl. Armada Dn. Joaquin Gundin comisionado por la superioridad y verificadas en 1791 ; A. Baleato ; B. Massa Escala [ca. 1:35273], 2 millas marítimas [=10'5 cm]. - 1791

1 carta náutica : ms. ; 31 x $43 \mathrm{~cm}$

Manuscrito firmado y fechado. A plumilla en tinta negra. - Coordenadas de la ciudad

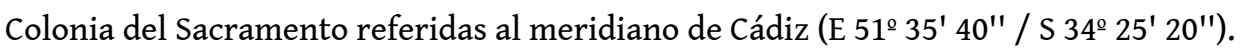
Orientado con lis en cuadrante. - Relieve representado por sombreado. - Indica veriles, bajos, fondeaderos y sondas batimétricas. Clave hidrográfica para determinar la calidad del fondo. - Nota relativa al fondeadero y a la variación de la aguja. - En el ángulo superior izquierdo: N.3.

Signaturas: MN. 44-C-3

COLONIA DEL SACRAMENTO (Uruguay) (Puerto). Cartas náuticas. 1: 49603.1777

Colonia de sacramento : situada a latitud de 34 grs, 18 minuts obsercados en la isla de Sn Gabriel.- Escala [ca. 1:49603] 
1 carta náutica : ms. ; $32 \times 44,5 \mathrm{~cm}$

orientada con lis. - Escala gráfica de media legua $=5,6 \mathrm{~cm}$.- Indica sondas, fondeaderos y arrecifes.

Signaturas : MN. 44-C-2

COLONIA DEL SACRAMENTO (Uruguay) (Puerto). Cartas náuticas.1:113960. 1777

Plano del Puerto de la Colonia del Sacramento : en latd $34^{\circ} 18^{\prime}$ Escala: Escala [ca. 1:113960], 4 millas $[=6,5 \mathrm{~cm}] .-1777$

1 carta náutica : ms. ; $29,4 \times 21 \mathrm{~cm}$

Indica veriles, bajos, fondeaderos y sondas batimétricas en brazas de 6 pies ingleses. Clave hidrográfica para determinar la calidad del fondo. - Manuscrito a plumilla en tinta negra. - Señala núcleos de población. - Indica la toponimia de la costa.

Signaturas: MN. 44-C-1

COLONIA DEL SACRAMENTO (Uruguay). Guerra naval. 1:60386.1777

Plano de la Disposición en que se colocaron las embarcs. de la esquada. de S.M.C. Para el bloqueo y ataque de la colonia del Sacramento Escala: Escala [ca. 1:60386], 3 millas marítimas $[=9,5 \mathrm{~cm}]$

1 carta náutica : ms., col ; 43,5 x $60 \mathrm{~cm}$

Orientada con lis en rosa de 16 vientos y nudo de rumbos. - Indica veriles y sondas batimétricas. - Relación de los principales buques indicados por clave alfabética. Pertenece a la colección de mapas de la expedición de Casa-Tilly.

Signaturas: MN. 40-A-8

COLONIA DEL SACRAMENTO (Uruguay). Mapas generales. 1:123456.1777

Plano de la colonia de Sacramento. - Escala [ca. 1:123456], 3 millas marítimas [= 4,5 cm]. 1 carta náutica : ms., col. ; 34,1 x $42 \mathrm{~cm}$

Título propio tomado del verso del documento. - Orientado con media lis en rosa de 16 vientos y nudo de rumbos. - Indica veriles y sondas batimétricas. - Manuscrito a plumilla en tinta negra y coloreado a la acuarela en gris y verde. - Relación de islas y arroyos indicados por clave alfabética. - Nota explicativa de lo representado en el mapa. - Pertenece a la expedición de Cassa-Tilly.

Signaturas: MN. 40-A-9

COLONIA DEL SACRAMENTO (Uruguay). Planos de población.1:4302. 1775?

Plano de la Colonia del Sacramento y del Territorio inmediato a ella, con sus Fortificnes [i.e. Fortificaciones] : Dedicado al Excmo. sor. Dn. Julián de Arriaga, Secretario de Estado y del Despacho Universal de Marina e Yndias Escala: Escala [ca. 1:4302]

1 carta náutica : ms., col. ; 111,5 x 73,5 cm

Presenta plano de población de la ciudad Colonia del Sacramento e islas de los Hornos y de San Gabriel en la desembocadura del río de La PLata. - Escala gráfica de 300 toesas [= $13,6 \mathrm{~cm}$ ]. Orientado con rosa de 8 vientos, nudo de rumbos y lis. - Relieve representado por sombreado. - Indica sondas batimétricas. - Manuscrito coloreado a la acuarela en 
varios colores. - Figura clave alfabética para situar edificios de carácter civil, religioso y militar, inserta en monumento del ángulo superior izquierdo. - Título y escala gráfica contenidos en cartela decorada con motivos alegóricos a la navegación.

Signaturas: MN. 40-A-10

COLONIA DEL SACRAMENTO (Uruguay).Guerra naval.1:57273. 1777

Plano de la Colonia del Sacramento : situada en el Rio de la Plata.- Escala [ca. 1:57273], 3 millas $[=9,9 \mathrm{~cm}]$

1 carta náutica : ms., col. ; 45,2 x $59 \mathrm{~cm}$

Orientado con media lis en rosa de 16 vientos prolongados. - Indica sondas batimétricas. - Manuscrito a plumilla en tinta negra y coloreado a la acuarela en carmín, verde y gris. - Relación de las principales embarcaciones indicadas por clave alfabética. - En el ángulo superior derecho cartela con la "Explicación del modo en que se colocaron las embarcaciones destacadas de la Esquadra del Mando del Exmo. Sr.

Marqués de Casa Tilly para bloquear esta plaza" .

Signaturas: MN. 40-A-1

Cuesta, Andrés de la; Academia de Pilotos de El Ferrol

GRANDE (Brasil) (Isla). Cartas náuticas. 1:173611. 1777

Plano de la Isla Grande en la Costa del Brasil : situada su mediania en la Latitud de 23 gs. y en la Longitud de 332 y 57ms. meridiano de Tenerife / en la Rl. Escuela de Nabegación del Departamento del Ferrol, por el Mro. de Dibujo don Andrés de la Cuesta. Escala [ca. 1:173611] Año de 1777

1 carta náutica : ms., col. ; 51,5 x $73 \mathrm{~cm}$

Escala de 4 leguas [ $=12,8 \mathrm{~cm}]$. Orientada con rosa de los vientos y lis. - Indica sondas batimétricas. - Manuscrito coloreado a la acuarela en verde, gris y carmín.

Signaturas: MN. 39-B-9

GRANDE (Brasil) (Isla). Cartas náuticas. 1:174978. 1777

Plano de la Isla Grande en la costa del Brasil : situado su mediana en la Latd. S. $23^{\circ} 11^{\prime}$ y en Longd. de $332^{\circ} 57^{\prime}$. Meridiano de Tenerife. -Escala [ca. 1:174978]

1 carta náutica : ms. ; 50,6 x 66,6 cm

Escala de 4 leguas [= 12,7 cm]. Orientado con media lis. - Indica sondas batimétricas.

Signaturas: MN. 39-B-8

SAN SEBASTIAN (Brasil). (Isla de). Cartas náuticas. 1:61050. 1777

Plano de la Isla y Puerto de San Sebastián : situada en la costa del Brasil, en la Latd. $23^{\circ} 40^{\prime}$ y Longd. $332^{\circ}$ Merdo. de Tenerife. Escala [ca. 1:61050]

1 carta náutica : ms. ; 50' 8 × 66' $6 \mathrm{~cm}$

Escala de 1 legua marítima [= 9,1 cm]. - Presenta el perfil de la isla y de la costa muy simplemente, con algunos, topónimos y muy pocos datos de sondeo batimétrico. Situación y plano esquemático de pueblo y fuerte. - Orientado con media lis.

Signaturas: MN. 39-B-15 
López, Tomás

SANTA CATALINA (Brasil) (Isla). Cartas náuticas. 310000. 1777

Plano de la Isla y Puerto de Santa Catalina : situado en la America Meridional Hallase su Puerto en la Punta del Norte en 27 grados 26 minutos de Latitud Austral y en 327 grados 36 minutos de Longitud contada desde el Pico de Tenerife / Sacado por el extracto que hizo estampar el año pasado de $1776 \mathrm{D}$. Cristobal del Canto habiendo tenido este el que formó el año de 1757 D. Estevan Alvárez del Fierro, en punto maior Por D. Tomás López.- Escala [ca. 1:310000] Madrid año de 1777

1 carta náutica : ms. ; 52,4 × $67 \mathrm{~cm}$

Comprende la isla de Santa Catarina y parte de la costa suroriental de Brasil. Presenta además, una perspectiva de la costa de las islas de Santa Catarina y Aboredo. - Escala gráfica en leguas marítimas. Coordenadas referidas al meridiano de Tenerife. Orientada con torre en rosa de 8 vientos. - Indica fondeaderos y sondas batimétricas. Clave hidrográfica para determinar la calidad del fondo. - Relieve representado por normales. - Figuran masas arbóreas. - Nota explicativa sobre las mareas y los vientos de la isla.

Signaturas: MN. 38-B-5

SANTA CATALINA (Brasil). (Isla de). Cartas náuticas. 1:190000. 1777

Carta de la isla y puerto de Santa Catalina en la costa de Brasil. - Escala [ca. 1:190000].

1 carta naútica : ms. ; 43,1 x 67,3 cm

Título redactado a partir del contenido del mapa.- Comprende la costa brasileña y con la isla de Santa Catalina, especificando las sondas,calidad del fondo y fondeaderos existentes en el puerto y costas de la mencionada isla. - Relación de los principales accidentes geográficos. - Orientado con nudo de 16 rumbos y media lis. Escala gráfica en millas. - Reproducción gráfica de las líneas de derrota seguidas por la Escuadra española. - Perspectivas de costas de varias islas dominando el ángulo inferior izquierdo. - Notas explicativas que informan de la configuración y metereología del área representada; y relación de varios puntos concretos con su posición latitudinal y longitudinal. - Se explica el desembarco de Pedro Ceballos y tiene añadida una nota donde D. Pedro Chunos manda que se lereconozca como virrey gobernador y capitan general de la provincia de Buenos Aires y Paraguay a Ceballos. Presenta un añadido por el que se continúa la representación gráfica del documento, y en cuyo verso destaca una carta manuscrita de Don Luis Chunos, instando a la población a que reconozcan el mando del virrey Gobernador, Don Pedro Ceballos. - Documento con forma irregular.

Signaturas: $\mathrm{MN}-38-\mathrm{B}-8$

SANTA CATALINA (Brasil) (Isla). Cartas náuticas. 1777

Plano de la isla y puerto de Santa Catarina y parte de la costa sudoriental de Brasil.Escala indeterminada.

1 carta náutica : ms. ; 41,2 x 32,4 cm

Título redactado a partir del contenido del mapa. - Indica sondas batimétricas. Clave hidrográfica para determinar la calidad del fondo. - Señala la toponimia de la costa. Notas y dibujos a lápiz que hacen suponer que estamos ante un documento inacabado. Indica los núcleos de población más importantes. 
Signaturas: MN. 38-B-1

SANTA CATALINA (Brasil) (Isla). Cartas náuticas. 1:185000. 1777

Plano de la Ya. de S. Cathalina : Situada en la Costa del Brasil por $27^{\circ} 30^{\prime}$ de Latt. S

Escala: Escala [ca. ca. 1:185000]

1 carta náutica: ms. ; 29,5 x $42 \mathrm{~cm}$

Presenta la isla de Santa Catalina y parte de la costa suroriental de Brasil. - Manuscrito rubricado. - Escala gráfica en leguas marítimas. Orientado con nudo de 4 rumbos y media lis.el norte al sur del plano - Indica sondas batimétricas y fondeaderos. - Clave toponímica. - Nota explicativa con información del canal que separa la isla de la costa.

Signaturas: MN. 38-B-3

SANTA CATALINA (Brasil) (Isla). Cartas náuticas. 1777

Plano general de la Ysla y puerto de Sta catalina situada a los 27 grads y 23 minutos de latitud austral sobre la costa del Brasil que comprende partede Tierra Firme de su frente con sus feligresias, playas, ríos y sondas de su puerto. - Escala de 45.000 varas castellanas $=20 \mathrm{~cm}$

1 carta náutica : ms. col. ; $80 \times 170 \mathrm{~cm}$

Orientado, el norte al este de la carta. -Expresa otras escalas en leguas marítimas y leguas legales españolas. - Sondas.- Clave toponímica expresando los castillos y fuertes.

Signaturas MN. 38.B-10

SANTA CATALINA (Brasil). (Isla). Cartas náuticas. 1:185000. 1776

Plano de Sta Catalina en la Costa del Brasil : situado en la Latd, S. de $27^{\circ} 42^{\prime}$ y en $327^{\circ} 40^{\prime}$ de longitud [sic] Escala [ca. 1:185000]

1 carta náutica : ms., col. ; 29'3 x 42'2 cm

Presenta la isla de Santa Catalina y parte de costa sudoriental de Brasil de la que es adyacente, determinando las sondas y fondeaderos, al tiempo que los principales accidentes geográficos y fortalezas, en consonancia con el índice que ocupa el ángulo superior derecho. - Graduado, y orientado con rosa de 4 vientos y media lis. Escala gráfica en leguas. - Poblado de árboles que se limitan únicamente a la isla.

Signaturas: MN. 38-B-2

Piñero, Gregorio; Baleato, Andrés

SANTA CATALINA (Brasil) (Isla). Cartas náuticas. 1:122000. 1775

Plano del Puerto e Ysla de Sta. Catalina en la Costa del Brasil / Levantado por el Piloto Dn. Gregorio Piñero el Año de 1775 ; Es copia de Baleato. - Escala [ca. 1:122000]

1 carta náutica : ms. ; 64,9 X $49 \mathrm{~cm}$

Comprende la costa sudoriental de Brasil, abarcando las islas adyacentes, de entre las que destaca la isla de Santa Catalina. - Manuscrito firmado y rubricado por el autor. Escala en millas marítimas. Coordenadas de un puerto de la isla de Santa Catalina, referidas al meridiano de París. Orientado con rosa de 8 vientos y lis. - Indica bajos, fondeaderos y sondas batimétricas en brazas de 6 pies ingleses. - Señala los principales accidentes geográficos, islas, núcleos de población y fuertes. - Notas explicativas que 
informan sobre la mejor forma de recalar en el puerto y sobre varios aspectos de la isla, vientos, mareas, relieve y su extensión y distancia respecto a la costa Materias:

Signaturas: MN. 38-B-7

SANTA CATALINA (Brasil). (Isla de). Cartas náuticas. 1:190000. 1777

Carta de la isla y puerto de Santa Catalina en la costa de Brasil. - Escala [ca. 1:190000].

1 carta naútica : ms. ; 43,1 x 67,3 cm

Título redactado a partir del contenido del mapa. - Comprende la costa brasileña y con la isla de Santa Catalina, especificando las sondas,calidad del fondo yfondeaderos existentes en el puerto y costas de la mencionada isla. - Relación de los principales accidentes geográficos. - Orientado con nudo de 16 rumbos y media lis.Escala gráfica en millas. - Reproducción gráfica de las líneas de derrota seguidas por la Escuadra española. - Perspectivas de costas de varias islas dominando el ángulo inferior izquierdo. - Notas explicativas que informan de la configuración y metereología del área representada ; y relación de varios puntos concretos con su posición latitudinal y longitudinal. - Se explica el desembarco de Pedro Ceballos y tiene añadida una nota donde D. Pedro Chunos manda que se lereconozca como virrey gobernador y capitangeneral de la provincia de Buenos Aires y Paraguay a Ceballos. Presenta un añadido porel que se continúa larepresentación gráfica del documento, y en cuyo verso destaca una carta manuscrita de Don Luis Chunos, instando a la población a que reconozcan el mando del virrey Gobernador, Don Pedro Ceballos. - Documento con forma irregular.

Signaturas: MN-38-B-8

SANTA CATALINA (Brasil) (Isla). Cartas náuticas. 1:190000. 1777.

Plano de la Ysla y Puerto de Santa Catalina en la Costa delBrasil : en la latd. S. de $27^{\circ} 42^{\prime}$ y en la longd. de 32800' Calculado al meridiano de Tenerife. - Escala [ca. 1:190000]

1 carta náutica : ms. ; 51,4 x 66,4 cm

Carta de la costa sudoriental de Brasil, abarcando la isla de Santa Catarina y otras adyacentes. - Escala gráfica en leguas de 20 al grado. Coordenadas referidas al meridiano deTenerife. Orientado con media lis. - Indica sondasbatimétricas. - Señala los puntos más importantes de la zona así como las iglesias, los fuertes y campamentos. Indica la toponimia de la costa. - En el ángulo inferior derecho aparece un número referencial, sin duda, posterior a la carta.

Signaturas 38-B-9

Berlinguero, Alejo

SANTA CATALINA (Brasil) (Isla). Guerra naval. 1777

Plano que manifiesta la Evolon. que hizo y posision que mantubo la Esquadra y Comboy del mando del Exmo. Sor. Marqués de Casa Tilly El día 18 de Febrero de 1777 a vista de la Esquda portuguesa sobre la Costa del Brasil. - Escala indeterminada

1 carta náutica : ms., col. ; 46,2 x 62,1 cm 
Orientada con media lis en rosa de 16 vientos prolongados con nudo de rumbos. - Indica fondeaderos y sondas batimétricas. - Manuscrito a plumilla en tinta negra y coloreado a la acuarela en verde y gris. Pertenece a la expedición de Cassa-Tilly.

Signaturas: MN. 40-A-4

Tilly y García de Paredes, Francisco Javier, Marqués de Casa Tilly

SANTA CATALINA (Brasil) (Isla). Guerra naval. 1:96618. 1777

Plano de la disposicion en que se colocaron las fuersas nabales de S.M. para el ataque del puerto de la Ysla de Sta. Catala. - Escala [ca. 1:96618], 6 millas marítimas [= 11,5 cm]

1 carta náutica : ms., col ; 48,1 x 64,8 cm

Orientada con media lis en rosa de 16 vientos y nudo de rumbos. - Indica sondas batimétricas. - Manuscrito a plumilla en tinta negra y coloreado a la acuarela en verde y gris. - Relación de los principales navíos y fragatas indicados por clave alfabética. Nota explicativa del ataque. - Pertenece a la colección de mapas de la expedición de Casa-Tilly.

Signaturas: MN. 40-A-6

TRINIDADE (Brasil) (Isla). Guerra naval. 1777

Plano que manifiesta la cituacion de la Esquadra, Comboy y Fragatas Descubridoras de las Embarcaciones que Recalen a Sotabento de la Ysla Trinidad para el logro de su Reunion.- Escala indeterminada.

1 carta náutica : ms., col. ; 46,2 x 62,1 cm

Orientado con media lis sobre rosa de 16 vientos. - Manuscrito a plumilla en tinta negra y coloreado a la acuarela en verde y gris. - Nota explicativa sobre la situación y nombres de los barcos componentes de la expedición. - Pertenece al aexpedición de Casa Tilly.

Signaturas: MN. 40-A-5

IV. TRATADO DE SAN ILDEFONSO 1777

Cruz Cano y Olmedilla, Juan de la

AMERICA DEL SUR. Mapas generales. 1:4305761. 1775

Mapa geográfico de América Meridional / dispuesto y grabado por D. Juan de la Cruz Cano y Olmedilla, geogfo. pensdo. [i.e. geográfo pensionado] de SM. individuo de la Rl. Academia de Sn. Fernando y de la Sociedad Bascongada de los Amigos del País, teniendo presentes varios mapas y noticias originales con arreglo a las observaciones astronómicas Año de 1775 ; la letra por Ricarte. - Escala [ca. 1:4305761] (O 81 39'-O 31 39'/N 13 0'-S 58 0'). Publicación: [S.l. : s.n.], 1775

1 mapa : montado sobre tela ; $228 \times 175 \mathrm{~cm}$

Escalas gráficas de 100 leguas de España de 17 1/2 al grado, 100 leguas de España de 20 al grado, 100 leguas legales de Castilla de $261 / 2$ al grado y 100 "medidas de horas de camino en país montañoso". Coordenadas referidas a los primeros meridianos, Pico de Tenerife, Madrid, Londres, París, Hierro y Toledo. - En el margen superior, orla conteniendo el símbolo de la orden de Carlos III, escudos de Castilla y León y Toisón de oro y en el margen inferior, recuadro con la explicación sobre los meridianos y la línea 
de demarcación que divide las posesiones de España y Portugal. - Título enmarcado en cartela decorada con motivos alegóricos, coronada por el busto de Colón con la leyenda: "A Castilla y León Nuevo Mundo dio Colon", y los escudos de las principales ciudades de América del Sur unidas entre sí. - Inserta: "Plano del sitio de Angostura donde se ha establecido el quartel general del R. Orinoco, la población de la Nueva Guayana y fortaleza de S. Gabriel Antonio Nro. Infante por disposición de D. Joaquín Moreno Mendoza gobernador de dichos establecimientos". Escala [ca. 1:17600] ; "Plano del puerto del Callao de Lima, ciudad capital del Reyno del Perú". Escala [ca. 1:155200]

Signaturas: MN. G-E-24 ; MN. G-E-25

AMERICA DEL SUR. SE. Fronteras. 1:1980000. 1777-1796

Mapa Esferico De las Provincias Septentrionales del Rio de la Plata : desde Buenos Ayres hasta el Paraguay Con los grandes Bosques q. separan las Misiones. españolas de los Establecientos. Portugueses y las Marcas que se pusieron desde la costa del Mar hasta la Laguna Merin y desde Sta Tecla al Monte-grande ó Sierra de Tape, en conformidad al Tratado Preliminar de 1777 entre España y Portugal, Construido segun las observaciones y reconocimientos hechos hasta 1796. - Escala [ca. 1:198000]

1 mapa : ms., col. ; 61,1 x $57 \mathrm{~cm}$

Pertenece a la primera partida.- Comprende el Río de la Plata, las cuencas de los ríos Uruguay y Paraguay hasta el río Paraná. - Manuscrito a plumilla en tinta negra y coloreado a la acuarela en gris, verde y carmín. - Escala hallada a partir de un grado de latitud $[=5,5 \mathrm{~cm}]$. Coordenadas referidas al meridiano de Asunción (O 2 40'-E 8 00'/s 25 $10^{\prime}$-S $\left.3510^{\prime}\right)$. Orientado con media lis en cuadrante. - Relieve de perfil.

Signaturas: MN. 42-B-7

AMERICA MERIDIONAL. Mapas generales. 1800

[América Meridional desde el Ecuador a Tierra de Fuego],- escala indeterminada.

1 mapa. : ms. col. ; $223 \times 160 \mathrm{~cm}$

Pertenece a la primera partida.-Manuscrito en tinta negra, lavado en azul y sepia.Primer meridiano, Buenos Aires. Abundantes topónimos.-En el margen inferior derecho en una cartela circular se dice que el constructor del mapa practicó reconocimientos en 1800 por orden de la superioridad y que "la explicación de esta carta se escribió al través por natural descuido. No va enmendada por lo dificil que es en la actualidad encontrar papel de su calidad. Es copia". lo que sugiere que debía llevar pegada una hoja con la explicacion de cúando, quien y porqué se hizo el mapa. Tiene un sello en tinta del Depósito Topográfico de Ingenieros.-Notas relativas a la $1^{\mathrm{a}}$ partida: "linea que debe trazarse según el articulo 10 del tratado de 1777". Posiblemente es copia de un mapa de Valera y Ulloa.

Signaturas : GE-34

Defechain, José; Casa Florez, Manuel Antonio de

AMERICA DEL SUR. Mapas generales. 1:1587300. 1777

Mapa geográfico que comprehende toda la América Meridional, con la división de sus provincias : advirtiendo que se ha copiado puntualmente, esto es, sin corrección de los muchos defectos que tiene su original de author portugues, cuyo mapa y carta se halló 
con dirección al Virrey del Brasil, en una Zumaca de aquella nación que se apreció ultimamente procedente de la plaza de la Colonia del Sacramento / por el Capitán de Navío de la Rl. Armada D. José Defechain, actual Comandante del Navío nombrado Sn. Agustín : Montevideo 9, de Marzo de 1777 ; Casa Florez. - Escala [ca. 1:587300]

1 mapa : ms., col. ; 127,5 x $97 \mathrm{~cm}$

Orientado con rosa de 16 vientos y lis. - Relieve representado por sombreado y de perfil. - Manuscrito coloreado a la acuarela en varios colores. - Indica los ríos más destacados.

Signaturas: MN. 26-A-1

Spinola, Manuel de Lugar:

ARGENTINA. Cartas náuticas. 1:2400000. 1798

Carta Esferyca que contiene la costa Patagonica : desde la Ensenada de los Castillos hasta Cayo Raso / Construyda con las noticias siguientes: desde la Ensenada de Castillos todo el Río de la Plata hasta Cavo Sn. Antonio por las Corvetas de S.M. Descuvierta y Atrevida, desde $\mathrm{N}$ a Z por la Carta de Zayfaria sacada del Viaje del P. José Cardier cuando intentó descubrir el Río Colorado, desde Z hasta la embocadura del Río Negro pr. las dichas Corvtas. Todo el Golfo de Sn. José hasta Punta Subrido pr. dicha Carta de Tafor Desde dha. punta, toda la Península de Sn. Jose y lo qe. continua hasta Cavo Raso es tambien travajado por dichas Corvetas ; Delineado en Cadiz pr. Dn. Manl. Spinola, Segundo Piloto de la Rl. Armada.- Escala [ca. 1:2400000].- Año de 17981 carta náutica : ms., col. ; 53,4 x 75,1 cm

Manuscrito firmado y fechado. - Escala hallada a partir de un grado de latitud [ $=4,3$ $\mathrm{cm}$ ]. Coordenadas referidas al meridiano de Cádiz (0 $6020^{\prime}-039$ 00'/S 33 00'-S $4420^{\prime}$ ). Orientado con media lis en nudo de rumbos. - Relieve representado por sombreado. Indica veriles, bajos, fondeaderos y sondas batimétricas. - Manuscrito a plumilla en tinta negra y coloreado en verde, amarillo, gris y carmín. - Señala toponimia costera. Representación de una bandera española (roja y gualda) con escudo de las armas de Castilla y León, en las proximidades de Montevideo.

Signaturas: MN. 45-D-13

López Royo, Francisco; Fernández Parrado, Vicente

BRASIL. Mapas generales. 1:1851851. 1777

Carta reducida de los terrenos y ríos que deven formar los límites entre el Brasil y los establecimientos españoles según el tratado del año 1777 / formado sobre las últimas observaciones hechas en aquella parte de América por Dn Francisco Lopez Royo Alferez de Navío de la Real Armada y caballero de la Orden de San Juan; delineada por el mismo y por el Pilotin de la Real Armada Dn Vicente Fernandez Parrado : según la carta esferica de buenos aires de d. Alejandro Malaspina, la carta de Valera y ulloa de 1779, la carta de Paraguay de Felix de Azara, la carta esferica de la provincia de Chiquitos por el capitan de fragata d.Antonio Alvarez de Sotomayor y la carta esferica del rio de las Amazonas, de mr de la Condamine que se hallan en el archivo de Buenos Aires. Escala [ca. 1:1851851]

1 mapa : ms., col. ; 237,4 x $110 \mathrm{~cm}$

Mapa general de la demarcación.-Graduado en un grado de latitud [=6 cm]. Coordenadas referidas en longitud al meridiano de Cádiz. - Figura el Tropico de 
Capricornio y la "Linea Equinoccial". - Nota explicativa sobre las coordenadas que da, basadas en cartas esféricas de Malaspina, Felix de Azara, Antonio Alvarez Sotomayor y de la de Pedro Lázaro de Rivera. - Título propio y nota explicativa enmarcados en cartela decorada con cinta entrelazada.

Signaturas: MN. 39-A-9

Oyarvide, Andrés de

BRASIL. SE. Cartas náuticas 1:1111112. 1783

Carta esférica sacada del viaje que hizieron desde la Ia. Sta. Catalina por tierra sobre la Costa del Mar hasta Río Grande los geógrafos portugueses para la demarcación de límites el año de 1783 / Oyarvide. - Escala [ca. 1:1111112]

1 mapa : ms. ; $51,2 \times 48,2 \mathrm{~cm}$

Pertenece a la segunda partida de límites. Manuscrito firmado por el autor. - Graduado 1 grado de latitud [ $=10 \mathrm{~cm}$ ]. - Relieve representado por normales. - Figuran las costas y aguas continentales coloreadas a la acuarela en verde. - Aparece anotación : "Quedó copia en el Depósito Hidrográfico de Madrid en 1798". - Nota explicativa bajo el título.

Signaturas: MN. 38-C-4

Varela y Ulloa, José

BRASIL. Fronteras. 1:424737. 1788

Plano topográfico que comprende la costa del mar desde la ensena[da] de Castillos hasta el Río Grande de Sn. Pedro : el Arroyo del Chuy, la laguna de la Manguera y la de Merín, con todos los Arroyos que desaguan en esta, el Piratini, las cabeceras del Río Negro y las del Ycabagua, las vertientes que bajan de la Cuchilla general al Yacuy y el Uruguay, con la boca del río a que los demarcadores pasados dieron el nombre de Pepiri, expresandose en el mismo plano los terrenos ya demarcados y los que están en disputa entre los Comisarios principales de los dos Soberanos, por cuya orden se hizo éste trabajo que empezó el año de 1784 y y se concluyó en el de 1788 / Josef Varela y Ulloa. - Escala [ca. 1:424737] (O 54º $\left.46^{\prime} 16^{\prime \prime}-\mathrm{O} 50^{\circ} 19^{\prime} 11^{\prime \prime} / \mathrm{S} 27^{\circ} 00^{\prime} 00^{\prime \prime}-\mathrm{S} 34^{\circ} 44^{\prime} 30^{\prime \prime}\right)$

1 plano : ms., col. ; 206,2 x 109,1 cm

Pertenece a la primera partida de límites. Manuscrito en colores, firmado por el autor. Escala gráfica de 50 millas $[=21,8 \mathrm{~cm}]$ y de 15 leguas de 17,5 al grado. Coordenadas referidas al meridiano de Ferro. Orientado con rosa y media lis. - Relieve representado por normales. Una parte del plano está en blanco.

Signaturas: $\mathrm{MN}-38-\mathrm{C}-11$

Valera y Ulloa, José

BRASIL. Mapas generales. 1:71225. 1784

Plano topográfico de los Arroyos de Chuy, Sn. Miguel y sus contornos hasta Castillos Chicos en que se manifiesta la línea perteneciente a los dominios de España establecida en cumplimiento del Tratado Preliminar de Límites de 11 de Octubre de 1777 por los primeros Comisarios de las dos Coronas de las Coronas de España y Portugal en el año

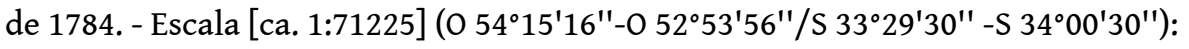


1 mapa : ms., col. ; 90,4 x 48,5 cm Notas: Escala gráfica de 5 millas [= $13 \mathrm{~cm}]$. Pertenece a la primera partida de límites. Longitud occidental del meridiano de Ferro. Orientado con media lis. - Relieve de perfil. - Manuscrito coloreado a la acuarela en verde y rosa. Figura trazada la línea de demarcación.

Signaturas: MN. 38-C-2

Varela y Ulloa, José; Cocq, Bernardo de; Gundín, Joaquín; Varela, Joaquín Vicente BRASIL. Mapas generales. 1:419634. 1786

Plano topográfico que comprende los Arroyos del Chuy, S. Miguel y Tahin, las Lagunas de la Manguera y Merin, los arroyos que baxan a esta desde la Cuchilla General y el Piratini que desagua en el Sangradero de la misma laguna / levantado por orden de los Primeros Comisarios de España y Portugal en 1786 ; Josef Varela y Ulloa; Cocq, Berndo. ; Joaqn. Gundin ; Joaquin Vicente Varela. - Escala [ca. 1:419634] (O 64 $58^{\prime} 16^{\prime \prime}-0$ $\left.51^{\circ} 43^{\prime} 16^{\prime \prime} / \mathrm{S} 31^{\circ} 15^{\prime} 00^{\prime \prime}-\mathrm{S} 34^{\circ} 25^{\prime} 00^{\prime \prime}\right)$

1 mapa : ms., col., montado sobre tela ; $91,6 \times 77,4 \mathrm{~cm}$

Pertenece a la primera partida de límites. Manuscrito firmado por los autores. - Escala gráfica de 12 leguas de 17,5 al grado $[=18,1 \mathrm{~cm}]$. Coordenadas referidas al 0 . del meridiano de Hierro. Orientado con rosa de los vientos y media lis. - Relieve de perfil. Manuscrito coloreado a la acuarela en verde, rosa y amarillo. - Nota explicativa bajo el título.

Signaturas: MN. 38-C-1

BRASIL. Fronteras. 1:264550. 1784

Costa oriental de la Laguna Mini ó Merín. - Escala [ca. 1:264550]

1 mapa : ms. ; 61,1 x 50,4 cm

Pertenece a la primera partida de límites. Graduado, 1 minuto de latitud [=0,7 cm]. Notas explicativas de los comisarios de la partida de reconocimiento.

Signaturas: MN. 38-C-7

Villarino, Basilio; Casaflrez

BRASIL. Cartas náuticas. 1:455373. 1777

Plano que contiene la costa del Brasil comprehendida entre los $25^{\circ} 30^{\prime}$ y los $29^{\circ} 15^{\prime}$ de latitud S. la ya. de Sta. Catalina, y sus adyacenters : con la demostrz. dela sonda y derrota que hicieronlas Fragatas del mando del Capitan de navío Dn. José Bustillo sobre el paralelo de la ya. Arboledo / Villarino ; Casaflores.- Escala [ca. 1:455373] Publicación: [1700?]

1 carta náutica : ms., col. ; 95,8 x 63,7 cm

Comprende desde PARANÁguá hasta Araranguá. - Escala gráfica de $1 \mathrm{~cm}$ de arco de meridiano $[=24,4 \mathrm{~cm}]$. Orientado con 2 nudos de 32 rumbos y lis. Coordenadas referidas, al parecer, al meridiano de Tenerife (E $328^{\circ} 20^{\prime}$-E $331^{\circ} 20^{\prime} / \mathrm{S} 25^{\circ} 30^{\prime}$-S $\left.29^{\circ} 15^{\prime}\right)$. - Indica bajos. Clave hidrográfica para determinar la calidad del fondo. - Manuscrito coloreado a la acuarela en verde y azul. - Indica la toponimia costera mediante clave. - Título enmarcado en cartela decorada . 
Signaturas: MN. 37-B-1

Saldanea, J. A.

BRASIL. SE. Mapas generales. 1:620000. 1783

Plano Topográfico da Costa do Mar n'America Meridional : desde a Barra do Norte da ilha de Sta Catalina ate a do Rio Grande de S.Pedro / rectificado com varias obervacoes de longitude, feitas em o anno de 1783; J. A. Saldanea observavit atque fecit.- Escala [ca. $1: 620000]\left(050^{\circ} 44^{\prime}-048^{\circ} 66^{\prime} / \mathrm{S} 27^{\circ} 20^{\prime}-\mathrm{S} 32^{\circ} 10^{\prime}\right)$

1 mapa : ms. ; $90,6 \times 59,1 \mathrm{~cm}$

Pertenece a la primera partida de límites. Graduado en longitud respecto del meridiano de Ferro. Escala hallada a partir de un grado de meridiano [= 17,9 cm]. - Leyenda explicativa sobre las observaciones previas realizadas para la elaboración del plano y tabla con coordenadas de numerosos puntos. - Toponimia costera.

Signaturas: MN. 39-A-2

Comisión de Límites del Sur del Brasil

BRASIL. Fronteras. 1:1683500. 1777

Plano corográfico de los reconocimientos pertenecientes a la demarcación del artículo 8º. del Tratado Preliminar de Límites del 11 de Octubre de 1777 / practicado por las segundas subdivisiones españolas y portuguesas en orden a desatar las dudas suscitadas entre sus respectivos comisarios. - Escala [ca. 1:683500] ; (O 56 54 $44^{\prime} 46^{\prime \prime}-0$ 50 $36^{\prime} 46^{\prime \prime} / \mathrm{s}$ $\left.20^{\circ} 50^{\prime} 00^{\prime \prime}-\mathrm{S} 31^{\circ} 21^{\prime} 00^{\prime \prime}\right)$

1 mapa : ms., col. ; 76,8 x 45,2 cm

Pertenece a segunda partida de límites. Escala gráfica de 10 leguas de 20 al grado [= 3,3 $\mathrm{cm}$ ]. Longitud occidental del meridiano de Ferro. - Relieve de perfil. - Manuscrito coloreado a la acuarela en verde y amarillo. - Señala la línea de demarcación entre los dominios de España y Portugal, así como la zona central situada entre ambos. - Notas explicativas bajo el título y en ángulo inferior izquierdo.

Signaturas: MN. 38-C-17

BRASIL. Costas. 1:220000. 1786

Plano de la laguna de Merim y de la Manguera en la costa meridional de Brasil : con la division de los dominios de España / Oyarvide. - Escala [ca. 1.220000] ; (O 54 $4^{\circ}-0$ 53 ${ }^{\circ}$ $\left.27^{\prime} / \mathrm{S} 32^{\circ} 24^{\prime}-\mathrm{S} 34^{\circ} 01^{\prime}\right)$

1 mapa : ms. ; $88,5 \times 62,9 \mathrm{~cm}$

Pertenece a la primera partida de límites. Título redactado a partir del contenido del mapa. - Escala hallada a partir de un un grado de meridiano $[=50,5 \mathrm{~cm}]$. Coordenadas referidas al meridiano de Ferro. Orientado con rosa y lis. - Señala las fronteras entre los actuales países de Brasil y Uruguay.

Signaturas: MN. 39-A-5

BRASIL. SE. Costas. 1:628000. 1784

Costa del Brasil : Desde la Barra del Rio Grande a la Ysla de Sta Catalina.- Escala [ca. $1: 628000]$ 
1 mapa : ms. ; 93,3 x 60,6 cm

Pertenece a la primera partida de límites. Título propio tomado del verso del mapa. Graduado enlatitud. Escala hallada a partir de un grado de meridiano [=17,6 cm]. Nota explicativa sobre la elaboración del mapa.

Signaturas: MN. 39-A-1

Comision de Límites del Sur del Brasil

BRASIL. Fronteras. 1:264550. 1786

Reconocimiento de los terrenos que baña el río Piratiny hecho por los comisarios de la $1^{\mathrm{a}}$ y $2^{\mathrm{a}}$ partida de limites / Copia de Oyarvide en 1786 - Escala [ca. 1:264550]

1 mapa : ms. ; $37,9 \times 42,5 \mathrm{~cm}$

Pertenece a segunda partida de límites. Título redactado a partir del contenido del mapa. - Graduado, 1 minuto de latitud [=0,7 cm]. - Relieve representado por normales. Figura trazada la ruta seguida por la 1a. y 2a. Partida de límites.

Signaturas: MN. 38-C-6

Azara, Félix de

BRASIL. Fronteras. 1:2172838. 1791

Bosquejo que manifiesta la posición respectiva de las misiones de Chiquitos, parte de los Moxos, el Distrito de Sta. Cruz de la Sierra y el curso y dirección de los principales ríos que corren por dhros [i.e. dichos] terrenos y circuyen su limites / dirigido a la superioridad por el Comisario de 3a. Partda. Demarcadora la en 12 de Diciembre de

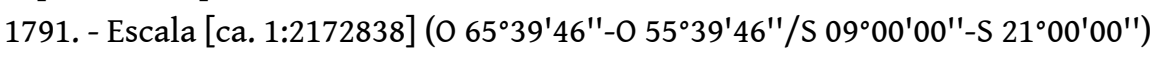

1 mapa : ms., col. ; 70'4 x 53'7 cm

Pertenece a la tercera partida de límites Escala de 22 leguas francesas de 25 al grado [= 4'5 cm]. - Longitud occidental del meridiano de París. - Orografía de perfil. - Trazada la línea divisoria en color rojo. - Toponimia de accidentes geográficos, núcleos de población, misiones y localización de los pueblos indígenas.

Signaturas: $\mathrm{MN}-38-\mathrm{C}-8$

BRASIL. Fronteras. 1:264550. 1786

Reconocimiento de los terrenos que baña el río Piratiny 1786 . - Escala [ca. 1:264550]

1 mapa : ms. ; $37,9 \times 42,5 \mathrm{~cm}$

Pertenece a la primera partida de límites. Título redactado a partir del contenido del mapa. - Graduado, 1 minuto de latitud [=0,7 cm]. - Relieve representado por normales. Figura la ruta seguida por la 1a. y 2a. Partida de límites.

Signaturas: MN. 38-C-6

Oyarvide, Andrés de

CASTILLO GRANDE (Urugay) (Ensenada). Cartas náuticas. 1:23540. 1804

Plano de la ensenada de Castillo Grande : y sus islas inmediatas / Levantado de Orden del Rey en Marzo de 1804 Para el Depósito Hidrográfico de Madrid; Andrés de Oyarvide.- Escala [ca. 1:23540], 2 millas marítimas [=11'8 cm] 
carta náutica : montado sobre tela ; 64 x 47'5 cm

Pertenece a la primera partida de límites Presenta además una vista de la costa. Manuscrito firmado, rubricado y fechado. A plumilla en tinta negra. - Orientado con media lis en cuadrante. - Relieve representado por normales. - Indica veriles, bajos, fondeaderos y sondas batimétricas. Clave hidrográfica para determinar la calidad del fondo. - Leyenda explicativa de la topografía, vegetación, mareas, calidad del fondo y advertencias para la navegación. - Señala enfilaciones para la entrada a puerto.

Signaturas: MN. 43-C-11

JEJUI (Paraguay) (Río). Mapas hidrográficos. 1:123456. 1788

Plano de los Rios Curuguay y Xesuy : lebantado en el año de 1788. - Escala [ca. 1:123456]

1 mapa : ms. ; $24 \times 42,2 \mathrm{~cm}$

Pertenece a la tercera partida de límites Escala hallada a partir de un minuto de latitud $[=1,5 \mathrm{~cm}]$. Coordenadas referidas al meridiano de Asunción. - Manuscrito a plumilla en tinta negra.

Signaturas: MN. 42-C-1

Oyarvide, Andrés de

LA PALOMA (Uruguay) (Rocha) (Puerto). Cartas náuticas. 1:19300. 1804

lano del Puerto de la Paloma y Fondeadero del Arrecife : sobre el Cabo de Sta. María, en la costa de Rocha, N.E. de Maldonado, Levantado por orden del Rey por Enero de 1804 / Para el Depósito Hidrográfico de Madrid Andrés de Oyarvide .- Escala [ca. 1:19300], 1 milla marítima $\left[=9^{\prime} 6 \mathrm{~cm}\right]$

1 carta náutica : ms., montado sobre tela ; 67,2 x 47,6 cm

Presenta dos vistas del perfil de la costa. - Manuscrito firmado y fechado. A plumilla en tinta negra. - Coordenadas del cabo referidas al meridiano de Montevideo (E $2^{\circ} 05^{\prime} 06^{\prime \prime}$ / S 34 40' 50"). Orientado con media lis. - Relieve representado por normales y sombreado. - Indica veriles, bajos, fondeaderos y sondas batimétricas en brazas de seis pies de Burgos. Clave hidrográfica para determinar la calidad del fondo. - Nota explicativa del mapa, tanto del Puerto de la Paloma como del fondeadero del Arrecife. Señala enfilaciones

Signaturas: MN. 43-D-9

Gundín, Joaquín; Baleato, Andrés; Massa, Gaspar

LA PLATA (Río). Cartas náuticas. 1:158729. 1791

Plano de la costa Septentrional del Río de la plata : desde la Colonia del Sacramento hasta el Puerto de Martín chico. Cartas no 1 y 2 / arreglado a las operaciones que verificó en 1791 el Primer Piloto de la Rl. Armda. Dn. Joaquín Gundin comisionado por la Superioridad, y agregada la Sonda desde el canal de Ynfierno hta. Buenos Aires practicada posteriormente ; A. Baleato, B. Massa. -: Escala [ca. 1:158729], 12 millas marítimas $\left[=10^{\prime} 5 \mathrm{~cm}\right] .-1791$

1 carta náutica : ms. ; 37'5 x 41'5 en h. de $61 \times 43^{\prime} 5 \mathrm{~cm}$

Pertenece a la primera partida de límites. Manuscrito firmado, rubricado y fechado. A plumilla en tinta negra. - Orientado con lis en cuadrante. - Relieve representado por 
normales. - Indica veriles, bajos, fondeaderos y sondas batrimétricas en palmos castellanos. Clave hidrográfica para determinar la calidad del fondo.

Buenos Aires (Argentina)Uruguay CDU: (282.281.6 La Plata)

Signaturas: MN. 43-C-1

Gundín, Joaquín; Baleato, Andrés; Massa, Gaspar

LA PLATA (Río). Cartas náuticas. 1:158729. (1791). 1809

Plano de la Costa Septentrional del Río de la Plata : desde la Colonia del Sacramento hasta la Punta de Sn. Gregorio. Carta nº 4 / arreglado a las operaciones del Primer Piloto de la Armada Dn. Joaquín Gundin ; A. Baleato ; B. Massa Escala: Escala [ca. 1:158729], 12 millas marítimas [10'5 cm]: 1809

1 carta náutica : ms. ; $30 \times 48 \mathrm{~cm}$

Pertenece a la primera partida de límites. Manuscrito firmado, rubricado y fechado. A plumilla en tinta negra. - Orientado con lis. - Indica sondas batimétricas. - Señala toponimia, relieve y simbología de vegetación. Signaturas: MN. 43-C-2

Gundín, Joaquín; Baleato, Andrés; Massa, Gaspar

LA PLATA (Río). Cartas náuticas. 1:158729. (1791). 1809

Plano de la costa Septentrional del Río de la Plata : desde la Punta del Espinillo hasta la de Jesús Mara. Carta n 5 / arreglado a las operaciones del Piloto de la Armda. dn. Joaqn. Gundin ; A. Baleato ; B. Massa,- Escala [ca. 1:158729], 12 millas marítimas [=10'5 cm].1809

1 carta náutica : ms. ; 30'6 x 43'2 cm

Pertenece a la primera partida de límites. Manuscrito firmado, fechado y rubricado en Montevideo. A plumilla en tinta negra. - Orientado con lis. - Indica sondas batimétricas.

Signaturas: MN. 43-C-3

Gundín, Joaquin; Baleato, Andrés; Massa, Gaspar

LA PLATA (Río). Cartas náuticas. 1:156053. (1790) 1819.

Plano de la costa Setentrional del Río de la Plata : desde el Cerro de Montevideo hasta la Punta de la Ballena, $\mathrm{u}$ occidental de la ensenada de Maldonado. Carta $\mathrm{n}^{\circ} 7$ / arreglado a las operaciones del 1er. Piloto de la Rl. Armada Dn. Joaquín Gudín comisionado por la superioridad, y verificadas en 1790 ; A. Baletao, B. Massa.- Escala [ca. 1:156053], 10 millas marítimas [ $\left.=8^{\prime} 9 \mathrm{~cm}\right]$

1 carta náutica : ms. ; 30' 3 x 73' $5 \mathrm{~cm}$

Pertenece a la primera partida de límites. Manuscrito firmado, rubricado y fechado.. Manuscrito a plumilla en tinta negra. - Orientado con lis. - Indica sondas batimétricas. Señala enfilaciones desde la Isla de Flores a varios puntos de la costa.

Signaturas: MN. 43-C-4

Gundín, Joaquín; Oyarvide, Andrés de

LA PLATA (Río). Cartas náuticas. 1:210000. 1792 
Carta Plana que manifiesta la Costa septentrional del Río de la Plata : desde la Ysla de Martin Garcia hasta el Fuerte de Sta. Teresa, los Arroyos que desaguan en ella desde sus cabeceras ú origenes, y las Yslas adjacentes... / de lo practicado por el primer Piloto de la Rl. Armada Dn. Joqn. Gundin ... por disposición del Excmo. Sr. Dn. Nicolas de Arredondo Virey y Capn. Gral de las Provincias del Rio de la Plata a solicitud del Brigadier de la Rl. Armda. Dn. Joseph Varela y Ulloa... ; Constr... por ... A. Oyarvide, primer piloto de la Rl. Armada... 1792 octubre - Escala [ca. 1:210000]

1 carta náutica : ms. ; 63' 8 × $128^{\prime} 5 \mathrm{~cm}$

Pertenece a la primera partida de límites Manuscrito firmado y fechado en Buenos Aires. A plumilla en tinta negra y coloreado a la acuarela en siena. - Escala hallada a partir de un minuto de latitud $\left[=0^{\prime} 9 \mathrm{~cm}\right]$. Coordenadas referidas al meridiano de

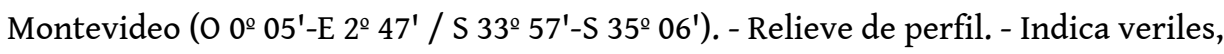
bajos y fondeaderos. - Tabla de signos convencionales para indicar núcleos de población de distinta categoría. - Señala coordenadas de algunos puntos y enfilaciones. - Nota explicativa sobre la construcción del mapa con datos de 1769 y 1777. - Inserta dos mapas de la punta de Rochas y la Ensenada de Castillos, respectivamente, con leyenda explicativa.

Signaturas: MN. 43-D-11

LA PLATA (Río). Cartas náuticas. 1:230000. 1788

Plano de la costa del Uruguay que comprende desde el arroyo del Miguelete a la laguna de la Palma o de Difuntos. 1788 / Joaquin Gundín.- Escala [ca. 1:230000]

1 carta náutica : ms., col. ; 83' 8 x 117' $5 \mathrm{~cm}$

Pertenece a la primera partida de límites. Título redactado a partir del contenido del mapa. - Manuscrito a plumilla en tinta negra y coloreado a la acuarela en verde y gris. Escala hallada a partir de un minuto de latitud $\left[=0^{\prime} 8 \mathrm{~cm}\right]$. Coordenadas referidas al

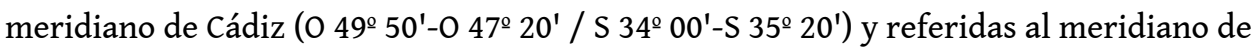
Montevideo. - Relieve de perfil. - Indica veriles, bajos y sondas batimétricas. - Señala enfilaciones y arrecifes. - Notas relativas a la composición del mapa.

Signaturas: MN. 43-D-7

Alvear y Ponce, Diego

LA PLATA (Río). Mapas generales.. 1:578703. 1794

Carta Reducida o Esférica del Río de La Plata : desde la confluencia de los Ríos Paraná y Uruguay que lo forman hasta su desaguadero en el Mar con parte de la costa septentrional hasta el arroyo del Chuy / Construida para el uso de la Navegación por los oficiales de la Segunda Partida de Límites Española del mando del Comisario y Capitan de Fragata de la Rl. Armada Dn. Diego de Albear y Ponce Año de 1794 enero. - Escala [ca. 1:578703]

1 mapa : ms. ; 59 × 92'6 cm

Pertenece a la segunda partida de límites. Manuscrito fechado en el Puerto de San Angel de las Misiones del Uruguay. A plumilla en tinta negra y coloreado a la acuarela en verde, amarillo, carmín y siena. - Escala hallada a partir de un grado de latitud [ $=19^{\prime} 2$

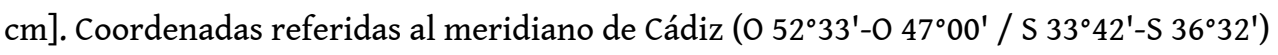
y referidas al meridiano de Montevideo (O $\left.2^{\circ} 30^{\prime}-\mathrm{E} 3^{\circ} 02^{\prime} / \mathrm{S} 33^{\circ} 42^{\prime}-\mathrm{S} 36^{\circ} 32^{\prime}\right)$. - Relieve de 
perfil. - Indica veriles, bajos y sondas batimétricas en brazas de a dos varas castellanas. Clave hidrográfica para determinar la calidad del fondo. - Nota relativa a la composición del mapa. - Señala coordenadas de las ciudades más importantes.

Signaturas: MN. 46-C-6

LA PLATA (Río). Cartas náuticas. 1:74074. 1788

Costa de Urugay : desde la Punta de Martín Chico en Río de la Plata hasta el fuerte Santa Teresa en el Atlántico.- Escala [ca. 1:74074]

1 carta náutica : ms., col. ; 63'3 x 213'5 cm

Pertenece a la primera partida de límites. Título redactado a partir del contenido del mapa. - Manuscrito a plumilla en tinta negra y coloreado a la acuarela en siena. - Escala hallada a partir de un minuto de latitud [=2,5 cm]. - Indica sondas batimétricas. - Forma irregular.

Signaturas: MN. 43-C-10

LA PLATA (Río). Cartas náuticas. 1:264550. 1780?

Mapa de la desembocadura del río de La Plata, desde Buenos Aires a Punta de Piedras en el litoral argentino, y hasta Montevideo en la costa uruguaya].- Escala [ca. 1:264550] 1 carta náutica : ms. ; 54,2 x 134,5 cm

Título propio redactado a partir del contenido del documento. - Escala hallada a partir de un minuto de latitud $\left[=0^{\prime} 6 \mathrm{~cm}\right.$ ]. Coordenadas rferidas al meridiano de Punta de Piedras, Montevideo (O $\left.2^{\circ} 20^{\prime}-\mathrm{E} 1^{\circ} 30^{\prime} / \mathrm{S} 34^{\circ} 20^{\prime}-\mathrm{S} 35^{\circ} 30^{\prime}\right)$. - Relieve representado por normales. - Indica veriles, bajos y sondas batimétricas y calidad del fondo. - Manuscrito a plumilla en tinta negra. - Señala las sondas sólo a lo largo de las líneas de derrota, con especificación del diario de las mismas

Signaturas: MN. 46-B-7

LA PLATA (Río). Cartas náuticas. 1:214000. 1788

Embocadura del Rio de la Plata que comprende la costa S. de Uruguay desde las islas Dos Hermanas hasta la pta. del Cerro / Andres de Oyarvide, 1788. - Escala [ca. 1:214000]

1 carta náutica : ms., col. ; 63'8 x $109 \mathrm{~cm}$

Título tomado del verso y del contenido del mapa. - Manuscrito a plumilla en tinta negra y coloreado en verde y siena. - Escala hallada a partir de un grado de latitud [ $\left.=52^{\prime} 7 \mathrm{~cm}\right]$. Coordenadas referidas al meridiano de Montevideo (O $2^{\circ} 24^{\prime}-\mathrm{E} 0^{\circ} 03^{\prime} / \mathrm{S} 33^{\circ}$ $\left.57^{\prime}-\mathrm{S} 35^{\circ} 06^{\prime}\right)$. - Relieve representado por sombreado. - Indica veriles, bajos y sondas batimétricas. - Señala líneas de derrota y enfilaciones.

Signaturas: MN. 43-D-6

MATTO GROSSO.(Brasil) Fronteras. 1:1683502. 1790

Mapa de Matto Grosso hasta los rios Jauru, Vermejo y Cuyaba .- Escala [ca. 1:1683502]

1 mapa : ms. ; $21,5 \times 32,1 \mathrm{~cm}$

Pertenece a la tercera partida de límites. Título redactado a partir del contenido del mapa. - Graduado, 1 grado de latitud [ $=6,6 \mathrm{~cm}]$. - Relieve representado por normales. Señala la línea de demarcación. 
Signaturas: $\mathrm{MN}-38-\mathrm{C}-5$

Oyarvide, Andrés de

MALDONADO (Uruguay) (Ensenada). Cartas náuticas. 1:27857. 1803

Plano Del Puerto de Maldonado y parte Oriental de la Ensenada del Potrero En la Costa Septentrional de la desembocadura del Rio dla Plata / Levantado de Orden del Rey En Agosto de 1803. Para el Depósito Hidrográfico de Madrid, Andrés de Oyarvide. - Escala [ca. 1:27857], 1000 toesas , pie de Burgos [=7 cm]

1 carta náutica : ms., montado sobre tela ; $76^{\prime} 0 \times 55^{1} 7 \mathrm{~cm}$

Pertenece a la primera partida de límites. Manuscrito firmado, rubricado y fechado. A plumilla en tinta negra. - Escalas gráficas de 1 milla marítima $\left[=7^{\prime} 8 \mathrm{~cm}\right]$ y 1000 toesas, pie antiguo de París $\left[=8^{\prime} 2 \mathrm{~cm}\right]$. Coordenadas de la Punta del Este referidas al meridiano

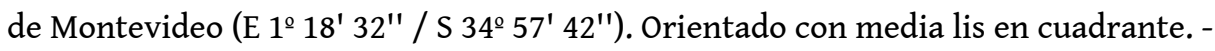

Relieve representado por normales. - Indica veriles y sondas batimétricas en brazas de 2 varas castellanas. Clave hidrográfica para determinar la calidad del fondo. - Señala derrotas, toponimia, meandros o dunas terrestres y situación de la ciudad de S. Fernando de Maldonado. - Nota relativa al Puerto de Maldonado y ensenada del Potrero (vientos, corrientes, bajos, características del fondo marino y en general de sus fondeaderos), diversas emtradas al Puerto de Maldonado (detallada descripción de la navegación por él) y una nota con explicación sobre las derrotas seguidas para la medición de las sondas, mareas... y tabla con las distancias y ángulos existente entre los diversos lugares y la Punta del Este.

Signaturas: MN. 44-A-5

Oyarvide, Andrés de

MONTEVIDEO (Uruguay). Cartas náuticas. 1:7600. 1784

Configuración De la Punta de Sn. José y sus fondos inmediatos / Oyarvide. - Escala [ca. $1: 7300], 100$ varas $[=1,1 \mathrm{~cm}]$

1 carta náutica : $\mathrm{ms}$; $40 \times 32,4 \mathrm{~cm}$

Manuscrito firmado por el autor. - Escala gráfica de pasos comunes $[=1 \mathrm{~cm}]$. Orientado con media lis. Gráfico de declinación magnética. - Indica veriles y sondas batimétricas en pies de Burgos. Clave hidrográfica para determinar la calidad del fondo. -

Manuscrito a plumilla en tinta negra y lápiz. - Señala perímetro de la ciudad de Montevideo, estando la representación planimétrica del interior de la urbe, a lápiz. - Al verso, "Plano de la Ciudad de Monte-video y el fondeadero de la Punta de San José"

Signaturas: MN. 44-B-3

Casaflórez

MONTEVIDEO (Uruguay). Planos de población. 1:2600. 1783

Plano de la ciudad de Montevideo : situado a los $34^{\circ} 55^{\prime}$ en la América Meridional sacado el año de 1783 siendo Virrey el Exmo. señor Don Juan Jose de Vertis y Salzedo Thete. General de los Reas. Exercitos de S.M. / Casaflorez, 1783.- Escala [ca. 1:2600], 200 varas castellanas $[=6,7 \mathrm{~cm}]$

1 plano : ms., col. ; 55,3 x 75,6 cm 
Manuscrito firmado y fechado por el autor. - Orientado con media lis. - Relieve representado por sombreado. - Manuscrito a plumilla en tinta negra y coloreado a la acuarela en varios colores. - Relación de las calles principales de la ciudad indicadas por clave numérica. - Indica caminos y masas forestales.

Signaturas: MN. 44-B-1

Casaflórez; Pallares, Domingo

MONTEVIDEO (Uruguay) (Puerto). Guerra naval. 1:26500. 1781

Plano de el puerto de Montevideo y Línea de defensa qe deben formar los buques qe se hallan en el, en caso de enemigos : con el N. de cañones qe hai montados en el recinto de la Plaza / Domingo Pallares ; Casaflorez. 1781 julio 30.- Escala [ca. 1:26500], 1 milla castellana $[=7 \mathrm{~cm}]$

1 mapa : ms., col. ; 35,6 x 45,6 cm

Presenta la posición de los buques en la bahía, de acuerdo con su táctica militar preconcebida en caso de enfrentamiento con el enemigo. - Manuscrito firmado y fechado en Montevideo. - Orientado con media lis en rosa de 8 vientos. - Relieve de perfil. - Indica bajos. - Manuscrito a plumilla en tinta negra y coloreado a la acuarela en amarillo, verde y sepia. - Relación de buques que intervienen en la maniobra militar, detallándose el armamento de que disponen y las baterías de la costa. - Figuran dibujados buques, en la ciudad de Montevideo.

Signaturas: MN. 44-B-7

MONTEVIDEO (Uruguay). Planos de población. 1784

Plano de la ciudad de Montevideo. - Escala indeterminada

1 plano : ms., col. ; 35,7 x 49,5 cm

Título redactado a partir del contenido del mapa. - Orientado con lis en rosa de 8 vientos prolongados. - Relieve representado por sombreado. - Manuscrito a plumilla en tinta negra y coloreado a la acuarela en varios colores. - Incompleto, cartela decorada vacía, escala sin equivalencia y anotaciones a lápiz.

Signaturas: MN. 44-B-8

MONTEVIDEO (Uruguay). Planos de población. 1:3500. 1771

Plano de la Plaza de Sn. Felipe de Montevideo en el Río de La Plata : en el que se demuestran sus Fortificaciones egecutadas y por executar, 1771. - Escala [ca. 1:3500], 700 varas castellanas $[=16,7 \mathrm{~cm}]$

1 plano : ms., col. ; 58,8 x 96,6 cm

Escala gráfica de 1920 pies ingleses igual a 700 varas castellanas $[=16,7 \mathrm{~cm}]$. Orientado con nudo de rumbos. - Manuscrito a plumilla en tinta negra y lápiz y coloreado a la acuarela en carmín. - Relación de la ciudadela, baluartes, baterías, etc. indicados por claves alfabética y numérica. - Notas a lápiz. - Manuscrito incompleto.

Signaturas: MN. 44-B-9

ORINOCO (Venezuela) (Río). Mapas hidrográficos. 1:106428. 1801--1802 
Plano primero de los Caños de Sotavento que comprende desde el primero punto en que remata el Caño de Manamo y Pedernales en el plano Quarto de los de la Costa, de Sotavento del Rio Orinoco, y siguiendo hacia el Sur manifiesta la dirección de estos dos Caños, y parte del de Cucuyna, hasta la punta del Morichal donde remata, con todas las Yslas y bajos correspondientes a dicho espacio, como asimismo los caños que se apartan y la dirección de estos : situado todo conforme a los reconocimientos practicados en los años de 1801 y 1802. Tercera parte.- Escala [ca. 1:106428]

1 carta náutica : ms., col. ; 65,0 x 83,0 cm Series: (Colección de planos del Río Orinoco. Tercera parte ; 1 )

En : Carpetilla de 85 x $65 \mathrm{~cm}$. de la tercera parte de la Colección del Río Orinoco. Longitud del meridiano de Cádiz. Graduado. Orientado con lis. - Indica sondas batimétricas y veriles con nota explicativa al respecto. - Sombreadas las riberas y dibujo de vegetación. - Lavado en ocre, amarillo, rojo, verde y azul, enmarcado en orla, igual que el título.

Signaturas: MN. 32-A-3a

ORINOCO (Venezuela) (Río). Mapas hidrográficos. 1:96450. 1797-1802

Plano primero del Rio Orinoco que manifiesta la entrada de la Boca Grande dicho Rio, y comprende hasta la separación de los dos Brazos de Ymataca, y Sacapana : con todas las Yslas, y bajos correspondientes a dicho espacio como asimismo los Caños que se apartan, y la dirección de estos, situado todo despues de seis prolijos reconocimientos practicados desde el fin del año de 1797 hasta el de 1802, hallándose el Río en sus tres quartas partes, y total vaciante. Primera parte.- Escala [ca. 1:96450]

1 carta náutica : ms., col., ; 65,0 x 83,0 cm Series: (Colección de planos del Río Orinoco)

En : Carpetilla de 85 × $65 \mathrm{~cm}$ de la primera parte de la colección de planos del Río Orinoco. - Longitud del meridiano de Cádiz. Graduado. - Orintado con lis. - Presenta batimetría y veriles sonda, calidad del fondo con nota explicativa sobre los mismos; las costas en su desembocadura y las riberas en su curso aparecen sombreadas ; presenta símbolos de vegetación ; su curso se ve interrumpido por numerosos islotes y cambios de dirección, meandros y multitud de afluentes que confluyen a su paso. - Lavado en ocre, igual que el título. - Inserta una vista de tierra con nota explicativa. - Aparece señalado un recuadro del mapa con línea carmín, de la que se hará referencia en el primer plano de la segunda parte que es continuación lateral de éste.

Signaturas: MN. 32-A-1a.

ORINOCO (Venezuela) (Río). Mapas hidrográficos. 1:102880. 1801-1802

Plano quarto de la Costa de Sotavento del Rio Orinoco que comprende desde el mismo punto donde concluyó el Tecero, hasta el bajo de la Punta de Benado donde remata : con todas la Yslas, y bajos correspondientes a dicho espacio,como asimismo las Entradas de los Caños de Pedernales, y del Manamo, y la dirección de estos hasta la union que tienen con el Plano de los de la tercera parte que por medio de éste, y el sellegan a incorporar con los del Orinoco, situado todo conforme a los Teconocimientos que quedan expresados en el 1er Plano de esta 2a. Parte Escala: Escala [ca. 1:102880] 1 carta náutica : ms., col. ; 65,0 x 88,0 cm Series: (Colección de planos del Río Orinoco, segunda parte ; 4) 
En : Carpetilla de $85 \times 65 \mathrm{~cm}$ de la segunda parte de la colección del rio Orinoco. Longitd del meridiano de Cádiz. Graduado. - Orientado con lis. - Presenta batimetría y veriles, calidad del fondo con nota explicativa sobre los mismos y el área representada ; las costas y riberas aparecen sombreadas, presenta símbolos de vegetación. - Lavado en ocre, amarillo, rojo,verde y azul y se presenta en marco orlado igual que el título.

Signaturas: MN. 32-A-2

ORINOCO (Venezuela) (Río). Mapas hidrográficos. 1:96450. 1798--1802

Plano quarto del Río Orinoco que comprende desde el mismo punto donde concluyó el tercero hasta la medianía de la Ysla del Medio situada al Ote. del Serro de Guarampo donde remata : con todas la Yslas, y bajos correspondientes a dicho espacio, como assimismo los Caños que se apartan y la dirección de estos, situado todo conforme a los reconocimientos que quedan expresados en el primer plano de este Río. Primera parte. Escala [ca. 1:96450]

1 carta náutica : ms., col. ; 65,0 x 88,0 cm Series: (Colección de planos del Río Orinoco ; Primera Parte; 4)

En : Carpetilla de $85 \times 65 \mathrm{~cm}$ de la primera parte de la Colección de planos del río Orinoco. - Longitud del meridiano de Cádiz. Graduado. - Orientado con lis. - Orografía por sombreado. - Indica sondas batimétricas y veriles. - Relación de fortines, mansiones, poblaciones indicado en clave. - Nota con una breve exposición de las caractrísticas del lugar donde el curso del río fluye a traves de meandros e islotes y se enriquece a causa de los afleuentes que convergen en él. - Lavado en ocre, amarillo, verde y azul, presentándose en marco al igual que el título en la cartela orlada.

Signaturas: MN. 32-A-1d

ORINOCO (Venezuela) (Río). Mapas hidrográficos. 1:112917. 1801-1802

Plano quinto de la Costa de Sotavento del Río Orinoco que comprende desde el mismo punto donde concluyó el cuarto, hasta donde finaliza la Ysla de Antica en el Golfo Triste donde remata [[mapa]] : con todas las Yslas, y bajos correspondientes a dicho espacio como asi mismo las entradas del Caño Canipo, y la del Rio Guarapiche hasta sus primeras bueltas, situado todo conforme a los reconcimientos que quedan expresados en el primer plano de esta Segda. Parte. Segund Parte.- Escala [ca. 1:112917]

1 carta náutica : ms. col. ; 65 x 83 cm Series: (Colección de planos del Rio Orinoco) En : Carpetilla de $85 \times 65 \mathrm{~cm}$ de la segunda parte de la colección del Río Orinoco. Longitud del meridiano de Cádiz. Graduado. - Orientado conlis. - Presenta batimetría y veriles sonda, cavidad del fondo con nota explicativa sobre los mismos; las costas y riberas aparecen sombreadas, presenta símbolos de vegetación. - Lavado en ocre, amarillo, rojo, verde y azul y se presenta enmarcado en orla, igual que el titulo.

Signaturas: MN. 32-A-2e

ORINOCO (Venezuela) (Río). Mapas hidrográficos. 1:93500. 1797--1802

Plano Quinto del Rio Orinoco que comprende desde el mismo punto donde concluyó el Quarto hasta la Punta de Chacon que se halla quatro millas mas al Ote. de la Ciudad de la Nueva Guayana donde remata : con todas las Yslas, y bajos correspondientes a dicho espacio,como asimismo los Caños que se apartan, y la dirección de estos, situado todo 
conforme a los reconocimientos que quedan expresadas en el primer plano de este Río. Primera Parte.- Escala [ca. 1:93500]

1 mapa. : ms., col. ; 65,0 x 88,0 cm Series: (Colección de planos del Río Orinoco, primera parte ; 5)

En : Carpetilla de $85 \times 65 \mathrm{~cm}$ de la primera parte de la colección de planos del río Orinoco. - Longitud del meridiano de Cádiz. Graduado. Orientado con lis. - Presenta sondas batimétricas, veriles y calidad del fondo ; las riberas aparecen sombreadas. Señala la localización de núcleos de población, fortalezas, misiones, etc., con una nota explicativa. - Inserta dos perfiles minúsculos. - Lavado en ocre, amarillo, rojo, verde y azul. Con orla. Título enmarcado en cartela con guirnalda vegetal.

Signaturas: MN. 32-A-1e.

ORINOCO (Venezuela) (Río). Mapas hidrográficos. 1:102880. 1801-1802

Plano segundo de la Costa de Sotavento del rio Orinoco que comprende desde mismo punto donde concluyó el primero hasta la boca del Cañito de Morichal situado al Ote. de la punta Negra con dicha Costa donde remata : con todas las Islas y bajos correspondientes a dicho espacio, como asi mismo las bocas de los Caños, y la dirección que estos siguen, situado conforme a los Reconocimientos que quedan expresados en el Primer plano de esta segunda parte. Segunda Parte. - Escala [ca. 1:102880]

1 carta náutica. : ms. col. ; 65,0 x 88,0 cm Series: (.Colección de planos del Río Orinoco)

En : carpetilla de $85 \times 65 \mathrm{~cm}$ de la segunda parte de la colección del río Orinoco. Longitud del Meridiano de Cádiz. Graduado. - Orientado con lis. - Indica sondas batimétricas, veriles y clave hidrográfica para determinar la calidad del fondo. Orografía por sombrado en las costas. - Símbolos para la vegetación. - Las costas en su desembocadura y riberas aparecen sombreadas ; presenta simbolos de vegetación. Lavado en ocre, amarillo, rojo, verde y azul, y se presenta en marco orlado igual que el título.

Signaturas: MN. 32-A-2b

ORINOCO (Venezuela) (Río). Mapas hidrográficos. 1:105218. 1801-1802

Plano segundo de los Caños de Sotavento que comprende desde el mismo punto en que remató el primero, y siguiendo la direccion de los Caños del Manamo, Pdernales y Cucuyna, manifiesta el paraje donde se une este con Pedernales, como asimísmo la incorporación de estos con el Manamo, y remata en el mismo sitio en que se unen los dichos Planos con los del Rio Orinoco : con todas las Yslas, y bajos pertenecientes a dicho espacio como asimísmo, los Caños que se apartan, y la dirección de ellos, situado todo conforme a los reconcimientos que quedan expresados en el 1er. Plano de esta Tercera Parte. - Escala [ca.1:105218]

1 carta náutica : ms., col. ; 65,0 x 88,0 cm Series: (Colección de planos del Río Orinoco ; tercera parte ; 2$)$

En : Carpetilla de $85 \times 65 \mathrm{~cm}$ de la tercera parte de la colección del Río Orinoco. Longitud del meridiano de Cádiz. Graduado. - Indica sondas batimétricas y veriles, con nota explicativa al respecto. Sombreadas las riberas y señalada la vegetación. - Lavado en ocre, amarillo, rojo y verde y en azul, orlado con greca, y enmarcado con guirnalda el título. 
Signaturas: MN. 32-A-3b

Boenechea, Domingo de

ORINOCO (Venezuela) (Río). Mapas hidrográficos. 1:98500. 1797-1802

Plano segundo del Río Orinoco que comprende desde el mismo punto donde concluyó el primero siguiendo los dos Brazos de Ymataca, y Sacaopana hasta la union de estos y remata en la boca del Caño de Guaraguau : con todas las Islas y bajos correspondientes a dicho espacio, como asimismo los Caños que se apartan,y la dirección de estos, situado conforme â los reconocimientos que quedan expresados en el primer Plano de este Río. Primera Parte. - Escala [ca.1:98500]

1 carta náutica. : ms. col. ; 65,0 x 83,0 cm Series: (Colección de planos del Río Orinoco)

En Carpetilla de 85 x $65 \mathrm{~cm}$ de la primera parte de la Colección de planos del Río Orinoco. - Longitud del meridiano de Cádiz. Graduado. - Orientado con lis. - Presenta batimetría y veriles de sonda, calidad del fondo con nota explicativa sobre los mismos ; las riberas aparecen sombreadas, existen símbolos de vegetación, ranchos y poblados indios explicados en nota ; el curso lineal del río se ve interrumpido por numerosos islotes y meandros que le hacen cambiar de dirección recogiendo numerosos afluentes que enriquecen su caudal. - Lavado en ocre, amarillo,rojo, verde y azul y se presenta su marco orlado, igual que el título en cartela orlado con guirnalda vegetal, como todas los de la colección.

Signaturas: MN. 32-A-1b

ORINOCO (Venezuela) (Río). Mapas hidrográficos. 1:102880. 1801-1802

Plano septimo de la Costa de Sotavento del Rio Orinoco que comprende desde el mismo punto donde concluyó el sexto siguiendo la costa del Golfo Triste hasta la Mision de Macuro donde finalizan los reconocimientos que quedan expresados en el pimer plano de esta Sgda. Parte. Sepreviene que la Costa que sigue desde el dicho Macuro hasta el remate de ella, como asimismo las Bocas de los Dragos, y parte de la Ysla de Trinidad, se han colocado con arreglo al plano levantado por los Ingleses el año de 1797 : Segunda Parte Escala: Escala [ca.1:102880]

1 carta náutica. : ms., col. ; 65 x 83 cm Series: (Colección de planos del Rio Orinoco; segunda parte ; 7)

En : Carpetilla de 85 x $65 \mathrm{~cm}$. de la segunda parte de la colección del Río Orinoco. Longitud del meridiano de Cádiz. Graduado. Orientado con lis. - Orografía de perfil y por sombreado. - Indica batimetría con nota explicativa. - Señala la locacilización de vegetación y plantaciones de algodón. - Lavado en ocre, rojo, verde y azul, y se presenta orlado, igual que el título.

Signaturas: MN. 32-A-2g

ORINOCO (Venezuela) (Río). Mapas hidrográficos. 1:104036. 1801-1802

Plano sexto de la Costa de Sotavento del Rio Orinoco que comprende desde el mismo punto donde concluyó el Quinto siguiendo la Costa del Golfo Triste, hasta el Pueblo de Guiría donde remata : con todas las Yslas, y bajos correspondientes a dicho espacio como asi mismo, la entrada del Caño del Pilar hasta su primera buelta, y la de los demas 
riachuelos, de dicha Costa situado todo conforme a los reconocimientos que quedan expresdos en el primer plano de esta Segunda Parte. - Escala [1:104036]

1 carta náutica : ms., col. ; 65,0 x 83,0 cm Series: (Colección de planos del Río Orinoco, segunda parte; 6)

En : Carpetilla de 85 x $65 \mathrm{~cm}$ de la seguda parte de la colección del Río Orinoco. Longitud del meridiano de Cádiz. Graduado. Orientado con lis. - Orografía de perfil, representados a gran tamaño. - Presenta sondas batimétricas y veriles, con nota explicativa sobre los mismos. - Señala la localización de núcleos de población, misiones, y campos de cultivo de algodón. - Lavado en ocre, amarillo, rojo, verde y azul y se presenta en marco orlado, igual que el título.

Signaturas: MN. 32-A-2f

ORINOCO (Venezuela) (Río). Mapas hidrográficos. 1:102880. 1801-1802

Plano Tercero de la Costa de Sotavento del Río Orinoco qu comprende desde el mismo punto donde concluyo el Segundo, hasta la Punta de Canoa situada en la Costa del Ote. de la boca del Caño de Cucuyna donde remata : con todas las Yslas y bajos correspondientes a dicho espacio como asimismo las Entradas de los Caños de Macaros y Cucuyna, y la dirección de estos hasta la unión que tienen con el Plano 3. de la Tercera Parte por medio del cual se llegan a incorporar con los del Orinoco, situado conforme a los reconocimientos que quedan expresados en el Primer Plano de esta Segunda Parte. Escala [ca. 1:102880]

1 carta náutica : ms., col. ; 65,0 x 88,0 cm Series: (Colección de planos del Rio Orinoco, Segunda parte ; 3 )

En : Carpetilla de 85 x $65 \mathrm{~cm}$ de la segunda parte de la colección del río Orinoco. Longitud del meridiano de Cádiz. Graduado. - Orientado con lis. - Presenta batimetría y veriles, calidad del fondo con nota explicativa sobre los mismos; las costas y riberas aparecen sombreadas. - Lavado en ocre, amarillo, rojo, verde y azul; se presenta en marco orlado igual que el título.

Signaturas: MN. 2-A-2c

ORINOCO (Venezuela) (Río). Mapas hidrográficos. 1:111557. 1801-1802

Plano Tercero de los Caños de Sotavento que comprende desde el mismo punto en que concluyó el Caño de Macareo en el Plano tercero de los de la costa de Sotavento, contiene también parte de los Caños de Marvisas como asímismo el Lagunazo del Baradero con los Caños de Mayorca y Guaraguahito, y siguiendo por Macareo hacia el sur remata en la union que este tiene con los del río Orinoco, con todas las Yslas, y bajos pertenecientes a dicho espacio : situado todo por los reconocimientos que quedan expresados en el 1er. plano de esta tercera parte. Tercera Parte. - Escala [ca. 1:111557]

1 carta náutica : ms. col. ; 65,0 x 88,0 cm Series: (Coleccion de planos del Río Orinoco. tercera parte ; 3 )

En : Carpetilla de 85 x $65 \mathrm{~cm}$, de la tercera parte de la colección del Río Orinoco. Longitud del meridiano de Cádiz. Graduado. - Indica veriles y sondas batimétricas, con nota explicativa al respecto. - Lavado en ocre, amarillo, rojo verde y azul. Se presenta el marco orlado y el título en greca con guirnalda vegetal.

Signaturas: MN. 32-A-3c 
ORINOCO (Venezuela) (Río). Mapas hidrográficos. 1:98500. 1797-1802

Plano tercero del rio Orinoco que comprende desde el mismo punto donde concluyó el segundo hasta el Serro del Imperial donde remata : con todas la Yslas y bajos correspondientes a dicho espacio, como asimismo los caños que se apartan, y la dirección de estas situado todo conforme a los reconocimientos que quedan expresados en el primer plano de este Río. Primera parte..- Escala [ca. 1:98500]

1 carta náutica : ms. col. ; 65,0 x 88,0 cm Series: (.- (Colección de planos del río Orinoco; primera parte ; 3 )

Coordenadas referidas al meridiano de Cádiz. Orientado con lis. - Orografía por sombreado. - Indica sondas batimétricas, veriles y calidad del fondo. - Señala la situación de fuertes, misiones y otras construcciones. - Lavado en ocre, amarillo,rojo, verde y azul, y se presenta su marco orlado, igualmente el título en cartela orlada. Nota sobre los fortines. - Inserta dos perfiles.

Signaturas: MN. 32-A-1C

PARAGUAY. Mapas generales. 1:760000. 1791

Carta Esferica ó Reducida delas Provincias del Paraguay, Corrientes y Misiones Guaranis / [Félix de Azara]. - Escala [ca. 1:760000]

1 mapa : ms. ; 105,8 x 75,5 cm

Pertenece a la tercera partida de límites. Comprende el río Paraná desde Sta. Lucía hasta el río Amanbay y el río Paraguay desde su desembocadura en el Paraná hasta el río Ipané. - Escala hallada a partir de un grado de latitud [= $15 \mathrm{~cm}]$. Coordenadas referidas al meridiano de Asunción (O 12 $25^{\prime}$-E $\left.3^{\circ} 45^{\prime} / \mathrm{S} 22^{\circ} 35^{\prime}-\mathrm{S} 29^{\circ} 00^{\prime}\right)$. - Relieve de perfil. - Manuscrito a plumilla en tinta negra. - Tabla de signos convencionales para indicar núcleos de población de distinta categoría. - Señala la toponimia. - Al verso consta que es copia de unos planos que estaban en la secretaría del virrey de Buenos Aires.

Signaturas: MN. 42-B-5

PARAGUAY (Río). Mapas generales. 1:1700000. 1787-1791

Carta Espherica de la Provincia del Paraguay : segun los ultimos reconocimientos particulares de la 3a. y 4a. Partida de Demarcación en el año de 1787 á 1791.- Escala [ca. $1: 1700000]$

1 mapa : ms. ; $34^{\prime} 2$ × $21^{\prime} 9 \mathrm{~cm}$

Pertenece a la tercera partida de límites.- Comprende desde la desembocadura en el Paraná hasta Itapucu, en el río Paraguay y el Paraná desde Corrientes hasta la ciudad del Corpus. - Manuscrito a plumilla en tinta negra. - Escala hallada a partir de un grado de latitud $\left[=6^{\prime} 3 \mathrm{~cm}\right]$. Graduado solo en latitud $\left(\mathrm{S} 23^{\circ}-\mathrm{S} 28^{\circ}\right)$. Red geográfica de $1^{\circ}$ en $1^{\circ}$. Relieve representado por normales. - Señala la toponimia.

Signaturas: MN. 42-B-3

Azara, Félix

PARAGUAY. Mapas generales . 1:760000. 1785 
Carta Espherica ó reducida delas Provincias del Paraguay, Corrientes y Misiones guarances : copia de la que remitio á este Virreynato de Buenos ayres desde la Asunción el Paraguay con oficio de 13 de octubre de 1785 el Comisario dela 3a. Partida de la División de Límites el Capn. de fragta. Dn. Felix de Azara. - Escala [ca. 1:760000]

1 mapa : ms., col. ; $93 \times 71 \mathrm{~cm}$

Pertenece a la tercera partida de límites Comprende el río Paraguay desde la desembocadura del río Sta. Lucia hasta la del Ypane, el alto Paraná hasta el río Iguatemí. - Escala hallada a partir de un grado de latitud [=14,3 cm]. Coordenadas referidas al meridiano de la Asunción, indicando su diferencia con los meridianos más importantes. - Relieve representado por normales. - Señala la toponimia de las principales poblaciones y los observatorios astronómicos. - Tamaño irregular.

Signaturas: MN. 42-B-1

PARAGUAY. Mapas generales. 1:74000. 1785.

Carta Espherica ó reducida delas Provincias del Paraguay, Corrientes y Misiones guaraníes y parte del territorio del Brasil .- Escala [ca. 1:740000]

1 mapa : ms. ; $106,5 \times 75,3 \mathrm{~cm}$

Título redactado a partir del contenido del mapa. -Pertenece a la tercera partida de límites Comprende desde Sta. Lucía hasta la desembocadura con el Río Jaguarey en el río Paraná y desde su desembocadura en éste hasta Itapucu Guazu en el Paraguay. Título propio redactado a partir del contenido del documento. - Parece un borrador de la 42-B-1.- Escala hallada a partir de un grado de latitud [=14,9 cm]. Graduado solo en latitud [S $22^{\circ}-\mathrm{S} 29^{\circ}$ ). - Manuscrito a plumilla en tinta negra y gris. - Señala toponimia Materias:

Signaturas: MN. 42-B-2

Azara, Félix de

PARAGUAY. Mapas generales. 1:8929187. 1793

Carta plana de grande parte del río Paraguay que expresa sus inundaciones anuales / hecha por los Demarcadores de límites españoles y lusitanos acordemente y con buenos Ynstrumentos el año de 1753 ; aumentada y corregida por D. Felix Azara, Capitán de Navío de la Real Armada y Comisario Principal de la 3a. Partida de Demarcadores de límites en la América Meridional. Año de 1793 . - Escala [ca. 1:829187]

1 mapa : ms. ; $82^{\prime} 3 \times 52^{\prime} 4 \mathrm{~cm}$

Pertenece a la tercera partida de límites Firmado y rubricado por el autor. - Escala gráfica de 20 leguas marítimas $[=13,4 \mathrm{~cm}]$ y de 20 leguas paraguayas $[=10,2 \mathrm{~cm}]$. Orografía representada mediante perfiles. - Abundante toponimia de los accidentes geográficos y localización de las tribus indígenas de la zona. - Notas explicativas bajo el título. - Manuscrito lavado en verde y ocre. - Montado en cartulina Materias:

Brasil

Signaturas: MN. 38-C-18

PARAGUAY (Paraguay) (Río). Mapas generales 1:745000. 1787 
Carta que Resulta de la derrota a los Pueblos de Sn Estanislao y Sn. Joaqn.. - Escala [ca. $1: 745000]$

1 mapa : ms. ; $41,6 \times 29,6 \mathrm{~cm}$

Pertenece a la tercera partida de límites.- Comprende desde la ciudad de Asunción hasta el río Jejuí Guazú. - Escala hallada a partir de un grado de latitud [= 14,4 cm]. Coordenadas referidas a un meridiano que no se especifica (E $0^{\circ}$-E $2^{\circ} / \mathrm{S} 24^{\circ}-\mathrm{S} 26^{\circ}$ ). Red geográfica de $30^{\circ}$ en $30^{\circ}$. - Relieve de perfil. - Manuscrito a plumilla en tinta negra. Señala la toponimia. - Al verso, "Se ignora si el Río Cajivari pasa al E o al o del Yerval de Sn. Estanislao, y también si el arroyo hondo, pasa al S o al N de los Cerros de Sn. Miguel"

Signaturas: MN. 42-B-4

Pazos, Ignacio

PARAGUAY (Río). Mapas generales. 1:619. 1790.

Carta reducida del Río Paraguay : desde la Asumpcion hta el Presidio de Coimbra en el estrecho de Sn Franc. seavr donde se establecieron los portugueses en / Lebantado por Dn Ignacio de Pasos 1r Piloto de la Rl Armada y Geógrafo de la 3a. Partida de Demarcación destinado a este reconocimiento con motivo dde dicho establecimto Portugues de que se tubo noticias estrajudicial en la Asumpn del Paraguay en septrê de 1790 ; Copia del original. - Escala [ca. 1:619], 100 varas [= $13^{\prime} 5 \mathrm{~cm}$ ]

1 mapa : ms. ; $99,6 \times 29,7 \mathrm{~cm}$

Pertenece a la tercera partida de límites Presenta además un plano del presidio de Coimbra. - Manuscrito a plumilla en tinta negra. - Orientado con flecha. - Anotaciones manuscritas a lápiz con posterioridad.

Signaturas: MN. 42-C-6

Azara, Félix de

PARAGUAY (Río). Mapas hidrográficos. 1:925925. 1794

Demostración Geographica del Rio Paraguay : desde de la ciudad de Corrientes hasta la de Asumpción, y Terreno emediatos a él. / Félix de Azara - Escala [ca. 1:925925], 10 leguas o medio grado $[=6 \mathrm{~cm}]$

1 mapa : ms., col. ; 38,5 x $26 \mathrm{~cm}$

Pertenece a la tercera partida de límites Incluye la ciudad de Asuncion Bajo el título: "Latitud de la ciudad de la Asumpción 25¹6'45"; Latitud de la Boca del Ro. Tibiguary $26^{\circ} 35^{\prime} 00^{\prime \prime}$; Latitud de la ciudad de Corrientes $27^{\circ} 29^{\prime} 00^{\prime \prime \prime " . ~-~ G r a d u a d o ~ e n ~ l a t i t u d ~(S ~} 25^{\circ}-\mathrm{S}$ $28^{\circ}$ ). Orientado con lis en cuadrante. - Manuscrito a plumilla en tinta negra y coloreado a la acuarela en verde.

Signaturas: MN. 42-C-2

PARANÁ (Río). Mapas generales. 1:1480000. 1792

Mapa esférico de la provincia del Paraguay : que comprehende la jurisdición de la Ciudad de Corrientes, y las Missiones Guaranis levantados por los Demarcadores de Límites entre estos Dominios y los del Brasil. 1792 - Escala [ca. 1:1480000] 
1 mapa : ms., col. ; 59' 8 x 44'6 cm

Pertenece a la tercera partida de límites.- Comprende el río Paraná desde Sta Lucía al río Jaguarey, y el Paraguay desde su desembocadura hasta el río Corrientes. -

Manuscrito a plumilla en tinta negra y coloreado a la acuarela en gris, verde y carmín. Escala hallada a partir de un grado de latitud $\left[=7^{\prime} 5 \mathrm{~cm}\right]$. Coordenadas referidas al

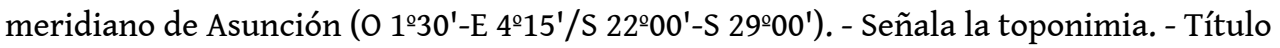
enmarcado en cartela con motivos florales y mitológicos.

Signaturas: MN. 42-B-6

PARANÁ (Paraguay) (Río). Mapas hidrográficos. 1788

Río Paraguay, Paraná y terrenos adyacentes . - Escala indeterminada

1 mapa : ms. ; 55,6 x $40 \mathrm{~cm}$

Título redactado a partir del contenido del mapa. - Comprende gran parte del río Paraná con su desembocadura en el río de la Plata. - Pertenece a la segunda partida de límites. Título redactado a partir del contenido del documento. - Manuscrito a plumilla en tinta negra y lápiz y coloreado a la acuarela en verde.

Signaturas: MN. 42-C-5

Azara, Félix de

PARANÁ. Mapas generales. 1:815000. 1788

Carta Reducida Del reconocimiento engargado al Capitán de Navio Dn. Félix de Azara : $1^{\circ}$ desde Buenos Ayres al Rio Salado en $17,2^{\circ}$ desde Buenos Aire a Sta. Fe 17.- Escala [ca. $1: 815000]$

1 mapa : ms., col. ; 102,5 x 68,7 cm

Pertenece a la tercera partida de límites Comprende desde el Río de la Plata y la cuenca del Paraná hasta Sta. Lucía y la cuenca del río Salado. - Escala hallada a partir de un grado de latitud [=14,2 cm]. Coordenadas referidas a los meridianos de Cádiz y San Fernando. - Relieve representado por normales. - Manuscrito a plumilla en tinta negra y coloreado a la acuarela en gris y verde. - Señala los itinerarios del viaje realizado por el Capitán D. Félix de Azara.

Signaturas: MN. 42-B-8

PARANÁ (Paraguay) (Río). Mapas hidrográficos. 1:102880. 1790

Curso del río Paraná .- Escala [ca. 1:102880]

1 mapa : ms., montado sobre tela; $90 \times 90,2 \mathrm{~cm}$

Pertenece a la tercera partida de límites.- Título redactado a partir del contenido del mapa. - Escala hallada a partir de un minuto de latitud [= 1,8 cm]. - Manuscrito a plumilla en tinta negra y cloreado a la acuarela en verde. - Figuran símbolos representando iglesia, poblados indígenas, villas etc.

Signaturas: MN. 42-C-9

Peña, José de la

PARANÁ (Río). Mapas hidrográficos. 1:453514. 1796 
Configuración del Desagüe del Río Paraná : que comprehende desde Buenos Aires a la población de Sn Pedro y tramo del Río Uruguay hasta el Arroyo de la China o villa de la Concepción / trazado en dos viajes que hizo el primer piloto de la Armada Dn Jph de la Peña con el bergantin Carmen y Sn Anto. - . Escala [ca. 1:453514]

1 mapa : ms., col. ; $80 \times 69,5 \mathrm{~cm}$

Pertenece a la tercera partida de límites Manuscrito a plumilla en tinta negra y coloreado a la acuarela en verde. - Escala hallada a partir de un grado de latitud [ $=24{ }^{\prime} 5$ $\mathrm{cm}$ ]. Coordenadas referidas al meridiano de Montevideo. - Indica derroteros. - Forma irregular ya que son 3 cuartillas pegadas.

Signaturas: MN. 42-C-8

PARANÁ (Paraguay) (Río). Mapas de misiones. 1790

Mapa de los ríos Uruguay y Paraná y las misiones guaraníes.- Escala indeterminada 1 mapa : ms. Col. ; $91 \times 91 \mathrm{~cm}$

Titulo y fecha deducidos del contenido del mapa.- Manuscrito en colores, entelado y encapsulado.- Presenta una gradución del 1 al 53 que es errónea, así como la indicación de linea equinocial. Indica puntos cardinales.- Rtepresenta la costa atlántica y el interior de Argentina y Paraguay, con indicación de las misiones jesuitas del paraguay.Abundantes topónimos de los rios y sus afluentes: Los pueblos y reducciones de indios a parecen numeradas lo que indica la existencia de un texto explñicativo y complementario que no se ha localizado.

Signaturas $42-\mathrm{C}-4$

Azara, Félix de

PARANÁ (Paraguay). (Río). Mapas hidrográficos. 1: 854700. 1790

Croquis del rio Paraná a su paso por Argentina y Uruguay / Félix de Azara.- Escala [ca. 1: 854700$]$

1 mapa : ms. ; 80, $5 \times 29,5 \mathrm{~cm}$

Pertenece a la tercera partida de límites.- Título redactado a partir del contenido del mapa.- Manuscrito a plumilla en tinta negra. - Escala hallada apartir de un grado de latitud en el ecuador $[13 \mathrm{~cm}]$.

Signaturas M;N 42-C-7

Oyarvide, Andrés de

PARANÁ (Río). Mapas hidrográficos. 1788

Plano del Río Paraná : Desde el Puerto de Candelaria hasta la barra del Río Yguazú / construído por las derrotas que ban señaladas con puntos, arregladas a las latitudes observadas en los parajes marcadas con este asterico Por el viaje de la 2a. Partida de la Demarcación de Límites entre España y Portugal / Andrés de Oyarvide. - Varias escalas 1 mapa : ms., col. ; 42,6 x 64,8 cm

Pertenece a la segunda partida de límites. Manuscrito firmado, rubricado y fechado. A plumilla en tinta negra y coloreado a la acuarela en verde. - Leyenda explicativa del mapa. 
Signaturas: MN. 42-B-9

PARANÁ (Río). Mapas hidrográficos. 1:208333. 1788

Plano Topográfico del Río Paraná : desde la barra del Yguazú o rio Grande de Cunituba hta. el salto grande / levantado por las Partidas Españolas y Portuguesas de la Segunda Subdivisión de la Demarcación de Limites en los meses de Julio y Agosto de 1788 .Escala [ca. 1:208333], 3 leguas $[=8 \mathrm{~cm}$ ]

1 mapa : ms. ; $94 \times 30,5 \mathrm{~cm}$

Pertenece a la segunda partida de límites. Manuscrito a plumilla en tinta negra. Graduado solo en latitud (S $24^{\circ} 03^{\prime}-\mathrm{S} 36^{\circ} 00^{\prime}$ ). Orientado con media lis.

Signaturas: MN. 42-C-3

PEQUIRI (Brasil) (Río). Mapas hidrográficos. 1:308000. 1788

Plano del Río Pequiriguazu : Desde la confluencia en el Uruguay hasta su 1er salto grande. - Escala [ca. 1:308000]

1 mapa : ms. ; 60,6 x 42,5 cm

Pertenece a la segunda partida de límites. Escala gráfica de 6 millas $[=10,7 \mathrm{~cm}]$. Orientado con media lis. - Señala detalladamente la toponimia a lo largo de dicho río.

Signaturas: MN. 39-A-10

PEQUIRY (Brasil) (Río). Mapas hidrográficos. 1:50000. 1789

Curso del Río Pequiriguazú. 1789 Diciembre 12.- Escala [ca. 1:50000], tres millas [= 10'7 $\mathrm{cm}]$

1 mapa : ms. ; $48^{\prime} 7$ x $37^{\prime} 8 \mathrm{~cm}$

Pertenece a la segunda partida de límites. Título redactado a partir del contenido del mapa. - Manuscrito a plumilla en tinta negra. - Indica la toponimia a lo largo del río Pequiry.

Signaturas: MN. 43-B-6

PIRATINY (Brasil) (Río). Mapas hidrográficos. 1:17300. 1789

Arroyo Piratiny. - Escala [ca. 1:17300], 1 milla de 60 al grado [= 10,7 cm]

1 carta náutica : ms. ; 209,4 x 49,4 cm

Pertenece a segunda partida de límites. Título tomado del verso del mapa. - Orientado con media lis. - Indica estudio batimétrico del río Piratiny. - Forma irregular con varias hojas cosidas.

Signaturas: MN. 43-B-8

Oyarvide, Andrés de

PUNTA DEL ESTE (Uruguay). Mapas generales. 1:7812. 1800

Mapa de la Punta del Este / [Andrés de Oyarvide].- Escala [ca. 1:7812]

1 mapa : ms. ; 30' $8 \times 42^{\prime} 7 \mathrm{~cm}$

Título propio y mención de responsabilidad tomados del verso del mapa. - Mención de responsabilidad tomada de obras de referencia. - Manuscrito a plumilla en tinta negra. - 
Escala gráfica de $10^{\prime} 6 \mathrm{~cm}$ equivalente a mil doscientos pasos comunes, también expresada en pies de Burgos. Orientado con media lis. - Relieve representado por normales. - Nota relativa a los médanos o dunas tanto de tierra firme como los situados bajo el mar. - Dibujado un barco para situar el fondeadero o puerto.

Signaturas: MN. 44-A-2

RIO GRANDE DO SUL (Brasil) (Puerto). Mapas generales. 1:79365. 1785

Plano de la villa y puerto del Rio Grande de Sn Pedro : en que se muestran los lugares en que existen las obras de Fortificación, tanto de la parte del Norte como del Sur Latitud de la villa de S. Pedro...32 $2^{\circ} 26^{\prime \prime}$ Longitud por Calculo... 324 $51^{\circ} 15^{\prime \prime}$ Declinacion de la Abuja en abril del año de 1752 Escala: Escala [ca. 1:79365], 1 legua de 3000 brazas de 10 pies $[=7 \mathrm{~cm}]$

1 mapa : ms., col ; 49,5 x 70,6 cm

Pertenece a la primera partida de límites. Orientado con lis y rosa de 16 vientos. Indica rumbos. - Manuscrito a plumilla en tinta negra y coloreado en varios colores.

Signaturas: MN. 38-A-9

Oyarvide, Andrés

RIO GRANDE DO SUL (Brasil). Mapas generales. 1:716846. 1785?

Plano del terreno del Río Grande del Sur.- Escala [ca. 1:716846]

1 mapa : ms. ; $37,2 \times 65,5 \mathrm{~cm}$

Título tomado de anotación en el mapa. - Graduado, 1 grado de latitud [= $15,5 \mathrm{~cm}]$. Pertenece a la segunda partida de límites. Relieve representado por normales. - Señala el itinerario seguido en los reconocimientos. - Pertenece a los mapas levantados por la Comisión de Límites del Sur del Brasil.

Signaturas: $\mathrm{MN} .38-\mathrm{C}-15$

Cuesta, Andrés de la

RIO GRANDE DO SUL (Brasil). Cartas náuticas. 1:41459. 17771 PARTIDA

Plano del Río Grande de San Pedro : situado en la Costa del Brasil y por latitud Austral de 32 gs 4 ms Longd. de 25 gs 45 ms Mero. de Tenerife / En la Rl. Escuela de Nabegacion del Departamento del Ferrol por el Mso de Dibujo Don Andrés de la Cuesta. Año de 1777. - Escala [ca. 1:41459]

1 mapa : ms., col ; 52 x 73,6 cm

Pertenece a la primera partida de límites. Escala gráfica de 3 millas marítimas de 60 al grado $[=13,4 \mathrm{~cm}]$. Orientado con rosa de los vientos y lis. - Indica veriles, fondeaderos y sondas batimétricas en brazas de 2 varas cada una. - Señala con un índice con localización de los lugares representados.

Signaturas: MN. 38-A-10

Rodríguez, Miguel; Ortiz, Juan José de;

RIO GRANDE DO SUL (Brasil). Mapas generales. 1:898691. 1773 
Plano de las Marchas y acampamt. de las tropas Españolas sobre el Río Grande y Río Pardo : en la expedición del año de 1773 / Mandada por el Governador y Capn Gral Dn Juan Josef de Ortiz ; Miguel Rodríguez [...] fecit.- Escala [ca. 1:898691].- 1773

1 mapa : ms. ; $27,5 \times 37,8 \mathrm{~cm}$

Manuscrito firmado por Miguel Rodríguez. - Escala gráfica de 11 leguas castellanas [= $6,8 \mathrm{~cm}$ ]. - Leyenda explicativa sobre el recorrido de la expedición reflejada en el plano. Figuran, en las orillas de los ríos, dibujados campamentos, formación de tropas y una población así como la orografía y árboles.

Signaturas: MN. 38-A-1

Agua y Fabro, Juan de Santibez

RIO GRANDE DO SUL (Brasil). Mapas generales. 1:444444. 1778

Plano del Río Grande de Sn Pedro : que comprende desde 7 leguas al Sur de Sta. Theresa hasta 9 leguas al Norte del Río Framanday expresa la entrada en dicho Río de Sn. Pedro, su sonda y la de toda la gran Laguna y Río Yacui, fondeaderos, Canales y bancos, como igualmente los caminos, y sendas que conducen a aquel puesto con los principales rios, Arroyos y Pantanos, sus vados y Pasos con todo cuanto se halla notable en este viaxe para el mas perfecto conocimiento ; y ultimamente se demuestran tamvien todos los caminos y veredas que de diferentes partes sales y dirigen a la fortaleza de Sta. Tecla / por Dn. Juan de Agua y Fabro capitan del Rexto de Zamora. Montevideo y Enero a 15 de 1778 ; Santibañez Escala: Escala [ca. 1:444444]

1 mapa : ms., col., montado sobre tela ; $50,9 \times 137,2 \mathrm{~cm}$

Pertenece a la primera partida de límites. Escala gráfica de 10 leguas castellanas $[=12,5$ $\mathrm{cm}$ ]. Orientado con lis, rosa de 8 vientos y nudo de rumbos. - Indica sondas batimétricas en brazas de 6 pies castellanos. - Manuscrito coloreado en varios colores. - Leyenda explicativa del plano mediante clave toponímica y notas aclaratorias. - En el ángulo izquierdo, en un recuadro, se encuentra la mención de responsabilidad. - Título y leyenda explicativa en cartela decorada con temas vegetales.

Signaturas: MN. 38-A-11

RIO GRANDE DO SUL (Brasil). Cartas náuticas. 1:85470. [1785]

Plano del Río Grande de Sn Pedro : situado en la latitd S de 32 gs y 3 ms. Longd 326 grs. y 45 ms. mro [i.e meridiano] de Tenerife. - Escala [ca. 1:85470]

1 mapa : ms. ; 42,1 x 31,0 cm

Pertenece a la primera partida de límites. Escala gráfica de 3 millas [= 6,5 cm]. - Indica sondas batimétricas expresadas en brazas de 6 pies, veriles y bancos de arena. - Figura clave alfanumérica. - Cartela decorada con estandartes, catalejo, flecha y ancla enmarcando el título.

Signaturas: MN. 38-A-2

RIO GRANDE DO SUL (Brasil). Fortificaciones. 1780

Plano del fuerte y baterias de la población de Río Grande de San Pedro / Riba Hernandez

1 plano: ms. col.; $32 \times 22 \mathrm{~cm}$ 
Original firmado.- Donación hecha al Museo por Casimiro Vigodet.

Signaturas MN. P19-1

Berlinguero de la Marca, Alejo

RIO GRANDE DO SUL (Brasil). Cartas náuticas. 1:170940. 1778

Plano del Rio Grande de Sn. Pedro : situado en latd. meridional de $32^{\circ} 4^{\prime}$ y longd. de $325^{\circ} 49^{\prime}$ / Alejo Berlinguero de la Marca, 1778. - Escala [ca. 1:170940]

1 plano : ms., col. ; 48,6 X $57 \mathrm{~cm}$

Pertenece a la primera partida de límites. Escala gráfica de 2 millas de 20 en grado $[=6,5$ $\mathrm{cm}]$. Orientado con nudo de rumbos y media lis en rosa de 16 vientos. - Indica sondas batimétricas en brazas de 6 pies ingleses. - Notas explicativas de todos los símbolos que hay en los alrededores y orilla del río.

Signaturas: MN. 38-A-7

RIO GRANDE DO SUL (Brasil) (Río). Mapas hidrográficos. 1:5573. 1776

Plano del río Grande : situado al NE del gran río de la Plata por latd. S. de $32^{\circ} 04^{\prime}$ y por long de $325^{\circ} 45^{\prime}$ del mer $^{\circ}$ [i.e. meridiano] de Thenes [i.e. Tenerife] segun la ulta. Corron [i.e. ultima corrección] del mes de marzo de 1776.- Escala [ca. 1:5573]

1 mapa : ms. ; 58,3 x $41 \mathrm{~cm}$

Pertenece a la primera partida de límites. Escala gráfica de 600 varas castellanas [= 9 $\mathrm{cm}$ ]. - Indica veriles, fondeaderos y sondas batimétricas en brazas de 6 pies ingleses. Indica un pequeño derrotero de la zona.

Signaturas: MN. 38-A-5

RIO GRANDE DO SUL (Brasil). Cartas náuticas. 1:1122.. 1784

Plano del Rio Grande [...] : situado por la latitud de 32 grados $3 \mathrm{~ms}$ Austral y longitud de 325 grados 45 minutos Meridiano de Thenerife.- Escala [ca. 1:1122]

1 mapa : ms., col. ; 68,2 x 48,1 cm

Pertenece a la primera partida de límites. Título incompleto por faltarle un trozo donde podría decir "...de San Pedro". - Escala graduada de 3 millas de 2432 varas castellanas [= $6,5 \mathrm{~cm}$ ]. Orientado con lis en rosa de 16 vientos. - Indica veriles, fondeaderos y sondas batimétricas. - Señala asentamientos de aldeas o poblados, dispersos por la zona representada. - Clave toponímica.

Signaturas: MN. 38-A-8

Casaflórez Lugar,

RIO GRANDE DO SUL (Brasil). Mapas generales. 1:185185. 1772

Plano de los caminos desde la villa de Río Grande de Sn Pedro hasta el Fuerte de Sta. Theresa : señalada por la costa del mar desde el Arroyo de Vayeta y por la de la laguna del Mini desde el Arroyo que llaman del Tahy / Casaflorez. Año de 1772. - Escala [ca. 1:185185]

1 mapa : ms., col. ; 47 x 96,5 cm 
Pertenece a la primera partida de límites Manuscrito firmado por Casaflorez. - Escala gráfica de 1 milla [= $3 \mathrm{~cm}$ ]. - Relación de los números localizados en el mapa. - Nota explicativa: "Este plano señala únicamente los Esteros y Bañados principales que impiden la comunicación de los caminos omitiendo para obviar confusión otros muchos que tiene el terreno y no los interrumpe".

Signaturas: MN. 38-A-4

RIO GRANDE DO SUL (Brasil). Mapas hidrográficos. 1:430000. 1777-1796

Plano hidrográfico de Río Grande De San Pedro y la isla Sta Catalina. - Escala [ca. $1: 430000]$

1 mapa : ms. ; $33,9 \times 41,9 \mathrm{~cm}$

Pertenece a la primera partida de límites. Comprende parte de las cuencas de los ríos Antas, Pelotas y Jacuí. - Título propio redactado a partir del contenido del documento. Escala hallada a partir de un grado de latitud $[=26 \mathrm{~cm}]$. Graduado solo en latitud (S $\left.28^{\circ} 00^{\prime}-\mathrm{S} 29^{\circ} 07^{\prime}\right)$. - Manuscrito a plumilla en tinta negra. - Señala toponimia y algunos caminos y rutas.

Signaturas: MN. 39-C-1

RIO GRANDE DO SUL (Brasil) (Río). Cartas náuticas. 1:1140. 1776

Plano del Rio Grande de Sn. Pedro : situado en la Costa del N del Río de la Plata por la latitud Austral de $325^{\circ} 3 \mathrm{~ms}$ Longd $325^{\circ} 45 \mathrm{~ms}$ según el Mro. [i.e. meridiano] de Tenerife / nuebamente lebantado en el mes de Febrero de 1776.- Escala [ca. 1:1140]

1 carta náutica : ms., col. ; 48,7 x 37,5 cm

Pertenece a la primera partida de límites. Escala gráfica de 3 millas de 2432 varas castellanas cada una $[=6,4 \mathrm{~cm}]$. Orientado con media lis en rosa de 16 vientos. - Indica veriles, fondeaderos y sondas batimétricas. - Nota explicativa sobre los signos y símbolos del mapa. - Incluye plano de la: "Jangada que el día 3 de febrero de 1776 salió del pueblo porttgués y vino hasta el sitio donde se halla el General y después se restituyo al mismo con cuyo intermedio se reconoció andar bien y salir a Barlobento"

Signaturas: MN. 38-A-3

ROCHA (Uruguay) (Departamento). Cartas náuticas. 1:71225.1788

Costa Oriental de América del Sur : Desde Santa Teresa al Chuy. -Escala [ca. 1:71225]

1 carta náutica : ms. ; 60'2 x 46'9 cm

Pertenece a la primera partida de límites. Título propio en el verso del mapa. Manuscrito a plumilla en tinta negra y coloreado a la acuarela en gris. - Escala hallada a partir de un minuto de latitud [= 2,6 cm]. Graduado sólo la latitud (533ํ40'-S 34º0 ') . Relieve representado por sombreado. - Indica veriles y bajos. - Señala itinerarios terrestres para el reconocimiento de la localización del fuerte Santa Teresa.

Signaturas: MN. 43-C-7

Oyarvide, Andrés de

SANTA LUCIA (Uruguay) (Río). Mapas hidrográficos. 1785 
Plano de la Embocadura del Río de Sta. Lucía : al O. de Montevideo / por Oyarvide .Escala indeterminada.

1 mapa : ms. ; 30,2 x 19,5 cm

Título tomado del verso del mapa. - Pertenece a segunda partida de límites. Manuscrito firmado y rubricado. A plumilla en tinta negra. - Indica toponimia cercana al río de Sta. Lucía, incluídos los arroyos, afluentes del mismo.

Signaturas: MN. 43-B-10

URUGUAY. Cartas náuticas. 1:700000. 1784

Carta de la costa desde Montevideo hasta la Boca del Río Grande. - Escala [ca. 1:700000]

1 carta náutica : ms. ; 75,3 x $64 \mathrm{~cm}$

Pertenece a la primera partida de límites. Escala hallada a partir de 1 grado de latitud [= $16 \mathrm{~cm}$ ]. Coordenadas referidas al meridiano de Cádiz (O 50 $10^{\prime}-\mathrm{O} 45^{\circ} 45^{\prime} / \mathrm{S} 31^{\circ} 15^{\prime}-\mathrm{S} 35^{\circ}$ $\left.50^{\prime}\right)$. - Relieve de perfil. - Indica veriles, bajos, sondas batimétricas y calidad del fondo. Manuscrito a plumilla en tinta negra.

Signaturas: MN. 43-D-10

URUGUAY. Cartas náuticas. 1782

Costa Septentrional del Río de la Plata : desde el cerro de Montevideo hasta la ensenada de Maldonado.- Escala indeterminada

1 carta náutica : ms. ; 30,8 x $82,0 \mathrm{~cm}$

Título redactado a partir del contenido del mapa. - Manuscrito a plumilla en tinta negra. - Orientado con lis. - Relieve representado por normales. - Indica veriles y bajos.

Signaturas. MN. 43-C-5

URUGUAY. Cartas náuticas. 1783

Costa de Uruguay : Desde la desembocadura del río Santa Lucía a la del río Garzón].Escala [ca.1:350000]

1 carta náutica : ms. ; 44 x 84,5 cm

Título redactado a partir del contenido del mapa. - Escala hallada a partir de un minuto de latitud $[=0,52 \mathrm{~cm}]$. Coordenadas referidas, al parecer, al meridiano de Montevideo ( 0 $1^{\circ} 00^{\prime}$-E $1^{\circ} 40^{\prime} / \mathrm{S} 34^{\circ} 35^{\prime}$-S $\left.35^{\circ} 30^{\prime}\right)$. - Relieve representado por normales. - Indica veriles, bajos, fondeaderos y sondas batimétricas. - Manuscrito a plumillaen tinta negra. Toponimia costera

Signaturas: MN. 43-C-8

Oyarvide, Andrés de

URUGUAY (Río). Cartas náuticas. 1785

Plano de un trozo de Costa en la embocadura del Río del Uruguay : al O. de la colonia del Sacramento / original por Oyarvide. - Escala indeterminada

1 carta náutica : ms. ; 41 x 52,4 cm 
Pertenece a la segunda partida de límites. Título tomado del verso del mapa. - Indica sondas batimétricas. - Manuscrito a plumilla en tinta negra.

Signaturas: MN. 43-B-11

URUGUAY. Cartas náuticas. 1:700000. 1788

Carta de la costa desde Montevideo hasta la Boca del Río Grande. - Escala [ca. 1:700000] 1 carta náutica : ms. ; 75,3 × $64 \mathrm{~cm}$

Pertenece a la primera partida de límites.- Escala hallada a partir de 1 grado de latitud [= $16 \mathrm{~cm}$ ]. Coordenadas referidas al meridiano de Cádiz (O 50 $10^{\prime}-\mathrm{O} 45^{\circ} 45^{\prime} / \mathrm{S} 31^{\circ} 15^{\prime}-\mathrm{S}$ $\left.35^{\circ} 50^{\prime}\right)$. - Relieve de perfil. - Indica veriles, bajos, sondas batimétricas y calidad del fondo. - Manuscrito a plumilla en tinta negra.

Signaturas: MN. 43-D-10

Oyarvide, Andrés de

URUGUAY. Fronteras. 1:205762. 1785

Terreno al oeste y norte de la laguna de Merin. / Oyarvide. [1785]. : Escala [ca. 1:205762] 1 mapa : ms., montado sobre tela; $80 \times 73,5 \mathrm{~cm}$, pleg. en $52 \times 73,5 \mathrm{~cm}$

Pertenece a la segunda partida de límites. Título propio redactado a partir de la zona representada y explicación incluida en el mapa. - Manuscrito firmado y rubricado por el autor. - Graduado, 1 minuto de latitud [=0,9 cm]. - Relieve representado mediante líneas normales. - Figuran trazadas las líneas de derrota y el itinerario seguido en los reconocimientos. - En el ángulo superior izquierdo, extensa nota explicativa. - Forma irregular, sobresaliendo en la parte inferior un rectángulo de $29 \times 42,5 \mathrm{~cm}$, incluido en las medidas generales del mapa.

Signaturas: MN. 38-C-13

URUGUAY (Costa oriental). Perspectivas de costa. 1804

Vistas de la costa oriental de Uruguay.- Escala indeterminada

19 vistas en $1 \mathrm{~h}$. : $\mathrm{ms}$. ; $31 \mathrm{~cm}$ o menor $42,5 \times 31,2 \mathrm{~cm}$

Título redactado a partir del contenido del mapa. - Fecha tomada de una nota bajo una de las vistas: "Vista a las 2 1/2 de la tarde 31 Enº 804 desde el cabo Sta. Maria...". Entrada vista figura una nota explicativa sobre el dia y hora y el punto desde donde se tomó la vista así como del tiempo que hacía. - Las vistas ocupan en su

totalidad el recto y el verso de la hoja.

Signaturas: $\mathrm{MN}-43-\mathrm{D}-12$

URUGUAY. Fronteras. 1:185185. 1787

Vertientes más prales [i.e. principales] del Cebollati. - Escala [ca. 1:185185]

1 mapa : ms. ; 63,4 x 64,9 cm

Pertenece a la primera partida de límites. Título tomado del verso. - Graduado, 1 minuto de latitud [=1 cm]. - Relieve representado por normales y de perfil. - Señala el itinerario seguido en el reconocimiento. - Parece un borrador de uno de los planos levantados por la Comisión de Límites del Sur del Brasil. 
Signaturas: MN. 38-C-14

Oyarvide, Andrés de

URUGUAY. Cartas náuticas. 1:260000. 1804

Carta Espherica Desde el Puerto del Maldonado hta. el Arroyo del chuy Límite del Dominio de España : Lebantada de Orden del Rey En los meses de Enero hta. Abril de 1804 / Andrés de Oyarbide, Para el Deposito Hidrográfico de Madrid.- Escala [ca. $1: 260000]$

1 carta náutica : ms. ; 67 × $107 \mathrm{~cm}$

Pertenece a la segunda partida de límites. Presenta dos perspectivas de la costa. Manuscrito en tinta negra, firmado y fechado.. - Escala hallada a partir de un grado de latitud $[=43 \mathrm{~cm}]$. Coordenadas referidas al meridiano de Montevideo (E $0^{\circ} 55^{\prime}-\mathrm{E} 3^{\circ}=42^{\prime}$ / S $\left.33^{\circ} 40^{\prime}-\mathrm{S} 35^{\circ} 10^{\prime}\right)$. - Relieve representado por normales. - Indica veriles, bajos y sondas batimétricas. Calidad de fondo. - Señala líneas de derrota, dirección de las corrientes y enfilaciones. Entelado.

Signaturas: MN. 43-D-5

URUGUAY (Río). 1786

Croquis de la banda oriental del rio Uruguay y Negro hasta la desembocadura del rio de la plata. 1786 / Oyarvide Andrés..- Escala indeterminada

1 mapa : ms. ; 65,9 x 22,2 cm

Pertenece a la segunda partida de límites. Título redactado a partir del contenido del mapa. - Manuscrito a plumilla en tinta negra. - Indica toponimia a lo largo del Río Uruguay.

Signaturas: MN. 43-B-5

URUGUAY (Río). Mapas hidrográficos. 1:53000. 1789

Parte del curso del rio Uruguaya y saltos del rio Pepirí-guazú. 1789 Diciembre.- Escala [ca. 1:53000], 3 millas [= 10' $6 \mathrm{~cm}$ ]

1 mapa : ms. ; 30'1 x 34'7 cm

Pertenece a la primera partida de límites. Título propio manuscrito con carboncillo en el verso del mapa. - Manuscrito a plumilla en tinta negra. - Nota sobre la calidad del fondo de las aguas del Río Uruguay. - En el margen inferior : "Puerto de las Canoas de donde salieron para el Uruguay los Geografos de la 1a. partida el 28 de Abril, la primera vez, y el 31 de Julio la segunda vez. Año 1778". - Indica la latitud de diferentes puntos localizados a lo largo del curso del río.

Signaturas: MN. 43-B-7

TREINTA Y TRES (Uruguay). Mapas generales. 1:206000. 1788

Uruguay : Depto. de los Treinta y Tres arroyos que lo bañan situados en los $33^{\circ}$ de latitud sur. - Escala [ca. 1:206000]

1 mapa : ms. ; $56,3 \times 42,8 \mathrm{~cm}$

Pertenece a la segunda partida de límites. Título propio manuscrito con carboncillo en el verso del mapa. - Escala hallada a partir de un minuto de latitud $[=0,9 \mathrm{~cm}]$. 
Coordenadas referidas unicamente a la latitud de un meridiano que no se especifica. Manuscrito a plumilla en tinta verde y coloreado a la acuarela en gris y verde. - Indica Mapas hidrográficos y montañas.

Signaturas: MN. 43-B-1

TREINTA Y TRES (Uruguay). Mapas generales. 1:206000. 1788

Uruguay Oriental : Parte del Dpto Treinta y Tres hasta la laguna de Merín.- Escala [ca. $1: 206000]$

1 mapa : ms. ; $74,4 \times 62,8 \mathrm{~cm}$

Pertenece a la segunda partida de límites. Título propio manuscrito con carboncillo en el verso del mapa. - Escala hallada a partir de un minuto de latitud [= 0'9 cm].

Coordenadas referidas unicamente a la latitud. - Manuscrito a plumilla en tinta negra. Indica una red de líneas rectas que unen fundamentalmente unos cerros con otros.

Signaturas: MN. 43-B-3

FONDOS DOCUMENTALES : TRATADO DE 1750

Comisiones de límites. Año 1750-1761

Ms. 124. Doc. 4. Informe en que se hace un breve y exacto diseño de la justicia del tratado de Límites, celebrado entre España y Portugal el 13 de enero de 1750, representado por siete puntos juridico-morales que corresponden a las siete preguntas de la carta que acompaña a este manuscrito. Anónimo parece de jesuitas

Comisiones de límites. 1757 diciembre 20, Madrid. Preparativos de la comision del norte de Brasil

Ms. 2464. Doc.8. Carta de Ricardo Wall a José de Iturriaga para que éste nombre un depositario de caudales de la expedición de límites.[2] h. ; $22 \mathrm{~cm}$.

Comisiones de límites. 1766 agosto 18, Ciudad Real de Orinoco. Partidas del norte de Brasil

Ms. 2464. Doc. 12. Poder y testamento otorgado a D. José Solano por José de Iturriaga. 18 h. $; 31 \mathrm{~cm}$.

Comisiones de límites. 1768 febrero 22, Caracas. Partidas del norte de Brasil

Ms. 2464. Doc.15. Testamento de José de Iturriaga. 19 h. ; $31 \mathrm{~cm}$.

Comisiones de límites. Años 1752-1762. Preparativos de la comision del norte

Ms. 571. Intrucciones para los comisarios de la parte norte. Aranjuez 24 de junio de 1752.

Contiene: Documentos relativos a la expedición de límites organizada con motivo de la firma del Tratado de Madrid el 13 de enero de 1750 entre los reinos de España y Portugal.

Instrucción dada por los ministros de ambos reinos a los comisarios encargados de fijar los límites establecidos por el tratado; Reales Cédulas y Órdenes relacionadas con la expedición; cartas e informes del virrey de Santa Fe, José de Solís Folch de Cardona, del comisario de límites, José Solano, el coronel Eugenio Alvarado, José de Iturriaga y Julián de Arriaga sobre la expdición . 432 h., 25 documentos; en caja de 27 x 40 x $13 \mathrm{~cm}$. 
Comisiones de límites. Años 1752-1762. Preparativos de la comision del norte de Brasil

Ms 572. Documentos relativos a la expedición de límites: Informes y cartas de Eugenio Alvarado y José de Solís Folch de Cardona sobre diversos asuntos de la comisión de límites.

Comisiones de límites. Años 1751-1762. Preparativos de la comision del norte de Brasil

Ms. 572. Tratado de límites entre España y Portugal en los dominios del virreinato de Santa Fe y Brasil (copia legalizada con sello, fechada el 17 de enero de 1751 en Madrid); Reales Cédulas y Provisiones de Fernando VI, nombrando comisarios para el tratado de límites a José de Iturriaga, José Solano, Eugenio Alvarado y Antonio de Urrutia y dando instrucciones a las autoridades americanas para que ayuden en todo a la comisión; Reales órdenes y cartas de José de Carvajal y Lancaster, el Duque de Huéscar, Ricardo Wall y Julián de Arriaga a José de Iturriaga, José Solano, José Diguja y José de Solís Folch de Cardona sobre asuntos de la comisión: instrucciones, ascensos de sus miembros, misiones, etc .338 h., 7 documentos; en caja de $27 \times 40 \times 13 \mathrm{~cm}$.

Comisiones de límites. Años 1750-1765. Preparativos de la comision del norte de Brasil

Ms. 573. Documentos relativos a la expedición de límites: informes sobre la comisión de reconocimiento realizada en la Guayana por Apolinar Díaz de la Fuente; cartas e instrucciones de Ricardo Wall y José de Carvajal y Lancaster a los comisarios José Solano y José de Iturriaga; noticias sobre la colección hecha por el naturalista Loefling en Cumaná, Trinidad y Guayana y nombramiento de Guillermo Bowles para clasificarla; distribución de caudales para la comisión y dificultades para obtenerlos; anulación del tratado de límites con Portugal en Brasil y disolución de la comisión formada para ello (1760); documentación diversa relacionada con la expedición .368 h., 29 documentos ; en caja de $27 \times 40 \times 13 \mathrm{~cm}$.

Comisiones de límites. Año 1769. Partidas del norte de Brasil

Ms. 176. doc. 6. Datos hidrográficos de algunos puntos de la Guayana (punta de Barina y rio Orinoco) por Manuel Centurion.

Comisiones de límites. Años 1754. Tercera partida del norte de Brasil

Ms. 176. Doc. 10. Diario del viaje hecho por orden de D. José Solano al reconocimiento de la banda del poniente de la isla Margarita en el mes de agosto de 1754.

Comisiones de límites. Años 1752-1809 Segunda partida del norte de Brasil

Ms. 564. Comisión del coronel Eugenio Alvarado para el reconocimiento de la provincia de Guayana, instrucciones del jefe de escuadra José de Iturriaga; informe reservado sobre los incidentes de la línea divisa entre España y Portugal y relación de los establecimientos de los jesuitas en el reino de Santa Fe. Idioma caribe de cuando estuve en el Orinoco. Memoria sobre los capitanes caribes . 478 h, 32 documentos; $32 \mathrm{~cm}$, en caja de $27 \times 40 \times 13 \mathrm{~cm}$.

Comisiones de límites. Años 1750-1762. Tercera partida del norte de Brasil

Ms. 919. Viaje al Orinoco de José Solano y Bote 1760.

Comisiones de límites. Años 1750-1762. Tercera partida del norte de Brasil

Ms. 176. Diversa documentación de la Comisión de José Solano y Bote 
Comisiones de límites. Año 1752-1762. Tercera partida del norte de Brasil

Ms. 564. Diario del viaje por tierra desde Caracas a la Angostura del Orinoco, por Francisco Fernández de Bobadilla. Misiones en el Alto Orinoco y río Negro; reconocimiento de esta zona por Apolinar Díaz de la Fuente, comisionado por José Solano. Noticias del bajo Orinoco y de la parte oriental de la Guayana de José de Abalos. Diversas noticias sobre ríos, poblaciones indígenas y cultivos de la zona. Noticias históricas, geográficas, botánicas y zoológicas de la provincia de Cumaná.

Comisiones de límites. Años 1750-1754. Tercera partida del norte de Brasil

Ms 176, doc. 10. Diario del viaje hecho de orden de D.Jose Solano al reconocimiento de la banda del poniente de la isla Margarita en agosto de 1754

Doc. 5 (7)Informe en el que se hace un breve y exacto diseño de la justicia del Tratado de limites celebrado entre España y Portugal el 13 de enero de 1750, representado por siete puntos juridico-morales que corresponden a las siete preguntas de la carta que acompaña este manuscrito (anónimo) .

Comisiones de límites. Año 1769. Partidas del norte de Brasil

Ms. 176, doc 6. Datos hidrográficos de algunos puntos de la Guayana por Manuel Centurion

Comisiones de límites. Años 1752-1762. Tercera partida del norte de Brasil

Ms. 564. Diario del viaje por tierra desde Caracas a la Angostura del Orinoco, por Francisco Fernández de Bobadilla. Misiones en el Alto Orinoco y río Negro; reconocimiento de esta zona por Apolinar Díaz de la Fuente, comisionado por José Solano. Noticias del bajo Orinoco y de la parte oriental de la Guayana de José de Abalos. Diversas noticias sobre ríos, poblaciones indígenas y cultivos de la zona. Noticias históricas, geográficas, botánicas y zoológicas de la provincia de Cumaná.

Comisiones de límites. Años 1752-1809. Segunda partida del norte de Brasil

Ms. 564.Comisión del coronel Eugenio Alvarado para el reconocimiento de la provincia de Guayana, instrucciones del jefe de escuadra José de Iturriaga; informe reservado sobre los incidentes de la línea divisa entre España y Portugal y relación de los establecimientos de los jesuitas en el reino de Santa Fe . 478 h, 32 documentos; 32 cm, en caja de $27 \times 40 \times 13 \mathrm{~cm}$..

Comisiones de límites. Año 1760. Tercera partida del norte de Brasil

Ms. 919. Solano y Bote. Viaje al Orinoco. 1760.

Comisiones de límites. Año 1756. Primera partida del norte de Brasil

Ms. 123. Doc. 3. Carta de José de Iturriaga al virrey Solis Folch de Cardona anunciandole que José Solano le lleva la comunicación del rey por via reservada sobre el desalojo de los 7 pueblos de guaranies a otros lugares ya que su territorio pasa a Portugal por los términos del tratado. Incluye una carta del provincial de los jesuitas al virrey. 24-12-1756. El territorio está entre los rios Ibicuy y Uruguay.

Comisiones de límites. Años 1754-1760. Partidas del sur de Brasil

Ms 125. Doc.4. Misiones en el Paraná y Uruguay

Comisiones de límites. Años 1750-1762. Partidas del sur de Brasil 
Ms. 124. Doc. 3. Compendio de lo acaecido en el establecimiento de la linea divisoria que las partidas enviadas al rio de la Plata han demarcado en la América meridional según el tratado de Limites de 13 de enero de 1750

Comisiones de límites. Año 1750-1762. Partidas del sur de Brasil

Ms. 123. Doc. 4. Efectos del tratado de limites y resistencia de los jesuitas a las ordenes del rey.

Comisiones de límites. Años 1753-1760. Tercera partida del sur de Brasil

MS.124. Doc. 3 (1) Diario de demarcación de la tercera partida, la cual empezó el día 11 de noviembre de 1753.

Doc. 3(2) Diario de las observaciones astronómicas de la tercera partida.

Doc. 4. Borradores y varios papeles sueltos de las tres partidas.

Comisiones de límites. Año 1756. Partidas del sur de Brasil

Ms. 123. Doc. 7. Parte de una carta escrita en Lima el 22 de mayo de 1756 sobre las órdenes dadas al marqués de Valdelirios para la entrega de los siete pueblos que hizo D. José de Andonaegui en 1755. Relación de dicha marcha a los pueblos guaranies.

Comisiones de límites. Año 1754.Partidas del sur de Brasil

Ms. 123. Doc. 8. Diario histórico de la guerra guarani desde el año de 1754. Incompleto.

Comisiones de límites. Año 1760. Partidas del sur de Brasil

Ms. 124. Doc. 11. Memorial del padre Josep Barrera, jesuita al marqués de Valdelirios sobre los términos del tratado y los pueblos guaranies.

Comisiones de límites. 1753-1760. Segunda partida del sur de Brasil

Ms. 125. Doc. 1. Reducciones de plano esférico de las derrotas y viajes y

reconocimientos de la $2^{\mathrm{a}}$ partida de la demarcación / Juan Lorenzo Marrón

Comisiones de límites. 1753-1760. Segunda partida del sur de Brasil

Ms. 124. Doc. 2. Prontuario de las observaciones de longitud, thermómetro, barómetro y variaciones de aguja con las medidas de lo ancho que tienen los ríos principales y los saltos del Uruguay e Iguazú, con algunas notas particulares que ocurrieron en toda la seria (sic.) de tiempo que duro la segunda partida hasta su vuelta al pueblo de San Nicolás, realizado por Juan Lorenzo Marrón. Año 1754-1760

Comisiones de límites. 1753-1760. Tercera partida del sur de Brasil

Ms. 628. Derrota y relación de la navegación que de buelta del rio de la Plata hace el theniente de navio de la Real ArmadaD. Atanasio Varanda al Exmo Sr. Don Andres Regio Brancifort Saladino y Colona....Teniente General de Real Armada y Comandante General en el Departamento de Cádiz. 1761. Incluye cinco planos que provienen de los trabajos de las partidas de limites de 1754 .

Comisiones de límites. 1753-1760. Tercera partida del sur de Brasil

MS 124. Doc. 3 Compendio de lo acaecido en el establecimiento de la línea divisoria que las partidas enviadas al Rio de la Plata por las Cortes de Madrid y Lisboa han demarcado en la America Meridional, según el Tratado de Limites del 13 de enero de 1750.[Atanasio de Varanda] 
Comisiones de límites. Año 1754-1760. Tercera partida del sur de Brasil

Ms 125.Doc. 3 (1-2) Diario de demarcación de la tercera partida, la cual empezó el día 11 de noviembre de 1753. (Manuel Antonio de Florez, C. de F. Atanasio Varanda, T de. F. Alonso Pacheco, A. de N. Manuel de la Quintana, T. de Infanteria, Jose Quiroga, jesuita) Diario de las observaciones astronómicas de la tercera partida. Borradores y varios papeles sueltos de las tres partidas.

TRATADO DE 1777

Comisiones de límites. General. 1775

Ms. 123. Doc. 1. Descripción del gran Chaco por Cosme Bueno, 1775.

Comisiones de límites. General. 1775

Ms. 123. Doc. 2. Apuntes sobre el obispado de Asunción del Paraguay por Cosme Bueno, 1775

Comisiones de límites. General. 1801

Ms. 283. Historia de las demarcaciones de límites en la América entre los dominios de España y Portugal / compuesta por D. Vicente Aguilar y jurado oficial $2^{\circ}$ de la Secretaría de Estado y por D. Francisco Requena, brigadier e yngeniero de los Reales Exercitos para acompañar al mapa general construido por este último, de todos los países por donde pasa la línea divisoria con arreglo al tratado preliminar de límites de 1777.

Comisiones de límites. Preparativos. 1770

Ms 122, doc. 9. Carta al marqués de Sobremonte, de Varela y Ulloa dándole su opinión sobre el diario de la navegación al río Negro de BasilioVillarino.

Comisiones de límites. Año 1784.

Ms 964. Demarcación de límites de América meridional. 1784.

Comisiones de límites. Año 1784.

Ms. 965. Demarcación de límites de América meridional. 1784.

Comisiones de límites. Años 1786-1787. Primera partida

Ms 125. Doc. 2 (1) Diario de las observaciones astronómicas hechas por los individuos de la primera partida de demarcación de límites al mando del capitán de la Real Armada D. José Varela y Ulloa

Ms. 125. Doc. 2 (2) Diario de las observaciones de latitud y longitud que sirvieron para corregir los planos que se levantaron por los geógrafos de la primera división de la demarcación de límites con la Corona de Portugal en la América Meridional, que estuvo a cargo del capitán de la Armada D. José Varela y Ulloa.

Ms. 125. Doc. 4. Papeles sueltos de la comision de Varela y Ulloa.

Comisiones de límites. 1794

Ms. 1754. Diarios del Río de la Plata de Oyarvide. 1794-1805. 68 fols.

Comisiones de límites. 1798

Ms. 1718. doc. 1. Diarios del Rio de la Plata de Oyarvide. 1798-1800 
Comisiones de límites. Años 1777-1791. Segunda partida

Ms. 282. Doc. 1. Descripción de la costa de América del sur desde el río Amazonas hasta Montevideo. Descripción del río Amazonas. Descripción del punta de Rodeo; puerto de la Paloma, fondeadero del Arrecife y cabo de Santa María. Descripción de la costa que continúa al norte del río de la Plata. Descripción del río de la Plata. Descripción de Montevideo. Descripción de recalada en el Amazonas y modo de tomar su embocadura. Descripción del río Pará. Ciudad de Belén. Río Parahiba. Descripción de rada, puertos y arrecifes de Pernambuco; bahía de Todos los Santos. Descripción de los Abrojos. Descripción del río Grande de San Pedro. Descripción del arroyo de Bayeta, de arroyo del Tahín y frontera del dominio portugués. Descripción del arroyo del Chuy, punta de Castillo grande y Polonio e islas adyacentes por Oyarvide.

Comisiones de límites. Años 1784-1793. Segunda partida

Ms. 128 Descripción histórica y geográfica de Brasil. Descripción del fondeadero de Buenos Aires. 1801. Navegación del Río de la Plata. 1783-1817. Derrotas entre Montevideo y Maldonado. Descripción geográfica, geométrica y colección histórica y jurídica de las costas del Brasil desde el Pará hasta el Río de la Plata. Descripción del fondeadero de Buenos Aires realizado por Oyarvide: salida de balizas y entrada de balizas. 2) Descripción sobre la entrada en el Río de la Plata con un croquis del mismo.

Ms. 1754. Diarios del Río de la Plata. Oyarvide. 1794-1805. 68 fol.

Ms. 1718. Diarios del Rio de la Plata. 1798-1800

78 fols.

Comisiones de límites. Años 1777-1791. Primera y segunda partidas

Ms. 282. Memoria geográfica de los viajes practicados desde Buenos Aires hasta el salto grande del Paraná por las primeras y segundas partidas de la demarcación de límites en la América meridional en conformidad del tratado preliminar de 1777 entre las Coronas de España y Portugal : con varias notas cronológicas de las poblaciones, circunstancias y estado actual de los países que se andubieron, y algunas otras sobre la división de terrenos de ambos dominios / por D. Andrés de Oyarvide, piloto de la Real Armada con exercicio de geógrafo en la $2^{\mathrm{a}}$ partida de la demarcación. Para el Departamento Hidrográfico de Madrid, 467 hojas.

Contiene:

Doc. 1 Copia del tratado de 1777

Doc. 2. Instrucciones de la Corte al virrey de Buenos Aires Vertiz, dadas por José de Galvez, ministro de Indias en 1778

Doc. 3 Nombramiento de individuos para la demarcación.

Doc. 4 Instrucciones del virrrey de Buenos Aires a los demarcadores

Doc. 5 Destinos de las partidas demarcadoras que están en Buenos Aires

Doc. 6 Noticia de los instrumentos que llevaban las partidas para las observaciones.

Doc. 7 Practica de las observaciones astronómicas.

Doc. 8 Noticias de los individuos que componen las partidas y sus habilidades 
Comisiones de límites. Años 1784-1801. Segunda partida.

Ms. 125 , doc. 1 (1)(2). Breve noticia de las operaciones de la $2^{\text {a }}$ partida de demarcación de límites con Portugal en el Paraguay a cargo del capitán de navío D. Diego de Alvear en los años de 1784 a 1801.

Comisiones de límites. Años 1784-1801. Segunda partida

Ms. 2055.América meridional.- Reconocimiento de las vertientes de la laguna Merín. Bases, rumbos, notas y marcaciones probablemente de D. Andrés de Oyarvide, geógrafo de la $2^{\mathrm{a}}$ partida de demarcación de límites entre España y Protugal, realizada al mando de D. Diego de Alvear.

Comisiones de límites. Años 1784-1801. Segunda partida

Ms. 850. Oyarvide. Reconocimiento del río Uruguay. 1801.

Comisiones de límites. Años 1784-1801. Tercera partida

Ms. 491. Descripción histórica, phisica, política y geográfica de la provincia de Paraguay / por D. Félix de Azara.

\section{ISLA DE STA CATALINA}

MS. 55. Fortificaciones de la Isla de sta Catalina

Ms. 175. Descripción de la Isla de Sta Catalina, sus fortificaciones, puerto y población

Ms. 229.Documentos referentes al congreso hispaño-portugués celebrado en Badajoz para tratar de la división y demarcación de la isla de San Gabriel o Colonia del Sacramento en la margen septentrional del Rio de la Plata.

Expedición de Casa Tilly a la isla de Santa Catalina. 1777

MS. 128. Instrucciones del marqués de Casa Tilly a su escuadra sobre la derrota a seguir desde el Puerto de Santa Catalina a Rio Grande del Sur.

Expedición de Casa Tilly a la isla de Santa Catalina

Ms. 153, 156, 158, 163, 172, 173.

Albiac, Maㅗ Dolores (2000). Félix de Azara. Zaragoza.

Almeida, Ferrand André (2001). “América del Sur, 1775”, en: Tesoros de la cartografía española. Exposición Biblioteca Nacional de España, Madrid, pp.181-182

Beerman, Eric (1996). Francisco Requena: la expedición de límites a la Amazonia 1779-1795. Compañía Literaria, Madrid.

Bermejo de la Rica, Antonio (1920). La colonia del Sacramento, su origen, desenvolvimiento y vicisitudes de su historia. Toledo.

Guedes, Max Justo (1998). “Três séculos de cartografia portuguesa do Brasil”, en: Cicle de conferences sobre Historia de la cartografía. 9è curs La Cartografía Iberoamericana. Institut Cartografic de Catalunya, Barcelona, pp. 87-141.

Guerreiro, Inacio (1999). "Fronteiras do Brasil colonial. A cartografía dos limites na segunda metade do século XVIII”, en Oceanos, № 40, pp. 24-44.

Lafuente, Antonio y M. Sellés (1988). El Observatorio de Cádiz (1753-1831). Ministerio de Defensa/Instituto de Historia y Cultura Naval, Madrid. 
Lucena Giraldo, Manuel (1991a). Laboratorio tropical: La expedición de límites al Orinoco, 1750-1767. Monte Ávila Editores, Caracas.

Lucena Giraldo, Manuel (1991b). Francisco de Requena y otros ilustrados y bárbaros: diario de la exploración de límite al Amazonas (1782). Alianza Editorial, Madrid.

Lucena Giraldo, Manuel (1992). “La expedición de Límites al Orinoco (1754-1761)”, en: Pehr Löfling y la expedición al Orinoco (1754-1761). Real Jardín Botánico, Madrid, pp. 131-145.

Martín-Merás, Luisa (1993). “La Casa de Contratación: escuela sevillana de cartografía”, en: Cartografía Marítima Hispana: La imagen de América. Editorial Lunwerg. Madrid, pp. 69-178

Ramos, Demetrio (1946). El tratado de limites de 1750 y la expedición de Iturriaga al Orinoco. CSIC, Madrid.

Sala Catalá, José (1990). “Ciencia y técnica en las expediciones de límites hispanoportuguesas: una aproximación”, en: Ciencia, técnica y estado en la España ilustrada. Ministerio de Educación y Ciencia, Madrid, pp. 241-247.

Varela, Jesús (2000). Castilla descubrió el Brasil en 1500. Seminario Iberoamericano de Descubrimientos y Cartografía, Valladolid.

\section{NOTAS}

1. La carta se encuentra en el Museo Naval de Madrid.

2. Los instrumentos astronómicos utilizados se encuentran en el Observatorio Astronómico de Cádiz; sobre esta institución científica fundada en 1753, en la época de Carlos III, véase: Lafuente y Sellés, 1988.

\section{RESÚMENES}

Este trabajo, como anuncia su título, pretende dar a conocer la documentación que se encuentra en el Museo Naval de Madrid relativa a las comisiones de límites en América del Sur que llevaron a cabo las dos naciones ibéricas en el siglo XVIII. Fueron comisiones resultado de tratados internacionales ajenos a la Marina, pero en las que sus individuos jugaron un papel muy importante como "demarcadores inteligentes" destinados en "comisión de servicios" al ministerio de Estado. Estos oficiales, al retornar a sus puestos en la Marina, entregaron a sus superiores los informes de sus comisiones y la documentación que manejaron en ellas para que constaran en sus expedientes personales y sobre todo a la Dirección de Hidrografía para que sirvieran para futuros trabajos cartográficos. Los aspectos técnicos y científicos en los que los oficiales participaron están recogidos exhaustivamente por medio de diarios, mapas, borradores, notas y correspondencia profesional. Al darlos a conocer aquí lo hacemos con el convencimiento de que son un necesario complemento de otras series documentales más importantes sobre las 
comisiones de límites en América del Sur que en España están todavía insuficientemente estudiadas.

As evidenced from the title, this work attempts to present the documentation deposited in Madrid's Navy Museum in relation to South America's Border Commissions conducted by the two Iberian countries in the eighteen century. These Commissions resulted from international treaties unrelated to the Navy, but in the development of which marine officers played a key role as "intelligent border-definers" appointed to "service commissions" by the government ministry. Upon returning to their posts in the Navy, these officers forwarded to their authorities the reports of the commissions leaded by them, along with the documentation derived from them, for filing in their personal archives and, above all, for submission to the Direction of Hydrography to serve for future cartographic work. The technical and scientific aspects in which officers participated are gathered comprehensively through diaries, maps, drafts, field notes and professional correspondence. They are included here under the premise that further supplementary work is required to analyze other most important documentary series on South America's Border Commissions which remain insufficiently studied in Spain.

\section{ÍNDICE}

Keywords: Navy Museum, Madrid, cartography, Brazil, eighteenth century

Índice cronológico: 1700, 1800

Índice geográfico: Brasil, América del Sur

Palabras claves: Museo Naval, Madrid, cartografía, Brasil, siglo XVIII

\section{AUTOR}

\section{LUISA MARTÍN-MERÁS}

Museo Naval de Madrid 